\title{
High School Coaches' Experiences with Openly Lesbian, Gay, and Bisexual Athletes
}

\author{
Meghan K. Halbrook
}

Follow this and additional works at: https://researchrepository.wvu.edu/etd

\section{Recommended Citation}

Halbrook, Meghan K., "High School Coaches' Experiences with Openly Lesbian, Gay, and Bisexual Athletes" (2017). Graduate Theses, Dissertations, and Problem Reports. 5737.

https://researchrepository.wvu.edu/etd/5737

This Dissertation is protected by copyright and/or related rights. It has been brought to you by the The Research Repository @ WVU with permission from the rights-holder(s). You are free to use this Dissertation in any way that is permitted by the copyright and related rights legislation that applies to your use. For other uses you must obtain permission from the rights-holder(s) directly, unless additional rights are indicated by a Creative Commons license in the record and/ or on the work itself. This Dissertation has been accepted for inclusion in WVU Graduate Theses, Dissertations, and Problem Reports collection by an authorized administrator of The Research Repository @ WVU.

For more information, please contact researchrepository@mail.wvu.edu. 


\title{
High School Coaches' Experiences with Openly Lesbian, Gay, and Bisexual Athletes
}

\author{
Meghan K. Halbrook \\ Dissertation submitted \\ to the College of Physical Activity and Sport Sciences \\ at West Virginia University \\ in partial fulfillment of the requirements for the degree of \\ Doctor of Philosophy in \\ Sport and Exercise Psychology \\ Jack Watson II, Ph.D., Chair \\ Dana K. Voelker, Ph.D. \\ T.Anne Hawkins, Ph.D. \\ Edward Etzel, Ed.D.
}

Department of Sport and Exercise Psychology

Morgantown, West Virginia

2017

Keywords: lesbian, gay, bisexual, high school, coaches

Copyright 2017 Meghan K. Halbrook 


\section{ABSTRACT \\ High School Coaches' Experiences with Openly Lesbian, Gay, and Bisexual Athletes}

\section{Meghan Halbrook}

Despite reports that there has been a positive trend in perception and treatment of lesbian, gay, and bisexual (LGB) individuals in recent years (Griffin, 2012; Loftus, 2001), sport, in general, is still an uncertain, and sometimes even hostile, environment for LGB athletes (Anderson, 2005; Beylin, 2006; Waldron \& Krane, 2005). These concerns may be even more prevalent at the high school level, with student-athletes putting a strong emphasis on attempting to develop an independent and positive social identity through group or team interactions (Grant et al., 2014; Taifel \& Turner, 1986). To gain more information on coach understanding and perceptions of the team environment, ten high school head coaches in the United States were interviewed to explore their experiences coaching openly LGB athletes. Qualitative analyses revealed four primary themes associated with coach experiences: team environment dogmas and observations, fundamental beliefs contributing to perceptions of LGB athletes, types and timing of sexual orientation disclosure, and differential LGB athlete characteristics. Future research should examine these primary themes in more detail through direct interviews with LGB athletes, as well as high school coaches in more traditionally masculine sports, such as football, men's basketball, and wrestling. The perspectives of these other populations will assist in developing a more holistic understanding of the high school sport environment for LGB individuals. 


\title{
Acknowledgements
}

\author{
A Tremendous Thank You to:
}

\section{My Committee Chair}

Dr. Jack Watson II - For believing in me since day one. Your humor and sincerity have gotten me through some of the toughest days. You have been a constant in my ever changing life and for that alone, I am forever grateful.

$\underline{\text { My Dissertation Committee }}$

Dr. Dana Voelker, Dr. T.Anne Hawkins, and Dr. Edward Etzel - For your feedback, positivity, and ongoing support. You all have contributed greatly to getting me to this point. Each of you provided me with an excellent role model and new perspectives. I will take this with me as I leave West Virginia University and start on my own career path.

\section{West Virginia University}

Sport and Exercise Psychology Program - Everyone who has passed through the program over the course of my five years. I have watched time and again as our group, faculty and students, have picked each other up and banded together. We truly have a unique program. I will never forget the connections I have made with each of you.

\section{My Family}

Mom and Dad - For wanting the best for me and working above and beyond to make sure I had it. From your presence at all those softball and soccer games to you both going out of your way to move me from state to state, each one further away from you, so I could chase my own dreams. It hasn't gone unnoticed.

Pepa - For being the one to first introduce me to a college classroom and being the voice in my head always telling me to put school first. You saw an educator in me way before I ever thought it possible.

Mema - For being my safe place and my biggest fan. I will always try to do right by your guidance by being a good person and by laughing at myself, because as you know, life is short. I hope I make you proud.

My Tribe

Megan Byrd and Stefanee Maurice - For allowing me to be authentic and loving me just the same. Thank you for challenging me, laughing with me, and commiserating when it was needed. "Here's to strong women. May we know them. May we be them. May we raise them."

\section{My Love}

Tammy Sheehy - For continually encouraging me and always finding a way to provide just what I need, whether it be patience, a keen eye, or simply more coffee. In you, I have met my match. 
Table of Contents

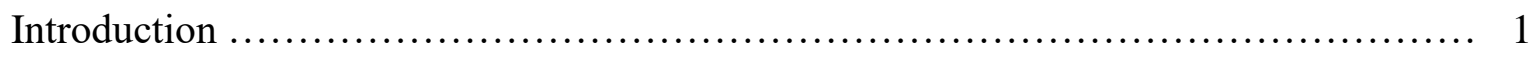

Public Perceptions of LGB Population $\ldots \ldots \ldots \ldots \ldots \ldots \ldots \ldots \ldots \ldots \ldots \ldots \ldots \ldots \ldots \ldots \ldots \ldots \ldots \ldots$

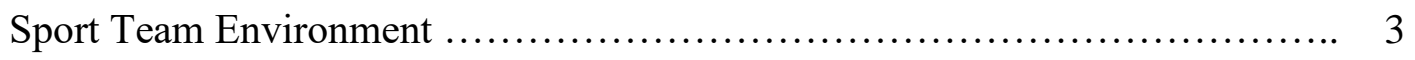

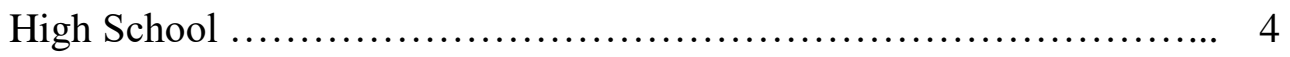

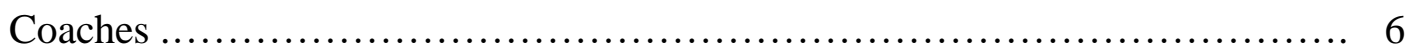

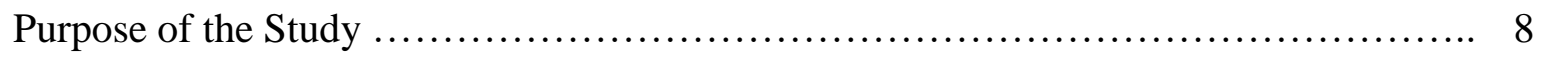

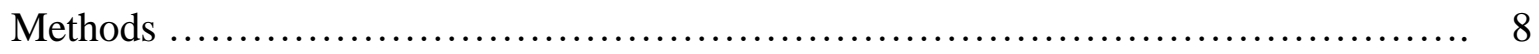

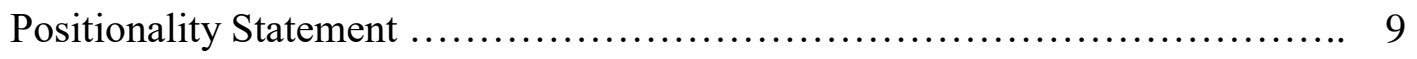

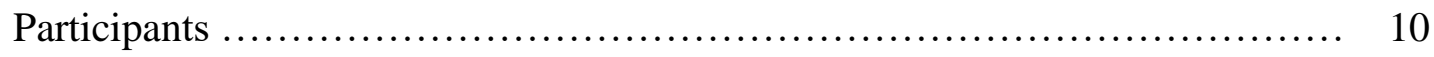

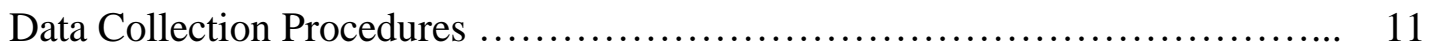

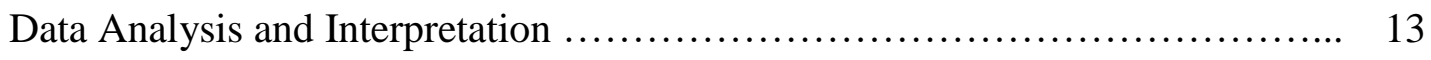

Research Quality and Ethical Concerns ............................... 14

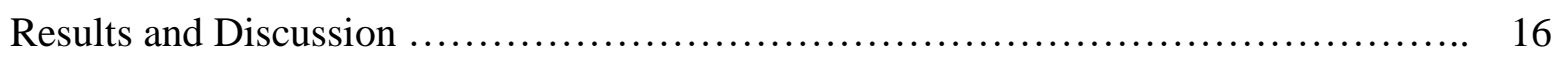

Connections to Research Questions .................................. 25

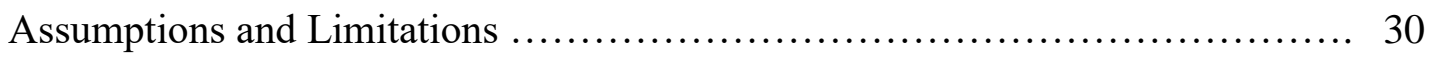

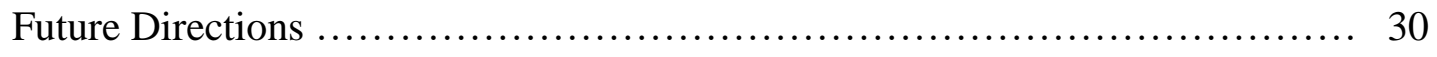

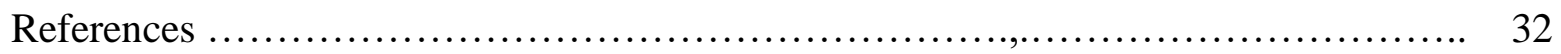

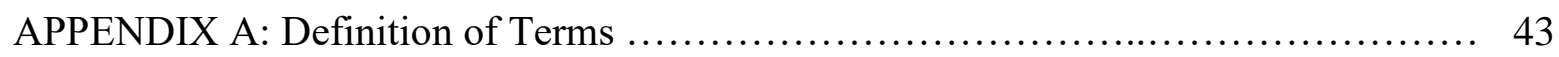

APPENDIX B: Extended Literature Review $\ldots \ldots \ldots \ldots \ldots \ldots \ldots \ldots \ldots \ldots \ldots \ldots \ldots \ldots, 45$

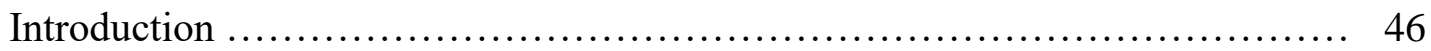

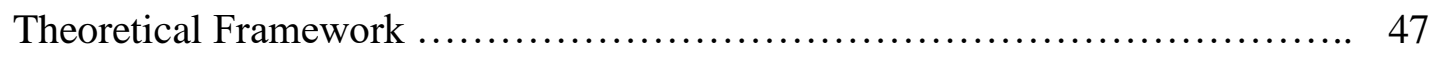

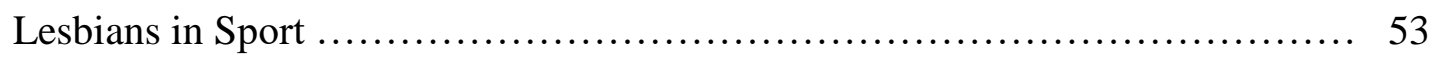

Gay Males in Sport ............................................ 57 
Bisexual Persons in Sport .............................................. 59

Additional Concerns Facing the LGB Community ......................... 60

Coaches and Supporting Roles ......................................... 65

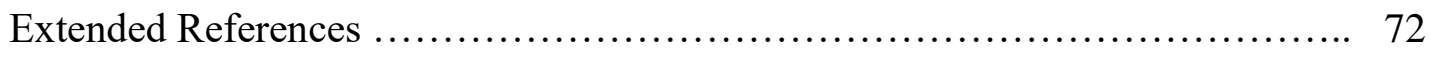

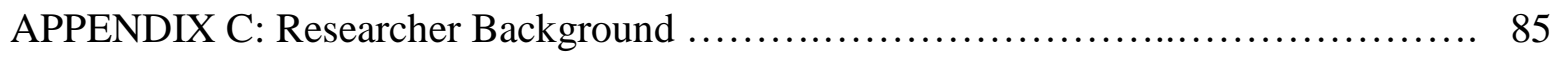

APPENDIX D: Previous Quantitative Study Results .............................. 92

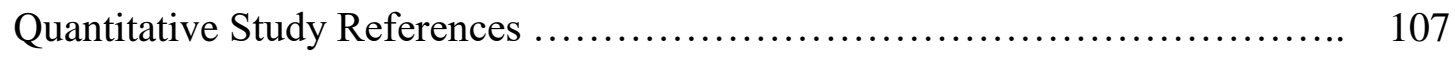

APPENDIX E: WVU Institutional Review Board Approval ........................ 110

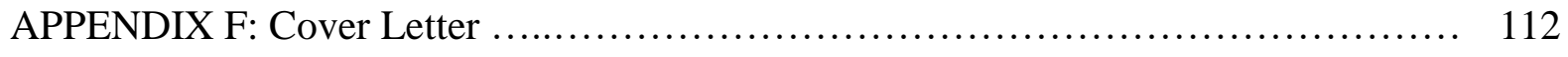

APPENDIX G: Interview Guide .............................................. 114

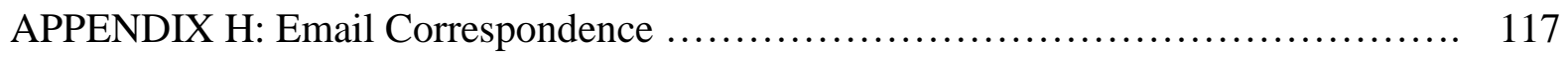

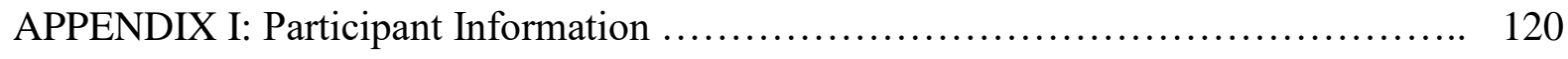

APPENDIX J: Table of Themes ............................................ 123

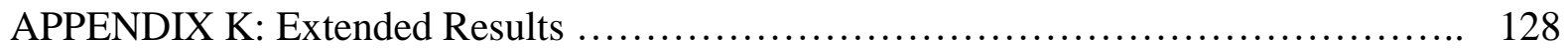

APPENDIX L: Future Coach Education Workshop …........................... 143

APPENDIX M: Quantitative / Qualitative Comparisons ............................. 146

APPENDIX N: Member Check Responses ....................................... 151

APPENDIX O: Analytic Memos ............................................... 153 


\section{High School Coaches' Experiences with Openly Lesbian, Gay, and Bisexual Athletes}

Sport has been labeled the "last closet" for lesbian, gay, and bisexual (LGB) individuals (Beylin, 2006). Despite accounts that LGB rights have grown and acceptance increased over the past 15 years (Loftus, 2001), with an acceleration over the last seven to nine years (Griffin, 2012), professional development opportunities for coaches at all levels still rarely include information about LGB athletes and homonegativity in the sport environment (Griffin, 1994). The silence that is generated with regard to LGB athletes is stifling, but is considered typical of the masculinized culture of sport. Sport culture, overall, has historically been considered a microcosm of society, reflecting changes in government policies and shifts in public opinion. For example, discriminatory racism and derogatory racial comments are now deemed unacceptable in the locker room, on the field, and in public forums, yet coaches, athletes, and citizens often use homonegative slurs as taunts or forms of motivation (McCormack \& Anderson, 2010). It is with this realization that researchers and activists, in and out of sport, continue to strive for a more inclusive environment for LGB athletes of all ages (Barber \& Krane, 2007).

\section{Public Perceptions of the LGB Population}

The reasons LGB individuals face hostility and discrimination, in and out of sport, are frequently discussed in the media and academic literature. Burr (2005) gives a candid, yet controversial examination of the background and perceptions of homosexuality. He reported that while the "gay gene" is still very much debated in politics and social settings, there would be more support for LGB individuals and less debate regarding human rights, if others believed that homosexuality was biological as opposed to a personal choice. In an attempt to show connections, trait profiles were compared between handedness and homosexuality. Strong similarities exist between these two traits (e.g. percent occurrence, detection ages, and sex differences). It was also noted that handedness can be altered by forcing a child to write with 
opposite hands. However, this forced handedness was merely a behavioral change that masked their "true orientation." Similarly, when individuals are encouraged to hide their sexual orientation or attempt to be heterosexual, this behavioral change is merely a mask that creates great strain on the person and their relationships.

The daily struggles that are felt by many LGB individuals are often due to heterosexism. Heterosexism is defined as the belief that heterosexuality is the only acceptable and viable life option (Turner \& Rubinson, 1993). Because of heterosexism, LGB individuals may struggle with their self-esteem and have a more difficult time developing a positive sexual identity (Blumenfeld \& Raymond, 1988). Having a positive sexual identity indicates that LGB individuals are more accepting of their same-sex sexuality and are more comfortable with others knowing of their sexual orientation, as well (Rosario, Schrimshaw, Hunter, \& Braun, 2006). Despite the two terms not being mutually exclusive, heterosexism, can lead to homonegativity. Being homonegative is different than being homophobic. Homophobia is an "irrational fear" of non-heterosexuals, but homonegativity is a purposeful, dislike of individuals who identify as LGB. Homonegative beliefs are developed through "a complex interrelationship of experiential learning, individual psychological defenses, and sociocultural and historical factors" (Remafedi, 1987, p. 224).

The social and psychological obstacles and strain that young LGB persons face can lead to negative coping strategies, such as alcohol and drug use, to escape feelings of isolation and self-hatred (Griffin, 1994). Other manifestations related to homonegativity may include depression, feelings of inferiority, self-defeating behaviors, poor self-esteem, under- or overachievement, physical and mental health problems, distrust, loneliness, shame, anger, defensiveness, and suicidality (Dempsey, 1994; Neisen, 1993). Lesbian, gay, and bisexual 
athletes report 4-5 times the number of depressive bouts than heterosexual athletes and LGB youth, in general, are 2-3 times more likely to attempt and complete suicide, which makes the psychological implications of this subject of the utmost importance (Department of Health and Human Services, 1989; Haas et al., 2011; Savin-Williams, 1994).

\section{Sport Team Environment}

It would be beneficial for all athletes, regardless of sexuality, to be exposed to an encouraging and inclusive environment, free of heterosexism, to combat the potential negative impacts on student-athletes' mental and physical well-being. Athletic and team participation is often believed to contribute to healthier physical well-being, positive relationship-building, and increases in self-esteem (Allender, Cowburn, \& Foster, 2006). However, the other sides of sport that are often overlooked are the social, psychological, and physical consequences that occur as a result of the exclusion of LGB athletes. To promote the safety and wellness of LGB athletes, social inclusion must be developed and sustained in the sport environment.

In order to create more inclusive environments, there is a need for more information at all levels Recognition of LGB individuals and issues in sport especially in high profile organizations is an important step. For instance, the LGBT College Athlete Report released by the NCAA stated that approximately five percent of the 8,481 NCAA student-athletes included in the study identified as LGBT, and $25 \%$ of those LGBT student-athletes were pressured to be silent about their sexuality by teammates (Rankin \& Merson, 2012). Incidences of harassment are also evident beyond sport, specifically on social media. In this same NCAA report, $21 \%$ of openly LGBT athletes self-reported that they had been targets of derogatory remarks on social media, which was double the percentage experienced by heterosexual teammates. 
High school. The use of homophobic language is an example of bullying, which has been largely discussed in high school settings. Nine out of 10 LGB students hear the word "gay" used in a negative way often in school and nearly three out of four LGB students reported hearing their peers make homophobic remarks, such as "dyke" or "faggot," often or frequently in school (Thinkb4youspeak, 2014). Many gay athletes reported hearing antigay language spoken by teammates and opponents in a sport setting, but did not report finding this particular language homophobic or homonegative due to it being experienced in a sport context (Anderson, 2000; Hekma, 1998; Price, 2000). However, even if the athletes do not perceive the language to be derogatory toward LGB individuals, youth LGB individuals hearing the phrase "that's so gay" may lead to feeling more isolated and experiencing physical health symptoms, such as headaches and altered eating patterns (Woodford, Howell, Silverschanz, \& Yu, 2012)

Griffin (2012) reported that there are an increasing number of LGB individuals coming out at younger ages, with the average being around 16 years, yet little attention has been focused specifically on high school athletics. The social importance and dynamics at the high school level can make for a complicated, but rewarding research exploration. Social identity theory (Taijel and Turner, 1979) states that there are three stages to social group membership. The first stage involves categorizing others (e.g. black or white, male or female). This categorization leads to the second stage, social identification. In this stage, a person decides to adopt the identity of a certain group and begins acting in the manner deemed appropriate for the particular group. The final stage is social comparison. It is in this third stage that discrimination may occur due to groups comparing themselves with other, sometimes rival, groups. Self-esteem can either be built or diminished depending on the whether a person is considered to be part of the "ingroup" or "out-group." 
If a person is in the "out-group", they may be exposed to more harmful situations and may behave in ways to maintain or strengthen their self-esteem. In the case of LGB individuals, a common response to others' disapproval and hostility is called "covering" or "passing," which involves one's attempts to hide their sexual orientation from others in order to avert potential homonegativism. This behavior can lead to high levels of stress, fear of discovery (SavinWilliams, 1994), and distancing self from others (Herek, 1991). The emotional and physical withdraw leads to declines in athletic and academic performance if LGB athletes feel uncomfortable or discriminated against by coaches or teammates (Rankin \& Merson, 2012). Lesbian, gay, and bisexual athletes may withdraw from teammates or lose interest in playing and cease participation totally (Griffin, 1994). Withdrawal from sport may lead to long-term consequences for LGB persons in terms of opportunities for relationship-building and physical activity adherence. Calzo and colleagues (2014) reported that LGB youth exercised at a moderate to vigorous level approximately 2 hours less each week and were 46-76\% less likely to participate in team sports than heterosexual youth.

National organizations, such as the Gay, Lesbian, Straight Education Network (GLSEN: Kosciw, Greytak, Bartkiewicz, Boesen, \& Palmer, 2012) are attempting to make the school environment safer and more respectful of LGB youth. However, even as there are more advocates and resources made available for coaches and athletes, there is an evident generational gap in comfort and awareness (Griffin, 2012). If coaches experience overt discomfort or even display an inadvertent lack of awareness, sport environments may continue to be plagued with homonegative language, LGB invisibility, docile interventions to bullying or discrimination, and heteronormativity will be sustained (Messner, 2002; Waldron \& Krane, 2005). 


\section{Coaches}

Due to their leadership role, coaches are the single most influential individuals for developing safe and inclusive team environments for LGB athletes. However, the generational gap between players and coaches can lead to the transmission of prejudice and intolerance (O’Bryan, Fishbein, \& Ritchey, 2004), creating numerous detrimental consequences.

Researchers surveyed 296 Division I and Division II collegiate coaches with regard to their confidence in working with LGB student-athletes (Vargas-Tonsing \& Oswalt, 2009), and results indicated that a vast majority of the coaches felt ineffective in their ability to identify available resources for LGB athletes and in preventing LGB issues from becoming a "distraction" on the team. This is of particular concern due to LGB athletes also having few LGB role models or other sources of support (Safren \& Rogers, 2001). Lack of resources and social support can create personal feelings of isolation and disconnection from team members.

Halbrook and Watson (2017) completed a follow-up study to Vargas-Tonsing and Oswalt's (2009) in an attempt to identify any similarities and differences in high school coaches' confidence in working with openly LGB athletes. The online survey was completed by 631 male and female high school coaches in the U.S. who represented 25 different sports. Respondents filled out coaching demographics, team demographics, and the Efficacy Scale to Coach Gay, Lesbian, and Bisexual Athletes (Vargas-Tonsing \& Oswalt, 2009). Results revealed that coaches who had higher efficacy with regard to LGB athletes were those coaches who had coached an openly LGB athlete previously, had some type of diversity training, and coaches who fell in the youngest age bracket, 18-29 years old.

Knowing the characteristics of coaches who feel more efficacious coaching openly LGB athletes is important, but both of the previous studies (Halbrook \& Watson, 2017; Vargas- 
Tonsing \& Oswalt, 2009) identified the need to further educate coaches on resources and supportive tactics for LGB athletes. Atkinson and DePalma (2009) state that in order to combat homonegativity, individuals need to disrupt heterosexual hegemonic behavior towards LGB individuals and attempt to understand such acts more deeply. The lack of intervention or confrontation from individuals in leadership positions may stem from the dominant discourse and, more simply, the lack of available resources or training for coaches. Discourse, in this case, refers to the "common language" and social structures of sport. Common language shapes how individuals view and interpret the world around them, perpetuating acceptable actions and beliefs (Krane, Waldron, Kauer, \& Semerjian, 2010; Rose, 2007). For example, homophobic or gendered slurs and phrases, such as "faggot", "dyke", or "playing like a girl” are disparaging comments that are still evident in men's and women's sport. The social structure of teams are often situated hierarchically. Coaches and those athletes who are perceived to be more stereotypically masculine or feminine are at the top of the social hierarchy, followed by an audience that emulates the leaders' behaviors (Messner, 2002).

Due to the overall sport culture, ethic, and engrained hierarchy, the dominant discourse can appear overwhelming when considering changing an overly masculinized culture to one of LGB acceptance and support. The task could potentially be made easier if specialized training and resources for parents, athletes, and coaches was made to be more known and accessible. Additional research projects, educational programs, and interventions are needed to help coaches create and foster a more encouraging and inclusive environment for LGB athletes and allies (Krane et al., 2010). 


\section{Purpose of the Study}

Currently, research regarding LGB individuals in sport is primarily limited to examining collegiate and professional athletes, personnel, and team environments, but there is a paucity of research conducted at the youth and high school levels. This is particularly problematic due to the average age of a person's coming out being 16 years old (Shilo \& Savaya, 2011). Therefore, through qualitative inquiry, the purpose of this phenomenological study was to explore the experiences and perceptions of high school head coaches in the United States who have coached an openly LGB athlete in their career, specifically regarding perceived strengths and weaknesses for providing support to openly LGB athletes and the impact of diversity training, or lack thereof, on coaching openly LGB athletes. This information will be used to improve the sport environment for LGB athletes by providing the data needed to begin the development of support resources dedicated to informing youth and high school coaches.

\section{Methods}

The researcher's ontological position is grounded in beliefs that (1) reality is created from multiple truths experienced through individual perception, called subjectivism (Ponterotto, 2005) and (2) there is one reality that can only be seen through each person's lens, called constructivism (Crotty, 1998). These perceptions are developed through each participant's past and current experiences and their social environment. Therefore, the paradigm directing the current project is social constructivism-interpretivism, which is intended to understand lived experiences and perspectives (Ponterotto, 2005). The researcher attempted to accurately describe these coaches' experiences and not attempt to manipulate or change coach perspectives or beliefs (Hoepfl, 1997; Patton, 2001). The "participant dominant" approach of the constructivist-interpretivist perspective promotes coach voices to be heard more fully by the 
researcher (Krane \& Baird, 2005) after acknowledging the researcher's own experiences and assumptions of society (Schwandt, 2007).

The researcher interviewed the participants using a semi-structured interviews and gained access to coach insights after building rapport (Shannon \& Gentner, 2007). These interviews drew on specific examples and the experiences coaches had while working with LGB athletes. Given the difficulty in gathering accurate information on this topic, often due to social desirability, a phenomenological interview was perceived to be the most effective technique for further exploration of coaches' experiences (Dale, 1996; Ryba, 2007). The phenomenological approach aligns well with social constructivism-interpretivism due to the method and research paradigm both focusing on the culturally assigned meanings of participant experiences.

\section{Positionality Statement}

In qualitative research, the researcher becomes part of the research process as an instrument, actively involved and immersed in the data collection process (Patton, 2001). The researcher's background, experiences, and her reasoning for embarking on this research study may shape her interpretations of coach experiences (Creswell, 2007). Due to the researcher playing such an essential role in the research process, it is imperative that she was able to clearly consider her own past experiences as both an openly LGB athlete and as the coach of openly gay athletes in order to bring awareness to any potential biases. These were very different experiences, as one might expect, and shaped much of her perspective of how discriminatory, but also accepting, teams can be at the high school and young adult ages. As a coach, the researcher worked with many age groups, ranging from 10 year olds participating in a competitive travel league to 18-23 year student-athletes at the junior college level. The researcher also coached two high school softball teams over the course of five years. 
Both high school teams she coached were located in the Midwest, but one team consisted of multiple openly lesbian athletes and a culture of acceptance, and the other team had no openly lesbian athletes. In both situations, the opportunity to interact with such a large variety of athletes, other coaches, and team environments helped shape her passion and perceptions of current issues and concerns for LGB athletes. Additionally, as a $\mathrm{PhD}$ student in Sport and Exercise Psychology, she developed beliefs about best practices for coaches and means of implementation through research and practice in order to create a safe and inclusive environment for LGB athletes. It was imperative that the researcher explored her own experiences and perceptions of this phenomena in her own life and sport experiences to make values and interpretive biases evident prior to engaging with participants.

\section{Participants}

Participants were selected from the sample of 225 male and female high school coaches who participated in a previous quantitative study conducted by the researcher (Blinded for Review). At the end of the previous quantitative survey, participants could select if they were interested in being part of a follow-up interview and research study. If they selected yes, they were then prompted to disclose their name, email, and phone number. All 225 participants who expressed an interest in participating in a follow-up study were considered for selection. The participants were selected using maximum variation sampling. According to Maykut and Morehouse (2000), maximum variation sampling is intended to represent a wide range of experiences related to the phenomenon of interest. It is not the goal to build a random and generalizable sample, but rather to represent a vast array of experiences. Therefore, the researcher attempted to select diverse participants, assigning particular weight to geographic locations, sports coached, racial/ethnic backgrounds, ages, and years coaching. Forty-three 
coaches were contacted for the current study. Eighteen coaches were no longer eligible for participation, 14 did not respond to email correspondence, and one declined to participate.

Ten high school head coaches (6 male, 4 female) participated in the current study. The coaches ranged in age from 31 to 68 years and had been coaching for between three and 30 years. The participants coached track \& field $(n=2)$, cross country $(n=1)$, volleyball $(n=2)$, softball $(n=2)$, women's basketball $(n=3)$, men's soccer $(n=2)$, women's soccer $(n=1)$, and men's and women's golf $(\mathrm{n}=1)$. The coaches self-identified as heterosexual $(\mathrm{n}=9)$ and gay $(\mathrm{n}=$ 1). Two female coaches identified as Black, one male coach identified as Caucasian/Asian, and the remaining coaches identified as Caucasian. Eight states were represented amongst the coaches.

\section{Data Collection Procedures}

A semi-structured interview guide was used to guide the interviews with coaches (Bernard, 1988). The interview guide contained questions regarding participants' experiences with diversity training (e.g. "how effective do you believe LGB diversity trainings would be/are to coach education?"), challenges or difficulties with coaching an openly LGB athlete (e.g. “What were the challenges associated with coaching an openly LGB athlete, if any?”), perceptions of support for openly LGB athletes, and changes they experienced through coaching openly LGB athletes (e.g. "How have your perceptions of LGB individuals changed after having coached an LGB athlete?"). Probes (e.g. "please tell me more about that") were used to extend the discussion and encourage participants to elaborate on their responses.

Institutional Review Board (IRB) approval was obtained, and each selected participant was emailed a recruitment message and cover letter. If interested in participating, the coach responded back to the researcher and the researcher checked to ensure coach eligibility. After 
participation eligibility was verified, the researcher and participant identified a day and time that was convenient for the participant to complete the interview. All participants were contacted via Go-To-Meeting to participate in the semi-structured interview. Go-To-Meeting was chosen as a form of media that allowed the researcher and the interviewee to have visual contact with each other, as opposed to only audio contact in a phone interview. This was a video conferencing service that could be accessed by anyone with the researcher established URL.

Prior to beginning, participants were reminded about confidentiality, including the agreement for recording of the interview and the use of synchronous technology. Specifically, within the cover letter, all participants were provided information about the risks to confidentiality associated with the use of technology (APA Ethics Code 4.02; Watson, Tenenbaum, Lidor, \& Alfermann, 2001). The researcher also took the precautionary steps of using a computer with an up-to-date firewall system and kept the interview recordings on a password protected computer in a locked room.

Scribie, an external transcription service was used to transcribe interviews. In order to maintain the confidentiality of participants, the audio files were split into smaller parts before being distributed to transcribers, not allowing for any one transcriber to have access to a full interview. All Scribie transcribers and employees are bound by a confidentiality clause within the company. Lastly, the audio files were only kept on the transcription site until transcription documents were completed and returned to the researcher. Once each transcript was returned, the researcher listened to each interview and reviewed the transcription for any grammatical or syntax errors. This review also allowed the researcher to listen to the interview a second time more slowly and to begin thinking about the interview meaning as a whole and potential themes 
(Kleiman, 2004). Once the transcriptions were reviewed and corrected, the researcher began the actual data analysis process. NVivo 10 was used to store and organize data for analyses.

\section{Data Analysis and Interpretation}

Phenomenological open coding reduces large amounts of data to a smaller set of themes that describe the coaches' experiences with openly LGB athletes (Kleiman, 2004). Each stage of the coding process was completed by the researcher and two additional individuals with experience in qualitative research in sport, the field of sport psychology, and coursework in the area of multicultural issues. Researcher or "analyst triangulation” (Denzin, 1978; Patton, 1999) benefitted the research process by increasing awareness of potential researcher biases and, therefore, increasing trustworthiness and credibility by helping to separate researcher experiences from those discussed by the participants (Colaizzi, 1973; Gadamer, 1996; Finlay, 2008). The researchers analyzed the interviews using a general inductive approach.

Assumptions underlying the use of an inductive approach are that data analysis is determined by the research objectives (deductive) and interpretations of the raw data (inductive) (Thomas, 2006). Furthermore, the research findings are a result of the assumptions and experiences of the researchers conducting and analyzing the data and researchers must make decisions about what is important in the data, eventually settling on 3-8 thematic categories (Creswell, 2002).

Following additional qualitative analysis suggestions and protocols from Gibbs (2007) and Ryan and Bernard (2003), the research team met four times over the course of the project, online and in-person. The first meeting occurred online and prior to beginning the interviews. This initial discussion involved the selection of possible participants from the pre-identified list of previous participants whom had agreed to participate. The next meeting was after the completion of all interviews and involved data labeling and revisions. In order to ascertain 
meaning from the transcripts and the identification of potential themes, the researchers read and reread each transcript and then labeled themes individually. These individual codes were then compared, refined, and themes were condensed into more specific categories eventually coming to a group consensus within the research team. During the third meeting, the researchers carefully considered the data in order to identify themes, similarities, and differences between comments and participant experiences. The final meeting with the research team was used to discuss connections between the quantitative data from the original quantitative study and the current qualitative responses.

\section{Research Quality and Ethical Concerns}

Utilizing additional experienced researchers is believed to increase the trustworthiness of analyses (Morrow, 2005). The choice to employ two researchers to examine methodology, transcripts, and the final report was done with the intent that peer debriefing would result in identification of over- or underemphasized points or themes, vague descriptions, errors, or evident biases (Glesne, 2006; Johnson, 1997; Marshall \& Rossman, 2011). Furthermore, due to the use of an inductive approach, the researcher connected all identified themes back to wellknown and established research (Flick, 2004).

Additionally, due to the researcher having access to quantitative data from the previous study with the selected coaches, interview responses were compared to the coaches' quantitative data, specifically the coaches' responses on the Efficacy Scale to Coach Gay, Lesbian, and Bisexual Athletes (Vargas-Tonsing \& Oswalt, 2009). This comparison provided an opportunity for the researcher to further analyze and detect inconsistent or even conflicting findings in the quantitative and qualitative responses. When such discrepancies occurred, the researcher had the opportunity to explore why these inconsistencies existed (e.g., change in coach experience/ 
perspective, coding issue, or simply unanticipated anomalies) (Miles et al., 2014). Triangulating with multiple data collection methods can help improve trustworthiness and credibility, strengthening the research (Mathison, 1988; Miles, Huberman, \& Saldana, 2014; Patton, 2001).

To further ensure reliability of the data, the researcher engaged in activities aimed at examining the research process and product (Hoepfl, 1997). First, the researcher completed four interviews with high school coaches whom the researcher knew, or was connected to by personal contacts, before beginning interviews with the selected research participants. These interviews allowed for the researcher to pilot the interview questions, format, and Go-To-Meeting software. It was also a chance for the researcher to bracket the thoughts and concerns that arose for her during the interviews, as well as to identify preconceived beliefs about LGB issues, athletes, and coaching. Once all the formal research interviews were completed and coded by the research team, the table of overall themes and descriptions were emailed to each participant to determine the accuracy of the findings (Creswell, 2009). Member checks have been considered the "single most important provision that can be made to bolster a study’s credibility (Guba \& Lincoln, 1989; Shenton, 2004, p. 68). Two coaches responded to the member check email. Neither coach offered any corrective feedback to the identified themes.

Lastly, the researcher kept analytic memos about these interviews and all subsequent interviews and research tasks. Analytic memos create transparency within the research process by engaging in self-reflection of the research design and data collection. The analytic memos allowed the researcher to regularly write about the research experience (Groenewald, 2008; Mills, 1959). The analytic memos were recorded throughout the data collection and analysis process as research design is continuous in qualitative research (Maxwell, 2012). The memos were kept in an electronic file, but were also recorded in transcription margins. Unlike more 
formalized qualitative reflection journals, analytic memos were completed for the sole purpose of expressing researcher thoughts.

\section{Results and Discussion}

The primary characteristic of phenomenological research is the focus on being able to identify and then describe the "essence" of an experience from the point of view of the individual being interviewed (Merriam, 2002). The findings of this study revealed four primary themes related to high school coaches' experiences with openly LGB athletes. Additional areas of interest included how coaches perceived themselves to be most and least effective when providing support for openly LGB athletes and how coaches' diversity training, or lack thereof, influenced their coaching of teams containing openly LGB athletes. The primary themes that emerged were team environment dogmas and observations, fundamental beliefs contributing to perceptions of LGB athletes, types and timing of sexual orientation disclosure, and differential LGB athlete characteristics. Each of these primary themes also exposed a number of subthemes that were developed from content in the various coach responses. Collectively, the experiences revealed by the coaches provide insight into the current climate and intricacies of high school athletics and coaching.

Team Environment Dogmas and Observations. A large focus of the current study was identifying coach experiences with openly LGB athletes, and this task was often achieved by learning about the team environment. Coaches generally felt that sport was, or should be "void of sexuality." To many of the coaches, sexuality was simply not a necessary topic of concern to be addressed in a team setting due to the perception that there were no issues associated with athlete sexuality on the team. This is not to say that coaches were unaware of athlete sexual orientation. Athlete sexual orientation was commonly acknowledged but not discussed, which is 
observed in other research studies regarding LGB athletes and coach responses (Viel \& Demers, 2013). Instead, emphasis was put on being a good teammate first, meaning that if the athlete is following team guidelines and is not causing issues, then they are fulfilling the necessary requirements. Christal, a 34-year-old track and field coach, was very direct in her beliefs:

...all I care about is, "Are you a good teammate? It doesn't matter your sexual preference or what you do, whenever you do it." "Did you come to practice? Are you a good teammate? Did you try your best?" That's all that should matter. To me, it's that simple.

However, there is a difference between the "don't ask, don't tell" culture (Anderson, 2005) and the "if you can play, you can play" or "changing the game" movements created by LGB and ally organizations. The former indicates tolerance, while the latter promotes a sense of acceptance. For example, despite Christal stating that she is indifferent regarding LGB athletes, the use of the word "preference" may indicates an underlying belief about sexual orientation.

Across all coaches, there was the belief that society today is much more accepting of LGB individuals and their rights (Loftus, 2001). In a recent meta-analysis, this belief was substantiated regarding societal acceptance of gay men (Newcomb \& Mustanski, 2011). However, many of the coaches believed that social acceptance on their teams was specifically due to athletes wanting to keep the peace and "follow the crowd." In short, coaches believed that athletes who held negative views of LGB teammates would be less likely to bring up concerns if they believed that other teammates were supportive of the LGB athlete. This hesitancy was exacerbated by the coaches' perspective that youth currently perceive being "different" as being “cool" or "in vogue."

Jeren; I would say it's very in vogue right now to be accepting of people of different mindsets and cultures. I think there is, especially at the junior high and high school level, there is a general feeling of not wanting to go against the grain. 
This type of example given by coaches identifies with the concept of pluralistic ignorance, which is the tendency to perceive others' attitudes as more positive or negative than they may actually be (Prentice \& Miller, 1993). Pluralistic ignorance has been observed to impact attitudes surrounding sexuality (Cohen \& Shotland, 1996).

Despite the belief that some athletes may enjoy having an LGB teammate, many of the coaches described instances where comments and jokes were made at the expense of the LGB athlete. Coaches often perceived these comments to be "in jest" or innocent, but there are concerns surrounding the use of heterosexist language around LGB individuals. For example, in a study by Woodford and colleagues (2012) with youth aged 18-25 years, hearing the phrase "that's so gay" equated to LGB individuals feeling more isolated and experiencing physical health symptoms, such as headaches and altered eating patterns. It was also reported in the study that "that's so gay" may be perceived as less intense than hearing more directed language, such as "dyke" or "fag." Two coaches specifically brought up the need to change athlete language after establishing that there was an openly gay male on their teams. This is representative of results found in other studies. In one example, male students tended to use sexually discriminatory language for bullying, regardless of their acceptance of gays or lesbians (Berlan, Corliss, Field, Goodman, \& Austin, 2010; Poteat \& Digiovanni, 2010). Therefore, even if coaches do not perceive these words or comments to be intended hostilely or even in a serious nature, the impact it may be leaving on the LGB athlete is unknown.

Fundamental Beliefs Contributing to Perceptions of LGB Athletes. The nature vs nurture debate regarding sexual orientation has been of much importance over the years. Generally, people either believe that sexuality is an inherent, biological characteristic or that sexuality is influenced by a child's upbringing, or that it is even a deliberate "choice" that one 
makes as they get older. In an article released by the Liberty Education Forum, a 2004 poll was completed to evaluate existing support for gay marriage. Seventy-nine percent of people who believed sexuality was a biological trait also supported gay marriage. However, for those individuals who believed that sexuality was a choice, only $22 \%$ supported gay marriage (Burr, 2005). For coaches, knowing how they perceive sexual orientation may lead to a better understanding of their perceptions regarding inclusivity and LGB rights. Of the current sample, there were varying beliefs. A few coaches made it clear that they believed sexuality was biological, but other coaches regularly used the words "choice", "preference", or "lifestyle" leading the researcher to believe that they felt that sexual orientation is something that is nurtured or chosen. Nikki was one of these coaches:

I have my own beliefs and I have my own opinions, but I'm not gonna be one of those that runs around and damns you to hell 'cause you've chose that lifestyle.

Like Christal, Nikki is seemingly expressing a level of acceptance by not condemning an LGB athlete. Yet, when asked how she dealt with having personal beliefs and opinions that contrasted with her position as a head coach, she stated that it "wasn't easy."

On both sides of the debate, coaches in the current study seemed to recognize that their beliefs were less important than the overall purpose of coaching. The role of the coach is one that is often discussed in the sport arena. Overall, the interviewed coaches had very clear perceptions about the purposes of their role as a head coach working with high school athletes, such as helping athletes become independent and courageous. In a study by Gilbert and Trudel (2004), coaches reported similar results to the current study, emphasizing the importance of creating a positive and safe team environment and encouraging personal growth and development. Ken, a 52-year-old women's basketball coach, often focused on being a role model for young student-athletes: 
You offer, as a coach, a moment of stability and structure every day, in some form or another during that season, and so I never forget the fact that how I carry myself is also a major influence on athletes.

Cook (1984) reported that a coaching position, or someone in a sanctioned authoritative role, does have the ability to influence perspectives and reduce prejudice towards minority groups. This is particularly true if coaches outwardly support LGB student-athletes and implement strategies to encourage positive interactions between openly LGB and heterosexual athletes. Furthermore, research indicates that treating athletes all the same vs "underdogs" may actually be more impactful in ridding an out-group of negative stereotypes (Brown, 1984).

Due to many of the coaches having the belief and approach that all athletes should be treated the same, regardless of sexual orientation, they were often in positions that required a reactive response when there was an area of contention. As stated previously, some coaches hesitated to openly discuss this topic because of their, generally, accepting beliefs surrounding LGB athletes or individuals and feeling like this should be the norm on the team. Other coaches reported that it was an "awkward conversation." Vargas-Tonsing (2007) found that youth coaches are more likely to pursue continuing education on a variety of topics if it is a requirement or is perceived to be relevant to their sport or team. For this reason, coaches should be encouraged to learn about evidence-based recommendations for promoting the health and safety of LGB youth from reputable institutions such as The Centers for Disease Control (CDC, 2012) and The Gay, Lesbian, \& Straight Education Network (GLSEN, 2012).

The development of a positive perspective surrounding LGB student athletes often began in childhood for the interviewed coaches. Many of them talked about family friends who were LGB or having experience playing on a team in high school or college that included an openly LGB athlete. Coaches' upbringing is what many attributed to their current perceptions of LGB 
individuals. Ken, a male coach from Oregon, credits his parents and their perspective of diversity with his current coaching approach to LGB athletes:

I think it was probably, as much as anything, upbringing, parents who were accepting of other people's differences in life, and so obviously that passed on to me. It's just the way I've always been, more or less.

This information supports Allport's contact hypothesis (1954), which states that exposure to a negatively stereotyped group should create fewer negative associations and beliefs surrounding that group. This is especially true if interactions between out-group members (LGB) and ingroup members (heterosexual) were cooperative, as is typically encouraged in a team setting (Deschamps \& Brown, 1983). Athletes at the high school level are still in the midst of identifying their moral and ethical value systems, which indicates that their experiences on sport teams may lead to the development of more positive or negative perceptions of LGB teammates and individuals into the future (Bowen \& Bourgeois, 2001).

Types and Timing of Sexual Orientation Disclosure. In the sample of 10 coaches for the current study, there were a myriad of ways that the sexual orientation of athletes became known to the coach. For some, coaches were linked to the athlete's social media accounts and were able to deduce from posts that the athlete was LGB. In some cases, it was more straightforward, with information about an athlete's sexual orientation coming from teammate disclosure or a direct conversation with the LGB athlete. In other common cases, coaches made an assumption about certain athletes, despite these athletes not being open about their sexual orientation. These assumptions were primarily based on appearance, rumors, mannerisms, or other unsubstantiated evidence. Craig, a 62-year-old cross country coach, referred to one athlete he had coached:

I coached her for five years, and the haircut, not going to prom, going to prom with girls, how she carried herself, those types of things. I inferred that probably, but maybe in the environment she was, she didn't feel...great coming out. 
According to Viel and Demers (2013), the modality through which an athlete chooses to disclose their sexual orientation is often due to the perception of the inclusivity of the sport environment or a specific life event. For example, one of the coaches in the current study talked about an athlete coming to him with relationship concerns and another reported that the athlete's sexual orientation disclosure was a "by-product" of a discussion involving playing collegiate sport.

Another common time for an athlete to choose to disclose their sexual orientation is at the end of their career due to feeling like they "have nothing to lose" (Viel \& Demers, 2013). In the case of the current study, this would be when the athlete graduates from high school and enters college. One coach, Jan, a 57-year-old women's volleyball coach, attributes the hesitancy to coming out in high school to potential bullying between teammates, specifically male athletes:

'Cause we actually had a couple that...Boys, and they didn't come out until after high school. And that's a different situation. They felt like they were picked on...

Jan also mentioned that she had other athletes that waited to come out about their sexual orientation for reasons unbeknownst to her. From the researcher's perspective, Jan's quote indicates that some of her male athletes felt "picked on" but she never elaborated on what she did to address these athlete's concerns. If she chose to not get involved, she was supporting those who were the bullies and perpetuating a homonegative environment.

Sexual orientation openness in college may also be preferred to the athlete due to perceptions of potential parental concerns or beliefs. Parents play a significant role in the young athlete's life, providing not only emotional support, but financial support as well. The athlete may be worried about disclosing his/her sexuality for fear of losing friends, love from family, financial stability, or even physical safety (Herriot \& Halcro, 2014). Therefore, if an athlete does disclose his/her sexual orientation or a coach becomes aware of an LGB athlete on their team, it is recommended that they follow the suggestions of Pat Griffin and colleagues (2002) who 
developed the "It Takes a Team!" education campaign for LGBT Issues in Sport. These suggestions include using inclusive language, learning about homonegativity and homosexuality in general, enlisting the team captain's assistance in monitoring team climate, treating everyone on the team with respect, and being open about addressing the possibilities of same-sex relationships.

Differential Characteristics of LGB Athletes. The last theme that emerged was related to the differences in athlete characteristics. One area which was more novel to the research than other themes identified, was the concept that the athlete's talent level potentially equates to preferential treatment by teammates and coaches. Several of the coaches made it clear that their openly LGB athlete was also one of, if not, the best players on the team. This status within the organization gave more power to the athlete, creating greater acceptance or at least a hesitancy to “cut down" the athlete. Jeren, a 31-year-old men's soccer coach, bluntly stated this notion:

This is going to sound like a horrendously superficial thing to say, but both were really good players. And so, when you're in a team environment, you could pretty much be a serial killer and if you're good enough, everybody's gonna accept it. I think that made things easier, especially on the boys' side. The young man was a phenomenal talent... This is just completely conjecture on my part, but I think if it had been the type of deal where...I think if it had been the case where he was a lesser talent...I don't think he would have had the social interaction that he displayed during practices and games, or the confidence that he had in himself and his orientation, if it had been a different level of talent.

This result is replicated in two previous studies, one with openly gay males (Anderson, 2002) and another with openly lesbian athletes (Anderson \& Bullingham, 2013). Yet, not every LGB athlete is going to be the best player on the team, so more research should be completed to assess differences in athlete feelings of inclusivity based on talent or starter status.

Even on teams with exemplary LGB athletes, coaches in the current study stated that they had heard homonegative language used by athletes on both male and female teams. This finding 
is similar to many other athlete experiences identified in previous research (Anderson, 2000;

Price, 2000). It did appear from the current study, though, that there may be more positive reactions to having an LGB teammate on female teams than on male teams. For example, teammates of a lesbian couple on one team would lie for the couple to one athlete's parent versus an apparent discomfort or silence surrounding the issue on male teams. Stoelting (2011) found that some lesbian athletes chose to disclose their sexualities because sport is perceived to be a "safe zone" where lesbian athletes can be their "true self."

The differences in teammate responses between male and female teams may be more dependent on the sport played than simply on sex differences. Coaches in the current study often felt that their sport was more accepting of athlete diversity than other, more masculinized sports, such as men's basketball or football. Linda, a 49-year-old women's basketball coach, brought up football during her interview after talking about how accepting her teams had been of openly LGB athletes:

And I could be totally off-base, but I would think that the football coaches would have a problem with it. But as I said, I don't know for sure, but just because of the whole macho, manly thing.

This viewpoint aligns with previous researched perceptions of traditional, masculine sports, especially those directly encouraging conformity and aggression (Loughran, 2009; Martens \& Mobley, 2005). However, it should be noted that even though males in and out of these masculinized sports may be more likely to experience discrimination or bullying related to their sexual orientation, or even their perceived sexual orientation, female students may be more affected, causing an increase in bouts of depression and thoughts of suicide (Sawyer, Bradshaw, \& O’Brennan, 2008). 
The last characteristic of athletes and teams which may impact the level of comfort an athlete has in being open about their sexuality is geographical location. Coaches referred to the perception that "the south" and areas falling into "the Bible belt" were generally less accepting than areas considered more liberal. This information is corroborated by the National School Climate Survey put out by GLSEN (Kosciw et al., 2016), which indicated that almost 50\% of LGBTQ students living in southern states heard the term "gay" used negatively, followed by $41 \%$ in the Midwest. These two geographical locations also had the most instances of verbal harassment, physical harassment, and physical assault based on sexuality. Nikki, a 31-year-old swimming and diving coach who coaches in North Carolina, discussed her perception:

A lot of times we are described as the Bible Belt. There is lots of opinions here, lot of church goers. I would label them as "Christians." I mean, I would consider myself a Christian as well, but there are a lot of, I would say, opinions, and people are not scared to really say it...

Fittingly, location is not the only factor that could contribute to athlete openness. Students who attended religious schools reported substantially higher rates of discriminatory behavior than public schools and private non-religious institutions. Therefore, though many of the coaches with teams in these areas felt that their team or school was accepting, it is important to be aware that the actual experiences of LGB students could be less accepting than coach perception.

\section{Connection to the Research Questions}

At the beginning of this research study, one primary and two secondary research questions were formed by the researcher. These questions provided some direction for the project, but were deliberately formed to obtain information related to the experiences of high school coaches in order to fill gaps in the current literature surrounding LGB athletes at the high school level. At the conclusion of the interviews and open coding process, the researcher was 
able to connect emergent themes back to the established research questions and directly address specific areas of emphasis.

\section{What are the experiences of high school coaches in coaching openly LGB athletes?}

The vast majority of interviewed coaches expressed uneventful experiences interacting with openly LGB athletes. They felt that if they were able to adequately fulfill the role of the coach, build a respectful program, and enforce their tolerant and inclusive beliefs that the heterosexual athletes would behave accordingly towards their openly LGB teammates. The teammate first approach was mentioned numerous times as an effective method of encouraging acceptance in high school sports. However, a few of the coaches did bring up issues they confronted over the years regarding openly LGB athletes. The first example involves the use of derogatory language, or potentially jokes, associated with LGB individuals.

The only thing that I had to curtail on the boys' side is the rampant use of the word "fag." The context that it's being used in isn't, "Hey, this is a derogatory slam on homosexuality in general." It's in that moment a commonly used put-down between two young men who are heterosexual. For me, I'm not the type of person that gets super offended when I hear that word. But in context of having a young man, who I knew is homosexual...I didn't want him to feel like that was a possibility. That the words that they were using were possibly aimed at having a genuine dislike for homosexuals.

The next example illustrates a "locker room" concern that is often a topic of discussion with regard to LGB athletes. It should be noted that although this scenario is a coach or teammate concern at times, only two coaches brought up the issue and only one coach had an actual incident to discuss:

I think she just wanted to kinda be modest, because you know changing bathing suits and stuff in front of the girls, I don't think she wanted to scare off her friends or make anybody uncomfortable...

The lack of specific incidents across this sample of coaches could be perceived as a positive shift in the high school sport culture of LGB acceptance. On the opposite side, the lack of memorable experiences also contributes to coach perceptions that sport is "void of sexuality" 
which is not true on many teams, in many locations within the United States. It should be noted that this perception could simply be due to the coaches being oblivious or unaware of issues associated with LGB athletes and, therefore, overlooking potentially negative behavior. In what areas do high school coaches perceive themselves to be most and least effective when providing support for openly LGB athletes on their teams?

As mentioned previously, coaches felt competent in their ability to create an accepting environment through communication, establishing expectations, and being a role model for both heterosexual and LGB athletes. Christal, a 34-year-old track and field coach, discussed the importance of taking time with each athlete to develop individual relationships, leading to more openness and honesty by all of her athletes:

It's the hardest, it's really a delicate balancing act to do. I do understand that. But I try to make it a point to have a moment with each one of them throughout the week, whether it be during the school day, before or after practice. I do talk to them one-on-one a lot. And I think if they know you care about them as a person, not just an athlete, then hopefully they will share what's going on with them.

Oftentimes, the expectations set for the team were reportedly established for all athletes, regardless of sexuality, indicating the "all the same" theme. Craig, a 62-year-old cross country coach, gives an example of the regulations he has used with his teams in the past:

...you just have to have your parameters up, you have to explain the behaviors that are and aren't accepted. For example, no public display of affection, we don't allow that, we're not gonna have that. No drug abuse, no alcohol, all that stuff. Well, part of my job is to make sure they don't have the ability to do that, so we have chaperones on every floor, all that stuff. Just real good coaching common sense.

"Real good common sense" looks different for each coach, but each coach interviewed had their own set of policies used to address player behavior and keep up with their athletes. Many coaches used a very contemporary way of keeping up with their athletes, social media. When the researcher asked about if or how the coaches' perceptions have changed after coaching an 
openly LGB athlete, only two coaches reported that their perceptions or behavior had altered. In both cases, the coaches stated that they became more protective or sensitive to the needs of the LGB athletes due to perceiving them as "underdogs."

The primary area where coaches felt least effective, which was also indicated in the quantitative data from the previous research study, was in their ability, or potentially just desire, to identify and utilize resources regarding LGB athletes. Only two coaches actually discussed times when they sought outside resources for assistance with LGB athletes. All other coaches discussed hypothetical situations in which they may feel the desire to seek resources. For example, Gregg, a 48-year-old men's and women's volleyball coach, utilized a co-worker:

She worked in campus ministry and she's gay. But coincidentally then this situation with Laura, so I really relied on Shannon to help me bring resources to our team as far as sexuality was concerned, and to talk about that...

In this example, Gregg found an outside person to come in and deliver content to the team about LGB athletes. In the only other example given by the coaches, Larry sought experience and advice from LGB acquaintances on how to approach situations and guidance on mindset and appropriate responses to different situations.

How do coaches perceive their diversity training, or lack thereof, to influence their coaching of teams that contain openly LGB athletes?

Only two coaches had actually experienced coach-specific structured training regarding diversity issues or LGB individuals. In fact, there was only one coach that intentionally attended a session at a national conference that was focused on coaching LGB individuals. Some of the coaches had received training, which may have included LGB issues, when they were in graduate school. This was memorable for several of the coaches who stated that it did impact their coaching. Nikki stated, "I walked away feeling like a better coach just because I've been exposed to information..." This sentiment was echoed by Craig, a cross country coach located in 
Virginia, who reported that he learned more about sexual orientation in general during the class, leading him to have a different perspective about LGB individuals. This is an example of how upbringing and perception of nature vs nurture can influence coaching:

For me, the enlightenment of how people got to where they are in their sexuality, that helped me a lot. I am extremely heterosexual. And so my brain doesn't quite...I can appreciate it, and I can accept it, but it helped me get the understanding of it. And then also understanding the continuum of sexuality, that helped me a lot too.

Despite many coaches not having structured training, they did see the benefits of having training available to high school coaches on the topic of LGB athletes. Larry, a 68-year-old veteran coach of 25 years, noted the importance of training for new coaches:

We're trying to bring in new coaches or having new coaches start without some kind of preparation in that area. Because, they're going to experience it. If they coach women's or men, either way, they're gonna experience it at some point in their career, if they stay in coaching very long, they're gonna have to be able to handle or know how they want to deal with some of those situations.

Gregg, a men's and women's volleyball coach in New Mexico, even expressed what he would like the training to include and how it should be facilitated for other coaches:

I don't want to know what Dr. John Smith, PhD has to say about it. I wanna know what these kids have to say about it, and ...I'd like to share my experiences with it, and I'd like for them to share their's, and I'd like for it to be more meaningful and less scholarly.

Yet, even with a desire for more available training and ideas of how to facilitate a training on this topic, many coaches expressed that seeking out additional training on top of their current coach responsibilities would be a reactive response to a situation and not an action done proactively in most cases. As Nikki, a four year head coach of swimming and diving, described:

I feel like it would just be another hoop that people would just jump through, and not take it seriously, and it'd be a waste of their time. And they'd just sit there and probably roll their eyes... You can barely get people to fill out their concussion forms...

Agreeably, it may be hard and challenging, but Steve was direct in his final statement, "the better educated everyone is, the stronger we'll all be." 


\section{Assumptions and Limitations}

For the current study, it was assumed that participants answered candidly to interview questions based on their personal experiences and perceptions (Wargo, 2015). The inclusion criteria for the sample was reviewed extensively and confirmed for each participant, with the primary criteria being that the high school head coach has worked with an openly LGB athlete. It was assumed that all participants self-selected to participate due to sincere interest in the research and did not have any ulterior motives. However, it can also be assumed that coaches who participated may have had preconceived biases and, therefore, were inclined to partake in the quantitative and qualitative studies. These biases may have influenced their responses in the current study. Only coaches were contacted and utilized in this study, despite openly discussing various student-athletes during the interviews. The interactivity between the coaches and openly LGB student-athletes were not corroborated, nor were stated experiences of head coaches or athletes, in general. This specific limitation is typical in phenomenological exploration.

The results of this study are not intended to be generalized to the entire population, but should be considered transferable to similar head high school coaches located in the United States who have coached openly LGB athletes. The selection of coaches for the current study purposefully allowed for a wide range of coach experiences and characteristics, such as age, sports coached, religion, ethnicity, and geographical location, to allow for such generalizations. The final number of coaches selected for interviews was determined once a level of saturation within the data was reached, indicating no new themes were being developed.

\section{Future Directions}

The data gathered during the interviews with coaches in the current study have the potential to have a positive and significant impact on high school sport and the experiences of 
LGB athletes. With the age of openly LGB individuals decreasing, indicating an increase in openly LGB athletes in high school, it is imperative that more attention be paid to this specific population. This realization is reinforced by research that leads one to believe that a homonegative environment is created and reinforced prior to athletes reaching the collegiate level (Ryan, 2000). Yet, the limited amount of research with youth populations creates questions regarding the perceptions and experiences of high school coaches with openly LGB athletes and their development of a diverse, inclusive atmosphere. For example, when should efforts begin within sport and education so that LGB youth are able to develop a positive self-identity and increase self-esteem (Grant et al., 2014)?

Through completion of the current study, many of the initial researcher questions were addressed. Yet, these answers only led to a more focused direction for future research exploration. For example, future research should target openly LGB high school athletes to discuss experiences with coaches and in the team setting from their own perspective. Many of the coaches reiterated that much of what they observed appeared accepting and inclusive on their respective teams, but that they were generally only able to witness interactions at practice and competitions. Being able to elucidate more information from the LGB athletes themselves about what happens in the locker room and social settings will provide a deeper understanding to the coaches' perspectives. The data from the current study and future studies surrounding this topic will fill a gap in recent literature and therefore lead to the development of topical content for future coaching education and workshops, with the intent to improve the experiences of everyone, regardless of sexual orientation, in high school sports. 


\section{References}

Allender, S., Cowburn, G., \& Foster, C. (2006). Understanding participation in sport and physical activity among children and adults: A review of qualitative studies. Health Education Research, 21(6), 826-835.

Allport, G. (1954). The Nature of Prejudice. Reading, MA: Addison-Wesley.

Anderson, E. (2000). Trailblazing: America's first openly gay high school coach. Hollywood, CA: Alyson Press.

Anderson, E. (2002). Openly gay athletes: Contesting hegemonic masculinity in a homophobic environment. Gender \& Society, 16(6), 860-877.

Anderson, E. (2005). In the game: Gay athletes and the cult of masculinity. Albany, NY: SUNY Press.

Anderson, E. \& Bullingham, R. (2013). Openly lesbian team sport athletes in an era of decreasing homohysteria. International Review for the Sociology of Sport, 50(6), DOI: $10.1177 / 1012690213490520$

Atkinson, E. \& DePalma, R. (2009). Un-believing the matrix: Queering consensual heteronormativity. Gender and Education, 21(1), 17-29.

Barber, H. \& Krane, V. (2007). Creating a positive climate for lesbian, gay, bisexual, and transgender youths. Journal of Physical Education, Recreation, and Dance, 78, 6-52.

Berlan, E.D., Corliss, H.L., Field, A.E., Goodman, E., \& Austin, S.B. (2010). Sexual orientation and bully among adolescents in the growing up today study. Journal of Adolescent Health, 46(4), 366-371.

Bernard, H. (1988). Research Methods in Cultural Anthropology. Newbury Park, CA: Sage Publications. 
Beylin, M. (2006). Homosexual athletes feel pressure to stay in the closet. The Campanile.

Blumenfeld, W.J. \& Raymond, D. (1988). Looking at gay and lesbian life. Boston: Beacon Press.

Bowen, A.M. \& Bourgeouis, M. (2001). Attitudes towards lesbian, gay, and bisexual college students: The contribution of pluralistic ignorance, dynamic social impact, and contact theories. Journal of American College Health, 50, 91-96.

Brown, R. (1984). The effects of intergroup similarity and cooperation vs competitive orientation on intergroup discrimination. British Journal of Social Psychology, 23, 21-33.

Burr, C. (2005). The only question that matters: Do people choose their sexual orientation? Washington, D.C.: Liberty Education Forum.

Centers for Disease Control and Prevention. Lesbian, gay, bisexual and transgender health. Available at: http://www.cdc.gov/lgbthealth/youth.htm.

Calzo, J.P., Roberts, A.L., Corliss, H.L., Blood, E.A., Kroshus, E., \& Austin, S.B. (2014). Physical activity disparities in heterosexual and sexual minority youth ages 12-22 years old: Roles of gender noncomformity and athletic self-esteem. Annals of Behavioral Medicine, 47, 17-27.

Cohen, L.L. \& Shotland, R.L. (1996). Timing of first sexual intercourse in a relationship: Expectations, experiences, and perceptions of others. The Journal of Sex Research, 33, 291-299.

Colaizzi, P.F. (1973). Reflection and research in psychology: A phenomenological study of learning. Dubuque, IA: Kendall Hunt Publishing.

Cook, S. (1984). Cooperative interaction in multi-ethnic contexts. In: Miller MBN, ed. Groups in Contact: The Psychology of Desegregation. New York: Academic Press. 
Creswell, J.W. (2002). Educational research: Planning, conducting, and evaluation quantitative and qualitative research. Upper Saddle River, NJ: Pearson Education.

Creswell, J.W. (2007). Qualitative inquiry and research design: Choosing among five approaches ( $2^{\text {nd }}$ ed.). Thousand Oaks, CA: Sage Publications.

Creswell, J.W. (2009). Research design: Qualitative, quantitative, and mixed methods approaches. Thousand Oaks, CA: Sage.

Crotty, M. (1998). The foundations of social research: Meaning and perspective in the research process. Thousand Oaks, CA: Sage Publications.

D’Augelli, A.R. (1994). Identity development and sexual orientation: Toward a model of lesbian, gay, and bisexual development. In E.J. Trickett, R.J. Watts \& D. Birman (Eds.), Human diversity: Perspectives on people in context. San Francisco: Jossey-Bass.

Dale, G.A. (1996). Existential phenomenology: Emphasizing the experience of the athlete in sport psychology research. The Sport Psychologist, 10, 307-321.

Dempsey, C.L. (1994). Health and social issues of lesbian, gay, and bisexual adolescents. Families in Society, 75, 160.

Denzin, N.K. (1978). Sociological Methods. New York, NY: McGraw-Hill.

Deschamps, J. \& Brown, R. (1983). Superordinate goals and intergroup conflict. British Journal of Social Psychology, 22, 189-195.

Finlay, L. (2008). A dance between the reduction and reflexivity: Explicating the "phenomenological psychological attitude." Journal of Phenomenological Psychology, $39,1-32$.

Flick, U. (2004). A companion to qualitative research. London: Sage Publications. Gadamer, H-G. (1996). Truth and Method. London: Sheed and Ward. 
Gay, Lesbian \& Straight Education Network. Four steps schools can take to address anti-LGBT bullying and harassment. Available at: http://www.glsen.org/cgi-bin/ iowa/all/library/record/2418.html.

Gibbs, G. (2007). Analyzing Qualitative Data. London: Sage.

Gilbert, W.D. \& Trudel, P. (2004). Role of the coach: How model youth team sport coaches frame their roles. The Sport Psychologist, 18, 21-43.

Gill, D.L., Morrow, R.G., Collins, K.E., Lucey, A.B. \& Schultz, A.M. (2006). Attitudes and sexual prejudice in sport and physical activity. Journal of Sport Management, 20, 554564.

Glesne, C. (2006). Becoming qualitative researchers: An introduction ( $3^{\text {rd }}$ ed.). New York, NY: Pearson.

Grant, J.E., Odlaug, B.L., Derbyshire, K., Schreiber, L.R.N., Lust, K., \& Christenson, G. (2014). Mental health and clinical correlates in lesbian, gay, bisexual, and queer young adults. Journal of American College Health, 62 (1), 75-78.

Griffin, P. (1994). Homophobia in sport: Addressing the needs of lesbian and gay high school athletes. The High School Journal, 77, 80-87.

Griffin, P. (2012). LGBT equality in sports: Celebrating our successes and facing our challenges. In G.B. Cunningham (Ed.). Sexual Orientation and Gender Identity in Sport (pp. 1-12). College Station, TX: Center for Sport Management Research and Education.

Griffin P, Perrotti J, Priest L, Muska M. Lopiano D, Snyder M, \& Thompson L.D. It Takes a Team: Making Sports Safe for Lesbian, Gay, Bisexual, and Transgender Athletes and Coaches. Women's Sport Foundation. http://www.womenssportsfoundation.org/ binarydata/WSF_ARTICLE/pdf_file/1057.PDF 
Groenewald, T. (2008). Memos and memoing. In L.M. Given (Ed.), The SAGE encyclopedia of qualitative research methods. Thousand Oaks, CA: SAGE Publications.

Guba, E.G. \& Lincoln, Y.S. (1989). Fourth generation evaluation. Newbury Park: Sage.

Haas, A.P., Eliason, M., Mays, V.M., Mathy, R.M., Cochran, S.D., D'Augelli, A.R., Silverman, M.M., Fisher, P.W., Hughes, T., Rosario, M., Russell, S.T., Malley, E., Reed, J., Litts, D.A., Haller, E., Sell, R.L., Remafedi, G., Bradford, J., Beautrais, A.L., Brown, G.K., Diamond, G., Friedman, M.S., Garofalo, R., Turner, M.S., Hollibaugh, A., Clayton, P.J. (2011). Suicide and suicide risk in lesbian, gay, bisexual, and transgender populations: Review and recommendations. Journal of Homosexuality, 58, 10-51.

Halbrook, M. \& Watson II, J.C. (2017). High school coaches' perceptions of their efficacy to work with lesbian, gay, and bisexual athletes. Manuscript submitted for publication.

Hekma, G. (1998). “As long as they don't make an issue of it...”: Gay men and lesbians in organized sports in the Netherlands. Journal of Homosexuality, 35, 1-23.

Herek, G.M. (1991). Stigma, prejudice, and violence against lesbians and gay men. In J. Gonsiorek and J. Weinrich (Eds.), Homosexuality: Research implications for public policy. Newbury Park, CA: Sage.

Herriott, T.K. \& Halcro, C.M. (2014). Safe Zone: 101 training manual. Dominican University of California: Office of Diversity and Equity.

Hoepfl, M.C. (1997). Choosing qualitative research: A primer for technology education researchers. Journal of Technology Education, 9(1).

Howard, V.A. \& Barton, J.H. (1988). Thinking on paper. Harper Perennial. 
Johnson, J.L. (1997). Generalizability in qualitative research: Excavating the discourse. In J.M. Morse (Ed.), Completing a qualitative project: Details and dialogue. Thousand Oaks, CA: Sage Publications.

Kleiman, S. (2004). Phenomenology: To wonder and search for meanings. Nurse Researcher, 11(4), 7-19.

Kosciw, J.G., Greytak, E.A, Bartkiewicz, M.J., Boesen, M.J., \& Palmer, N.A. (2012). The 2011 National School Climate Survey: The experiences of lesbian, gay, bisexual and transgender youth in our nation's schools. New York: GLSEN.

Krane, V. \& Baird, S. (2005). Using ethnography in applied sport psychology. Journal of Applied Sport Psychology, 17(2), 27-107.

Krane, V., Waldron, J.J., Kauer, K.J., \& Semerjian, T.Z. (2010). Queering Sport Psychology. The Cultural Turn in Sport Psychology (pp. 153-179). Morgantown, West Virginia: Fitness Information Technology.

Kvale, S. (1983). The qualitative research interview: A phenomenological and a hermeneutical mode of understanding. Journal of Phenomenological Psychology, 14, 171-196.

Lather, P. (2006). Paradigm proliferation as a good thing to think with: Teaching qualitative research as a wild profusion. Qualitative Studies in Education, 19(1), 35-57.

Loftus, J. (2001). America's liberalization in attitudes toward homosexuality, 1973 to 1998. American Sociological review, 66(5), 762-782.

Loughran, M.J. (2009). Counseling the LGBTQ student athletes: Issues and intervention strategies. In E.F. Etzel (Ed.), Counseling and psychological services for college studentathletes. Morgantown, WV: West Virginia University 
Marshall, C. \& Rossman, G.B. (2011). Primary data collection methods designing qualitative research. Los Angeles, CA: Sage Publications.

Martens, M.P. \& Mobley, M. (2005). Straight guys working with gay guys: Homophobia and sport psychology service delivery. In M.B. Anderson (Ed.), Sport psychology in practice. Champaign, IL: Human Kinetics.

Mathison, S. (1988). Why triangulate? Educational Researcher, 17(2), 13-17.

Maxwell, J.A. (2012). Qualitative research design: An interactive approach (3 ${ }^{\text {rd }}$ ed.). Los Angeles, CA: SAGE Publications.

Maykut, P. \& Morehouse, R. (2000). Beginning Qualitative Research: A Philosophic and Practical Guide. London: Routledge.

McCormack, M. \& Anderson, E. (2010). The re-production of homosexually-themed discourse in educationally-based organized sport. Culture, Health, \& Sexuality, 12, 913-927.

Merriam, S. B. (2002). Qualitative research in practice: Examples for discussion and analysis. San Francisco: Jossey-Bass.

Messner, M.A. (2002). Taking the field: Women, men, and sports. Minneapolis: University of Minnesota Press.

Miles, M.B., Huberman, A.M., \& Saldana, J. (2014). Qualitative data analysis: A methods sourcebook and the coding manual for qualitative researchers. Thousand Oaks, CA: Sage Publications.

Mills, C.W. (1959). On intellectual craftsmanship. In C.W. Mills (Ed.), The sociological imagination. London: Oxford University Press.

Morrow, S.L. (2005). Quality and trustworthiness in qualitative research in counseling psychology. Journal of Counseling Psychology, 52(2), 250-260. 
Neisen, J. (1993). Healing from cultural victimization: Recovery from shame due to heterosexism. Journal of Gay and Lesbian Psychotherapy, 2(1), 49-63.

Newcomb, M.E. \& Mustanski, B. (2011). Moderators of the relationship between internalized homophobia and risky sexual behavior in men who have sex with men: A meta-analysis. Archives of Sexual Behavior, 40, 189-199.

NFHS. (2016). High school sports participation increases for $27^{\text {th }}$ consecutive year. National Federation of State High School Associations. Retrieved on September 17, 2016.

O’Bryan, M., Fishbein, H., \& Ritchey, P.N. (2004). Intergenerational transmission of prejudice, sex role stereotypes, and intolerance. Adolescence, 39, 407-426.

Patton, M.Q. (1999). Enhancing the quality and credibility of qualitative analysis. Health Services Research, 34(5), 1189-1208.

Patton, M.Q. (2001). Qualitative evaluation and research methods ( $2^{\text {nd }}$ ed.). Thousand Oaks, CA: Sage Publications.

Ponterotto, J.G. (2005). Qualitative research in counseling psychology: A primer on research paradigms and philosophy of science. Journal of Counseling Psychology, 52(2), 126-136.

Poteat, V.P. \& Digiovanni, C.D. (2010). When biased language use is associated with bullying and dominance behavior: The moderating effect of prejudice. Journal of Youth and Adolescence, 39(10), 1123-1133.

Prentice, D.A. \& Miller, D.T. (1993). Pluralistic ignorance and alcohol use on campus: Some consequences of misperceiving the social norm. Journal of Personality and Social Psychology, 64, 243-256.

Price, M. (2000). Rugby as a gay men's game. Unpublished Ph.D. diss., University of Warwick, Coventry, UK. 
Rankin, S. \& Merson, D. (2012). LGBTQ College Athlete Report. Campus Pride. http://www.campuspride.org

Remafedi, G. (1987). Homosexual youth. Journal of the American Medical Association, 258, 222-225.

Rivadeneira, A. W., Gruen, D. M., Muller, M. J., \& Millen, D. R. (2007). Getting our head in the clouds: Toward evaluation studies of tagclouds. Proceedings of the SIGCHI conference on human factors in computing systems, (pp. 995-998). New York, NY: ACM Press.

Rosario, M., Schrimshaw, E.W., Hunter, J., \& Braun, L. (2006). Sexual identity development among gay, lesbian, and bisexual youths: Consistency and change over time. Journal of Sex Research, 43(1), 46-58.

Ryan, S. (2000). Examining social workers' placement recommendations of children with gay and lesbian adoptive parents. Families in Society, 81, 517-528.

Ryan, G.W. \& Bernard, H.R. (2003). Techniques to identify themes. Field Methods, 15, 85-109.

Ryba, T.V. (2007). Cartwheels on ice: A phenomenological exploration of children's enjoyment in competitive figure skating. Athletic Insight, 9(2), 58-73.

Safren, S.A. \& Rogers, T. (2001). Cognitive-behavioral therapy with lesbian, gay, and bisexual clients. Journal of Clinical Psychology, 57, 629-643.

Savin-Williams, R.C. (1994). Verbal and physical abuse as stressors in the lives of lesbian, gay male, and bisexual youths: Associations with school problems, running away, substance abuse, prostitution, and suicide. Journal of Consulting and Clinical Psychology, 62(2), 261-269. 
Sawyer, A.L., Bradshaw, C.P., \& O’Brennan, L.M. (2008). Examining ethnic, gender, and developmental differences in the way children report being a victim of "bullying" on selfreport measures. Journal of Adolescent Health, 43(2), 106-114.

Schwandt, T. (2007). Dictionary of qualitative inquiry ( $3^{\text {rd }}$ ed.). Thousand Oaks, CA: Sage Publications.

Shannon, V. \& Gentner, N. (2007). Interview. Association for Applied Sport Psychology. Louisville, KY.

Shenton, A.K. (2004). Strategies for ensuring trustworthiness in qualitative research projects. Education for Information, 22, 63-75.

Shilo, G. \& Savaya, R. (2011). Effects of family and friend support on LGB youths' mental health and sexual orientation milestones. Family Relations, 60, 318-330.

Taijel, H. \& Turner, J.C. (1979). An integrative theory of intergroup conflict. The Social Psychology of Intergroup Relations, 33, 47

Thomas, D.R. (2006). A general inductive approach for qualitative data analysis. American Journal of Evaluation, 27(2), 237-246.

Turner \& Rubinson (1993). Contemporary human sexuality. Prentice Hall College Div. Vargas-Tonsing, T.M. \& Oswalt, S.B. (2009). Coaches' efficacy beliefs towards working with lesbian, gay, and bisexual athletes. International Journal of Coaching Science 3, 29-42.

Waldron, J.J. \& Krane, V. (2005). Whatever it takes: Health compromising behaviors in female athletes. Quest, 57, 315-329.

Wargo, W.G. (2015, August 15). Identifying assumptions and limitations for your dissertation. Academic Information Center. Retrieved on June 1, 2016. 
Watson II, J.C. \& Halbrook, M. (2014). Incorporating technology into practice: A service delivery approach. In J.G. Cremades \& L.S. Tashman (Eds.), Becoming a sport, exercise, and performance psychology: A global perspective. New York, NY:

Routledge/Psychology Press.

Watson II, J.C., Tenenbaum, G., Lidor, R., \& Alfermann, D. (2001). Ethical uses of the internet in sport psychology: A position stand. International Journal of Sport Psychology, 31, 201-222.

Woodford, M.R., Howell, M.L., Silverschanz, P., \& Yu, L. (2012). “That's so gay!”: Examining the covariates of hearing this expression among gay, lesbian, and bisexual college students. Journal of American College Health, 60(6), 429-434.

Vargas-Tonsing, T.M. (2007). Coaches’ preferences for continuing coaching education. International Journal of Sports Science and Coaching, 2(1), 25-35.

Vargas-Tonsing, T.M. \& Oswalt, S.B. (2009). Coaches' efficacy beliefs towards working with lesbian, gay, and bisexual athletes. International Journal of Coaching Science 3, 29-42.

Viel, B. \& Demers, G. (2013). Coaching LGBT athletes: The needs, challenges, and fears of toplevel coaches. Coaches Plan, 1(3), 35-37. 
APPENDIX A 


\section{Definitions of Terms}

Ally - is a person who is a member of the dominant or majority group (e.g. heterosexual) who works to end oppression by supporting and advocating for the LGB population

Bisexual - a person that is mentally, physically, and emotionally attracted to both sexes

Gay - a person of the male sex that is attracted mentally, physically, and emotionally to other persons of the male sex. (derogatory slang: "That's so gay!")

Gender Identity - refers to a person's internal sense of being on the spectrum of male or female

Heterosexism - belief that heterosexuality is the only acceptable and viable life option (Turner \& Rubinson, 1993)

Homonegativity - "purposeful, not irrational, negative attitudes and behaviors towards nonheterosexuals" (Krane, 1996).

Homophobia - an irrational fear, aversion to, or discrimination against the LGB population Lesbian - a person of the female sex that is attracted mentally, physically, and emotionally to other persons of the female sex

Queer - an umbrella term for sexual and gender minorities that are not heterosexual (derogatory slang: used offensively toward other individuals to describe them in a negative way)

Questioning - exploring one's gender, sexual identity, and/or sexual orientation

Transgender - a person who does not conform to general "guidelines" in terms of gender identity, gender expression, or gender specific behavior that is typically associated with the sex to which they were assigned at birth. 


\section{APPENDIX B}




\section{Extended Literature Review}

Many assumptions and misconceptions exist surrounding the topic of athletics and the LGB populations. Outdated stereotypes would suggest that gay men are too feminine to play masculine sports; females in contact sports are lesbians; and if someone is LGB, they will likely make advances toward other teammates. Pervasive homonegativity within society continues to use these falsehoods to fuel discrimination and harassment, leading to widespread hostility, differential treatment, and violence based solely upon a person's sexual orientation (Herek, 1992). While creating an accepting and inclusive team environment requires work, the ideal environment would foster players' psychological development, respect for diversity, and freedom from harassment, fear, and derogatory slang towards LGB athletes, coaches, or persons in general.

Unfortunately, the harassment, fear, as well as silence, that is generated with regard to young LGB athletes can be stifling, but is considered typical of the masculinized culture of sport (Griffin, 1994). Sport culture, overall, has historically been considered a microcosm of society, reflecting changes in government policies and shifts in public opinion. For example, Wolf Wendal, Toma, and Morphew (2001) stated that even though Caucasian attitudes regarding race have been liberated, the same cannot be said for heterosexual attitudes towards homosexuality. While discriminatory racism and derogatory racial comments are now deemed unacceptable in the locker room, on the field, and in public forums, coaches, athletes and citizens often use homonegative slurs as taunts and/or forms of motivation (McCormack \& Anderson, 2010). It is with this realization that researchers and activists, in and out of sport, continue to strive for a more inclusive environment for LGB athletes of all ages (Barber \& Krane, 2007). 


\section{Theoretical Framework}

Sociological Perspectives - Functionalist theorists view sport through a positive lens. Sport experiences can lead to character building, friendship forming, and a fun, competitive environment that builds resiliency and the acquisition of life skills. Social action is often encouraged through functionalism by promoting the development and growth of organized sports, increasing the supervision and control of athletes, and mandating coaching education programs. However, it is also often true that the positive consequences of sport may be overstated, as the Functionalist Theory does not recognize that sports benefit some individuals and social groups more than others (Coakley, 2001).

On the other hand, conflict theorists state that sport experiences often reward the most powerful members of a group and segregate minorities such as women, various ethnicities, individuals in lower socioeconomic classes, as well as lesbian, gay, and bisexual (LGB) individuals. The discrimination experienced by less powerful groups causes some individuals to take social action by focusing on class inequalities and how it can be minimized through sport participation (Coakley, 2001). Using conflict theory to further assess LGB experiences in sport and physical activity, the current study uses a critical theory lens.

Critical Theory aims to critique current societal structures and power (e.g. sport environment and coaches) in an attempt to promote social change by challenging and highlighting discriminatory practices. Much research using critical theory focuses on the meaning and organization of sport. Furthermore, it is believed that sports can challenge the perspective of the majority by offering more and more diverse opportunities for all individuals. Unfortunately, critical theories have not identified a unified strategy for dealing with social problems, conflict, and injustice, in or out of sport (Coakley, 2001). 
Queer Identity Theories. Critical and Conflict Theory can be recognized in the development of Gender and Queer Theories, such as Cass' Model (Cass, 1996). While working with gay and lesbian individuals in Australia, "Cass identified six stages of perception and behavior, moving from minimal awareness and acceptance of a gay or lesbian identity to a final stage in which gay or lesbian identity is integrated with other aspects of self" (Evans, Forney, Guido, Patton, \& Renn, 2010, p. 307-308). The coming out process is crucial to the positive development of a person's identity. Not all gay and lesbian individuals move through each stage sequentially or at all. Unlike some Sexual Identity Models, Cass (1996) does not include bisexuality as a final identity, but instead offers bisexuality as a transitional phase. In 1996, Cass further developed her model to identify when movement and foreclosure may take place within the stages. Additionally, in 1996, Cass included a component that reviewed how the individual feels about her own and others' perceptions (Evans et al., 2010).

The first stage in Cass' model is the Prestage, which occurs before Stage 1. In this stage "individuals perceive themselves to be heterosexual and recognize this as a preferred state of being" (Cass, 1996). It is important to note that the individuals "perceive" themselves to be heterosexual and may or may not actually end up identifying as heterosexual in the future. Individuals, especially at younger ages, perceive heterosexuality to be a "preferred state of being" due to the media and other cultural beliefs instilled within the family unit. In Stage 1 (Identity Confusion), individuals begin to become aware that their thoughts, feelings, and behaviors may not coincide with being heterosexual, which can then cause "curiosity, confusion, or anxiety" (Cass, 1996).

In order to move out of Stage 1 into Stage 2 (Identity Comparison), an individual must accept that they may be gay or lesbian. While this acceptance can be very comforting, it can also 
produce fears associated with ostracism from social and family circles (Cass, 1979; Cass, 1996). Once individuals have acknowledged they are probably gay or lesbian, they will begin to enter Stage 3 (Identity Tolerance) where they seek others who are gay and lesbian. This step allows individuals to begin determining how they feel about their new identity as well as how they feel about others who share their identity (Cass, 1979).

Stage 4 (Identity Acceptance) is most commonly when gay and lesbian individuals begin to selectively self-disclose to others about their homosexual identity. Additionally, friendships with other gay and lesbian individuals continue and become closer. It is through these interactions that the individual learns how to present themselves to others (Cass, 1990). The level of comfort in "coming out" will vary for each individual and depends on family openness to cultures and sexualities outside of the norm. However, as individuals move to Stage 5 (Identity Pride), the gay or lesbian individual starts focusing on issues and activities associated with being gay or lesbian. They take pride in being gay and supporting gay rights and often feel anger and frustration towards policies and individuals who are "anti-gay." This anger can lead gay and lesbian individuals to be advocates and confront oppressive societal behaviors (Cass, 1996). This can be seen in our current society with the fight for same-sex marriage and Gay Pride events in cities all over the United States.

The final stage in the model is Stage 6 (Identity Synthesis). In this stage, even though pride in being gay or lesbian may remain, homosexual and heterosexual worlds are not seen as completely separate. Heterosexual individuals are not seen as enemies and are judged by personal characteristics rather than sexuality (Cass, 1996). The gay or lesbian individual becomes more comfortable with herself and sees her sexuality as a part of her whole being rather 
than her entire identity. Individuals in this stage are often less conflicted and view society more positively.

It is important to understand personal identity stages, but on a team setting, being able to identify how relationships are effected in each stage is also essential. D'Augelli's (1994) Model of Lesbian, Gay, and Bisexual Development has a few key similarities and differences from Cass' model. The first similarity is the Identity Development Process. Much like Cass's model, D'Augelli identifies six processes of LGB identity development. However, even though both models start the same (exiting the heterosexual identity), D'Augelli's model focuses more on relationships in each phase as opposed to personal identity. D'Augelli (1994) stated that this perspective was due to varying social circumstances and environments that an individual is in throughout their life. The person's identity becomes more of a "social construction," shaped by others' perceptions and actions. Furthermore, evident even in the title of D'Augelli's Model, bisexual individuals are included in this model instead of being simply viewed as a stage of foreclosure or transition as in Cass' Model.

D’Augelli's model uses three sets of interrelated variables to discuss the six stages of lesbian, gay, and bisexual identity formation. The first variable is "personal subjectivities and actions." These subjectivities and actions include the LGB individual's perceptions, feelings and behaviors related to their sexual orientation. According to Krane (1996), this stage may include "Identity Commitment" (Stryker \& Burke, 2000), which ascertains that it is easier to embrace and accept potential stigmatization rather than trying to "pass" as heterosexual. The second variable in D'Augelli's model is “interactive intimacies," which includes how family members, peers, and romantic partners influence the individual. It should also be noted that the LGB individual may also influence others who are close to them or who they interact with in a group 
setting (Evans et al., 2010). The third variable is "sociohistorical connections." This is the broadest of the three variables, examining the social norms and policies of the geographical area where the LGB individual resides, as well as the values represented in the current historical period. For example, the challenges of sexual identity formation of someone growing up today are significantly different from those faced by individuals even a decade ago.

D’Augelli's Model of Lesbian, Gay, and Bisexual Development is highly relatable to positive identity formation in high school LGB athletes. This model provides a rationale for the importance of coaches being aware, accepting, and trained in the unique needs of youth LGB athletes in team and individual sports. While the model states that the LGB individual is ultimately responsible for their own identity development, "hormonal changes, social circumstances, and peer relationships at different life stages" contribute to the individual's development. With the average age of "coming out" being 16 years of age, hormonal changes and peer relationships at this stage in life are of substantial consideration. These factors, described together, have been termed "developmental plasticity," meaning that the ability to respond and adapt will vary throughout the person's life.

Having information about Cass' and D’Augelli’s Models of Sexual Identity Development can be very helpful for lesbian, gay, and bisexual individuals that may approach coaches and administration at the high school or university level. Due to the cognitive nature of "coming out," Cass (1996) stated that individuals' behaviors alone may not be a true indication of what the person may be thinking or feeling with relation to their sexuality. It is not enough to simply be aware of this model, but to also understand the intricacies associated with movement or foreclosure of a stage. Furthermore, because of the importance of establishing a supportive and safe group of friends with the same identified sexuality, schools should not only support the 
continuum of sexualities but provide spaces or organizations that can be easily accessed by students.

As stated previously, having information on a variety of Sexual Identity Models can be beneficial, but there are also several limitations associated with Sexual Identity Development Models. First, not every gay or lesbian individual will go through a stage that causes anger towards heterosexual individuals (i.e. teammates, coaches, teachers). Additionally, as with most other research, Cass' primary subjects were white, gay males. Therefore, the research and models may not be generalizable to lesbians, bisexuals, or individuals of different races or ethnicities. Lastly, it is widely assumed that an individual must "come out" and publicly identify as gay or lesbian in order to achieve a positive sense of self, which is simply not always the case (Chan, 1995). Yet, when LGB athletes attempt to hide or deny their sexuality to avoid discrimination, they divert much of their energy away from sport performances. Personal reactions to homonegativity can lead to decreased athletic performance, distrust of teammates, and isolating oneself from the team (Nelson, 1991). Negative reactions may lead to increased stress and decreased self-esteem. Positive reactions from others can enhance self-acceptance and self-esteem (Krane, 1996).

Social Identity Perspective. Sexual Identity Models can be utilized to better understand individual athletes, but the Social Identity Perspective can be employed to describe LGB inclusion in a sport environment. Simply, Social Identity Theory states that individuals may benefit emotionally from group involvement when the group is successful or perceived positively by others (Taifel \& Turner, 1986). Conversely, an individual's self-esteem can be hindered when their attached group does not perform well or is viewed negatively. A negative perception surrounding a team or group can cause an "in-group" bias to develop. In these cases, group 
members may be discriminate against individuals who are considered outsiders (End, 2001), even going as far as to create reasons for a person's personal or athletic shortcomings (End et al., 2003).

In order to avoid being ostracized or singled out, group members will attempt to form a social identity that is consistent with the norms and values of a specific team or sport culture in general (Krane \& Barber, 2003). Once these identities are developed, further social identification and comparison often occurs as people evaluate their social group relative to other groups (Hogg \& Abrams, 1988). As a dominant group is identified, the members of that group attempt to strengthen and preserve group superiority and propogate dominate beliefs by developing and using stereotypes about outside groups and individuals (Leyens, Yzerbyt, \& Schadron, 1994). By creating stereotypes, the dominate groups can more easily oppress and discriminate against others outside of the group. To avoid discrimination, athletes, LGB and heterosexual, must negotiate their social identities as athletes and individuals with social expectations (Russell, 2004). For example, female sports often portray examples of hegemonic femininity, like athletes wearing make-up on the field and intentionally growing their hair out to avoid the group or public perception of being a lesbian.

\section{Lesbians in Sport}

It cannot be assumed that the experiences of gay male athletes are the same as the experiences of lesbian athletes. While both gay males and lesbians often receive a "double dose" of intolerance or discrimination, first in society and then magnified in the sport environment, the belief that the "queer" identity, regardless of sex or orientation, creates similar experiences, and discounts the effects of sexism in society. One of the most notable differences is that closeted high school male athletes are less likely to be identified because their athletic interest is contrary 
to popular images of gay males, while high school lesbian athletes are participating in an activity that already casts suspicion on their femininity, and therefore, heterosexuality (Griffin, 1994).

Suspicion does not generally indicate approval. Sport is often viewed as hostile or unjust toward all women and even more so for lesbians (Lenskyj, 1992). The term "femininity" is often a code word for heterosexuality (Griffin, 1992), and historically "femininity and heterosexuality have been seen as incompatible with sporting excellence. This indicates that either sport made women masculine, or sportswomen were masculine at the outset.” (Lenskyj, 1986, p. 95). Conversely, while sport serves as a space in which women can contest traditional ideas about sexuality and resist sexual prejudice (Ravel \& Rail, 2008), the contradiction between acceptable female behavior and successful athletic behavior, with subsequent consequences, shows that homonegativity is very much alive and well in women's sport, not just in men's.

For example, if women exhibit strength, aggression, and physicality (characteristics required in most competitive, organized sports), they risk being labeled a lesbian (Cahn, 1994; Griffin, 1998), regardless of actual sexual orientation or readiness to be open about one's sexuality. This "lesbian label" has been used to dissuade females from sport participation (Griffin, 1992). Many private high school and college coaches have even been found to implement "negative recruiting" strategies when meeting with potential athletes. The tactic is a longtime and underhanded attempt at discouraging players from attending rival programs by suggesting that opposing programs are immoral or not "family focused," meaning coaches or athletes on the team are LGB (Nelson, 1991). One of the most notable cases involved Rene Portland, head basketball coach of Penn State University for 27 years, who openly had a "no drinking, no drugs, and no lesbians" rule for her team. It was only after a federal lawsuit from a player who was dismissed from the team for her sexual orientation that Penn State University 
took action against Rene Portland's overt discrimination, causing her eventual resignation in 2007. Lack of punishment for coaches who promote homonegativism leads to the belief that these actions are acceptable and that LGB individuals are not welcome in sport (Young, 1995).

There are beliefs that prevent women in sport from challenging homonegativity and allowing cases like that of Penn State University and Rene Portland to escalate or continue to occur over time. These beliefs include viewing sexual identity as a private issue, feeling that lesbians call attention to themselves, that lesbians are bad role models, considering oneself to be a feminist (and consequently not homophobic), and maintaining institutionalized silence. Fortunately, many collegiate programs and coaches do not take this extreme discriminatory stance. In fact, some collegiate lesbian athletes choose to disclose their sexual identities because they believe sport to be a "safe zone" due to overt support from the university and the presence of other lesbian teammates or athletes (Stoelting, 2011). Others echo the argument that sport is an atmosphere where lesbian athletes are able to be their "true self." Others state that acceptance may vary from sport to sport, as certain female sports are assumed to be more supportive of lesbian athletes. In Stoelting's (2011) study, sports such as hockey, rugby, and softball were all mentioned to house supportive environments to be openly lesbian. 


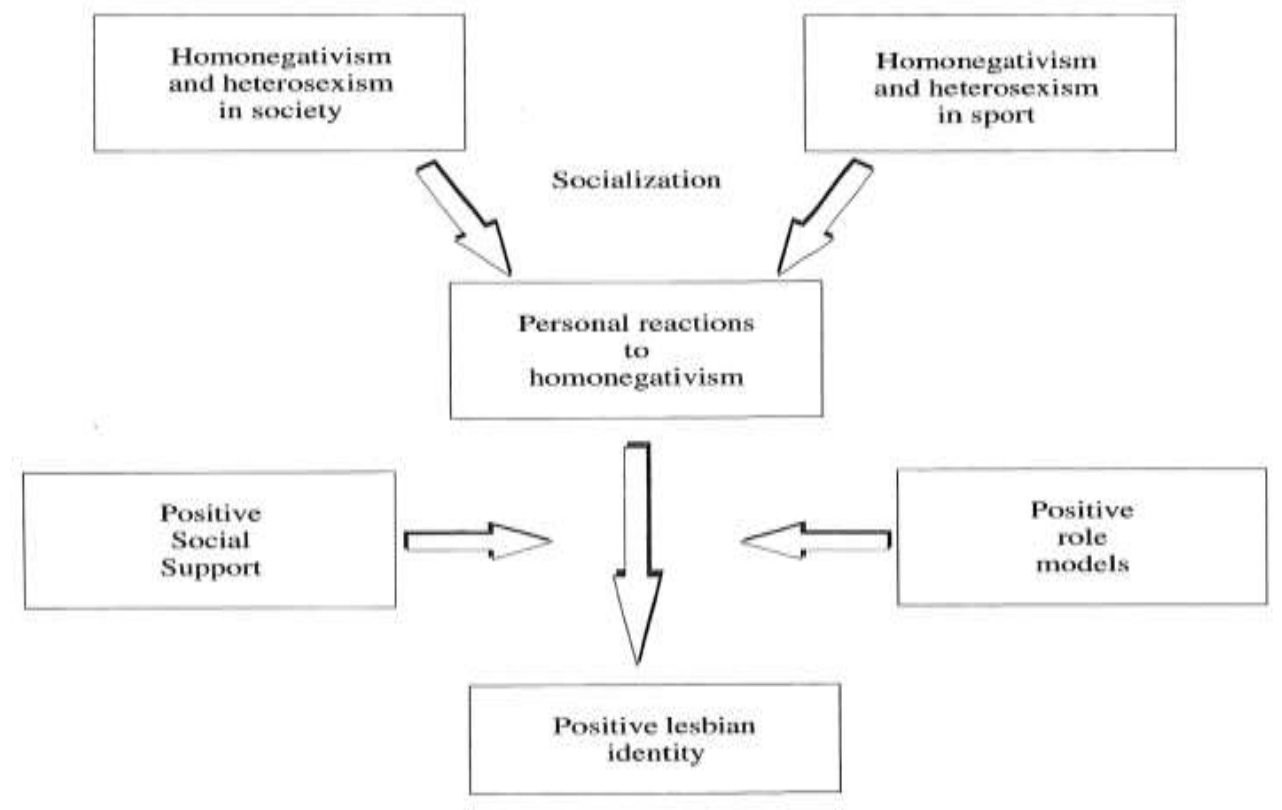

\section{Figure 1 - Conceptual model for Studying Lesbians in Sport}

Krane (1996) identified a conceptual framework for understanding and studying lesbians in sport, which is depicted in Figure 2. This model is predicted from previous research findings and four feminist theoretical beliefs: 1) Sport is a patriarchal institution and is considered masculine in our society (Griffin, 1994; Lenskyj, 1990), 2) negative perceptions of lesbians are perpetuated in the sport environment (Blinde \& Taub, 1992; Griffin, 1992), 3) the institution of sport promotes compulsory heterosexuality (Lenskyj, 1990), and lastly, 4) the previous conditions lead to the creation and maintenance of a hostile environment for lesbians. More simply stated, homonegativism experienced within society, and therefore in sport, leads to socialized personal reactions to the homonegativism experienced. However, if the athlete has positive social support from her coach or teammates or other positive lesbian role models, she will have a better chance of developing a positive lesbian identity.

Unfortunately, faced with invisibility or hostility from coaches, young female athletes often lose access to important adults in their lives who could help delineate fears and misconceptions surrounding their identity. At times, without support or lesbian role models, 
these athletes may develop "internalized lesbophobia," which is defined as the dissatisfaction of being associated with being a lesbian (Guthrie, 2005). Internalizing a negative image of one's own identity has been linked to greater body dissatisfaction, weight preoccupation, fat phobia, and other eating disordered attitudes and behaviors. Lesbian athletes may also resort to hiding their identity behind the "protective camouflage" of heterosexuality (Griffin, 1994), due to feeling like secrecy is the only option if they have hopes of pursuing a future career in athletics.

\section{Gay Males in Sport}

Society's prejudice towards gay males is exacerbated in the traditional, masculine sports arena (Martens \& Mobley, 2005), where conformity and aggression are encouraged (Loughran, 2009). Sport, especially team sports, often reject homosexuality and, instead, promote hyperheterosexuality (Griffin, 1998; Wolf-Wendal, Toma, \& Morphew, 2001).

Hyperheterosexuality is the exaggerated adherence to the traditional male or female gender role, whichever matches the assigned sex of the person, and the promotion of heterosexual relationships. Homohysteria is defined as the fear men have of being perceived as gay (Anderson, 2008). Athletics provides one of the few contexts, other than family, in which affection between males and the physical expression of emotional closeness is publicly acceptable (Griffin, 1994). Gay men may end up avoiding emotional intimacy and homosocial touch toward teammates to avoid the stigma of being considered gay, even going as far as to overtly demonstrate discrimination and homonegativity themselves to be perceived as masculine (Kimmel, 1994).

Openly gay males, therefore, have not traditionally been accepted in, or in some cases, even granted access to, sport. Furthermore, Hekma (1998) reported that because gay males are not given space within the masculine context of sport, they may become uncomfortable in a team 
sport setting (Pronger, 1990). This discomfort may be slightly decreased, and acceptance increased, if the gay male is perceived as valuable to the team with regard to being highly skilled athletically, and therefore helping the team win.

Women's sport is perceived to have "safe" sports for open lesbians, but the same cannot be said for men's sports. The hyperheterosexual and homonegative strategies to maintain "norms" in men's sports are used as frequently at the top of the masculine sport hierarchy (e.g. football) as they are in more marginalized sports such as cross-country running (Anderson, 2002). This consistent negative treatment of gay males within all levels of sport creates a uniform hesitancy for participation, regardless of sport. It is well-known that many current and former gay athletes choose to remain silent about their sexuality due to concerns surrounding being cut from teams, verbal and physical harassment and/or retribution, and to protect their career and financial status (Martens \& Mobley, 2005). For example, one can see how intimidating it could be for a gay male to openly participate in sport when retired NBA player Tim Hardaway publically stated on a radio show in 2007 that he "hates gay people" and "would not want a gay player" on his team (Kian \& Anderson, 2009).

The hesitation to be openly gay on a team can be further convoluted when the gay male athlete is considered traditionally masculine, hence becoming a contradiction to most people's assumptions and stereotypes of gay males being effeminate and "silly" (Pronger, 1990). This contradiction can create discomfort and confusion for heterosexual teammates, coaches, and fans who may hold on to socially learned expectations of the generalized actions and persona of gay males. Another motivation that could contribute to the scarcity of openly gay male athletes in sport may potentially be due to the fact that once an athlete does come out of the closet, he may be more likely to drop out of the sport due to no longer feeling that he needs the false 
representation of being heterosexual that being an athlete often offers (Pronger, 2000). The current study aims to identify further, more specific reasons related to high school coaches' perceptions and experiences that may contribute to openly gay males choosing to continue or discontinue sport participation in the future.

\section{Bisexual Persons in Sport}

Despite being included in the common "LGB" abbreviation, there are distinct differences associated with bisexuality as opposed to lesbian, gay, or even heterosexual experiences in sport. Unlike gay males and lesbians, very little research has been conducted that exclusively examines bisexual experiences within the sport environment. The potential reasons for the dearth of exploration vary, but one consideration would be the idea of "biphobia." Sexual orientation has been shown to exist on a continuum, yet bisexuals often feel pressure from heterosexuals and homosexuals to "choose" one side (i.e. sexuality) or the other, creating a "complex social challenge" (Connor, 2003). The feeling of discrimination from heterosexual and homosexual persons leads to feelings of invisibility or overt exclusion.

An example of the exclusion felt by bisexual persons in sport is evident in the 2010 legal case between three bisexual male softball players from San Francisco and the North American Gay Amateur Athletic Association (NAGAAA). Following "an allegedly disturbing inquisition process" (Ziegler, 2011) to determine their true sexuality, the three bisexual players were disqualified from the 2008 Gay Softball World Series due to the league only allowing two "nongay" players per team. The National Center for Lesbian Rights took the case, leading to the bisexual players being retroactively reinstated to the league and the team's second place finish recognized. Additionally, the NAGAAA now encourages team rosters to include an unlimited amount of LGBT players on a team, not just openly gay, but still diligently restricts self- 
identified heterosexual players to two. This case is considered an important step in creating a more inclusive community overall, in sport and the LGBT population.

However, as with any group of individuals, experiences vary. Fink, Burton, Farrell, and Parker (2012) found that bisexual athletes often reported positive "coming out" experiences and, although often unanticipated, support from teammates. Athletes in Fink et al.'s (2012) qualitative study stated that while they still struggled with and were resistant to stereotypes, having a single ally within the athletic department or team made them more comfortable and confident when deciding to disclose their sexual identity. In line with the purpose of the current study, athletes also noted that they perceived their sport organizations to have little structure and few policies in place to ensure consistent, positive experiences for LGB student-athletes.

\section{Additional Concerns Facing the LGB Community}

Athletic and team participation is often perceived to contribute to healthier physical wellbeing, relationship building, and increases in self-esteem. However, the other side to sport that is often overlooked and avoided, is the inclusion of openly lesbian, gay, and bisexual (LGB) athletes. Athletics, in general, have been described as a hostile environment for LGB individuals and issues (Anderson, 2005; Gill, Morrow, Collins, Lucey, \& Schultz, 2006; Wolf-Wendel, Toma, \& Morphew, 2001). Hostility can be viewed in many ways. For instance, the LGBT College Athlete Report released by the NCAA stated that approximately five percent of the 8,481 NCAA sampled student athletes in the study identified as LGBT and 25\% of those LGBT student-athletes were pressured to be silent about their sexuality by teammates (Rankin \& Merson, 2012). Other examples of hostility may include bullying, hate crimes, and generalized homonegativity. 
Bullying. Bullying, specifically on social media, has been largely discussed in the high school academic realm, but incidences of harassment are also evident within sport at all levels. An NCAA report released in 2012, focused on and identified LGB collegiate athletes’ experiences. In the self-reported sample, $21 \%$ of openly LGB athletes were targets of derogatory remarks on social media which doubled the percentage experienced by heterosexual teammates (Rankin \& Merson, 2012). Furthermore, nine out of 10 LGB students heard the word "gay" used in a negative way often or frequently in school, and nearly three out of four LGB students reported hearing their peers make homophobic remarks, such as "dyke" or "faggot," often or frequently in school (Thinkb4youspeak, 2014).

Alarmingly, many gay athletes reported frequently hearing antigay language spoken by teammates and opponents in a sport setting, but did not report finding this particular language homophobic due to it being experienced in a sport context (Anderson, 2000; Hekma, 1998; Price, 2000). Even if the LGB athlete did find the language offensive, an earlier study by D'Augelli (1992), found that $82 \%$ of the sampled population of gay and bisexual male undergraduate students reported that they had failed to report at least one incident of verbal and/or physical victimization, generally because of fear of further harassment, such as an escalation to a hate crime. Hate crimes (i.e. overt and overly aggressive language, physical assault) are generally viewed as more severe than homonegativism and are often used to send messages to and "terrorize" the gay community with the idea that violence could happen to anyone who identifies as LGB (Herek, 1992).

Homonegativism. The hindrances that are felt by many LGB individuals are due to heterosexism. Heterosexism is defined as the belief that heterosexuality is the only acceptable and viable life option (Turner \& Rubinson, 1993). Homonegative beliefs are developed through 
“a complex interrelationship of experiential learning, individual psychological defenses, and sociocultural and historical factors" (Remafedi, 1987, p. 224). Homonegativism experienced within society, and therefore sport, leads to socialized personal reactions to the homonegativism experienced. If the athlete has positive social support and role models, she will have a better chance of developing a positive lesbian identity. Because of heterosexism, LGB individuals may constantly struggle with their self-esteem and have a harder time integrating a positive sexual identity (Blumenfeld \& Raymond, 1988). Many times, the response to homonegativism is “covering" or passing," which involves one's attempts to hide their sexual orientation from others in order to avert potential external homonegativism. This behavior can lead to high levels of stress, fear of discovery (Savin-Williams, 1994), and distancing self from others (Herek, 1991). The emotional and physical withdraw leads to athletic and academic performances suffering if LGB athletes feel uncomfortable or discriminated against by coaches or teammates (Krane, 1996). Lesbian, gay, and bisexual athletes may withdraw from teammates or lose interest in playing and quit participation (Griffin, 1994).

Hate crimes would be considered "external homonegativism." External homonegativism is described as cultural beliefs and actions which intimidate and promote a negative image of nonheterosexuals, but internal homonegativism is an individual's reaction to these culturally perpetuated negative beliefs (Griffin, 1992; Hudson \& Ricketts, 1980; Lenskyj, 1990; Peper, 1994). The unfortunate expectation and fear associated with long-term verbal and physical harrassment creates internal homonegativism in the targeted person. A prime example of internal homonegativism was discussed in a study by Anderson (2000). The article outlined how, even when athletes are discriminated against, many fail to see the inequality or severity. This could be attributed to athletes having preconceived ideas of what "coming out" could be 
like and then comparing those experiences to worst case scenarios or to others who experienced more negative "coming out" experiences. For example, one athlete reported that only 2-3 of his teammates stopped talking to him after he came out, when he expected to lose all of his teammates' friendships (Anderson, 2000).

The social and psychological obstacles that young LGB persons face can lead to negative coping strategies such as alcohol and drug use, often used as a way to escape feelings of isolation and self-hatred (Griffin, 1994). Other manifestations related to homonegativity may include depression, feelings of inferiority, self-defeating behaviors, decreases in self-esteem, under- or over-achievement, physical or mental health problems, distrust, loneliness, self-hatred, shame, anger, and defensiveness, and suicide as the most extreme consequence (Dempsey, 1994; Neisen, 1993). Sadly, LGB athletes report 4-5 times the amount of depressive bouts than heterosexual athletes and LGB youth, in general, are 2-3 times more likely to attempt and complete suicide, making the psychological implications of this subject of the utmost importance (Department of Health and Human Services, 1989; Haas et al., 2011; Savin-Williams, 1994).

If athletes experience long-term heterosexism and cannot adequately cope with the experiences, they may develop post-traumatic stress disorder (PTSD). This particular type of PTSD "may be especially severe or long lasting when the stressor is of the human design" (Diagnostic and Statistical Manual of Mental Disorders). Stated further, "We want desperately to be liked, loved, and in control of our lives; and intentional, overt, human hostility and aggression - more than anything else in life - assaults our self-image, our sense of control, our sense of the world as a meaningful and comprehensible play, and, ultimately, our mental and physical health." 
The age group that may need the most immediate consideration with regard to homonegativity are high school student-athletes. Griffin (2012) reported that there is an increasing number of LGB individuals coming out at younger ages, with the average being around 16 years (Shilo \& Savage, 2011), yet little attention has been focused specifically on high school athletics. In high school culture, male "jocks" are perceived to be a high status group among school peers (Varenne, 1982). The popular persona creates numerous opportunities for influence on teams, in class, and even in school policy in some cases. This influence on others can be observed in jocks perceptions and treatment of LGB peers. Sexual prejudice among adolescents is complex, requiring consideration of multiple determinants (Collier, Bos, Merry, \& Sandfort, 2013). The outcomes of the findings may come from associations with religiosity (Morrison, McLead, Morrison, Anderson, \& O’Connor, 1997), gender role attitudes (Hoover \& Fishbein, 1999), and intergenerational transmission of prejudice (O’Bryan, Fishbein, \& Ritchey, 2004). Intergenerational transmission of prejudice may come from parents, administrators, coaches, or others who are in a role model or leadership role for the student-athletes.

Prejudice against LGB individuals, whether players, coaches, or sport administrators, has been the norm in sport (Griffin, 2012) despite recent evidence of positive poll changes within the United States with regard to sexual minorities and their civil rights. More National organizations, such as The Gay, Lesbian, Straight Education Network (GLSEN: Kosciw, Greytak, Bartkiewicz, Boesen, \& Palmer, 2012), are attempting to make the school environment safer and more respectful of LGB youth and have even developed a project aimed directly at athletics, titled "Changing the Game." However, even as there are more advocates and resources made available for coaches and athletes, there is an evident generational gap in comfort and awareness (Griffin, 2012). With or without the knowledge and awareness of best practices for LGB athletes, high 
school athletic directors, coaches, and teammates will likely soon be faced with more opportunities to contribute to a more positive or negative sport experience for LGB team members.

\section{Coaches and Supporting Roles}

The sport environment has been labeled the "last closet" for lesbian, gay, and bisexual (LGB) individuals (Beylin, 2006). Despite the suggestion that several important developments have occurred over the past 15 years for LGB rights and acceptance (Loftus, 2001), with an acceleration over the last 2-4 years (Griffin, 2012), professional development opportunities for coaches at all levels still rarely include information about LGB athletes and homonegativity in the sport environment (Griffin, 1994). While many factors mentioned previously in this paper may not be directly within coach's personal control, the level of support and encouragement an athlete receives is in the coach's control, and can be addressed accordingly in a team setting. However, this may be a difficult task when coaches do not have experience with, training on, or accessible resources for LGB athletes.

In one study by Stoelting (2011), 16 openly lesbian athletes were interviewed. The purpose was to identify the factors that contributed to an athlete feeling comfortable enough to disclose their sexuality to their respective teams and coaches. Thirteen of the 16 openly lesbian athletes stated that they attributed their openness to disclosing their sexuality to coaches and teammates to the degree of closeness they felt with each and the potential of developing closer friendships with teammates (Stoelting, 2011). Other, more internal, motivations for disclosing sexual identity included a desire to self-accept and normalize their own identity. Normalization involves redefining a stigma with the hope of the stigma losing its strength and potential (Blinde $\&$ Taub, 1992). Furthermore, nine of the 16 openly lesbian athletes in the Stoelting (2011) study 
mentioned honesty or unwillingness to lie as a factor that influenced their decision to come out (Stoelting, 2011).

Stoelting (2011) used the approach of disclosure as an interaction, a rarely utilized approach, in the "coming out" process of athletes. Individuals reported disclosing their sexual identity for personal health reasons, to relieve psychological stress and anxiety, and to increase self-confidence or self-esteem (Bredemeier, Carlton, Hills, \& Oglesby, 1999). However, as an interaction, the person still chooses whether to disclose their sexual identity or not, but that decision may be based on the anticipated reaction of the person and/or the context or setting in which they choose to disclose (Montini, 2000). This can be problematic when an athlete does not feel safe enough to disclose their identity to the coaches and/or team, creating the potential for increased stress and decreased self-esteem.

A myriad of events can contribute to athletes remaining silent about their sexual orientation or feeling comfortable enough to disclose their identity to coaches and teammates. In another study with male athletes, Anderson (2011) interviewed an openly gay athlete who reported that "only adults" had a hard time with the athlete's sexuality, further indicating the importance of coach impact. He discussed a situation in which he was approached and asked, “Why don't you just choose to be straight?" In an article published by Liberty Education Forum, Burr (2005) gives an honest, yet controversial look into the background and perceptions of homosexuality. He reported that while the "gay gene" is still very much debated in politics and social settings, there would be more support for LGB individuals and less debate regarding human rights, if others believed that that homosexuality was biological as opposed to a personal choice. Therefore, in an attempt to show likeness, trait profiles were compared between handedness and homosexuality. Data shows strong similarities between these two traits (e.g. 
percent occurrence, detection ages, and sex differences). It was also noted, that handedness can be altered by forcing a child to write with opposite hands, but this is simply a behavioral change, "masking the true orientation." Therefore, when individuals are encouraged to hide their sexuality or attempt to be heterosexual, this behavioral change does not indicate a choice or change, but merely a mask. The mask can create great strain on a person and the relationships that the person has with others.

The disconnect between adolescent and young adult athletes and coaches with regard to LGB understanding can create detrimental consequences. Conservative values and lack of privacy, which are generally apparent in a team setting, can create an uncomfortable and intimidating place for those individuals seen as "different. One way that coaches can build their knowledge, awareness, and understanding in order to build, instead of strain, relationships is through creating and taking advantage of opportunities to interact with LGB individuals and athletes, in and out of the sport arena. Contact with sexual minorities has been shown to positively influence attitudes toward and relationships with LGB individuals. The Contact Hypothesis (Pettigrew, 1998) states that the more interactions people have with dissimilar others, the more positive their attitudes are likely to be toward those persons. These interactions are considered part of the socialization process for all involved.

Socialization is the process by which individuals learn the accepted norms, values, and behaviors of a social group or culture (Kramer, 1991). One potential outcome of socialization is learning prejudiced beliefs, lack of acceptance, and discrimination toward non-heterosexuals (Duckitt, 1992; Krane, 1996). For this reason, coaches may be the single most influential individuals for instilling values and a sense of inclusivity in a team setting. Beliefs about another's attitude can cause personal cognitive and behavioral changes in peers in an attempt to 
be more in line with the other person's (i.e. coaches"') beliefs. This term is identified as "pluralistic ignorance" and means that the beliefs that a person holds may not be what they express outwardly if they believe others around them, meaning people in power positions, would disagree (Bowen \& Bourgeouis, 2001). Attempting to fulfill the perceived desires of others can lead to harassment towards LGB athletes.

In 2009, researchers surveyed 296 Division I and Division II collegiate coaches with regard to their efficacy in working with LGB student-athletes (Vargas-Tonsing \& Oswalt). Results indicated that coaches felt they had a high efficacy for instilling an attitude of respect for all athletes, regardless of sexual orientation. However, a majority of the coaches felt less efficacious about their ability to identify available resources for LGB athletes and preventing LGB issues from becoming a distraction on the team. Specifically, male coaches were less confident when coaching gay athletes when compared to female coaches' beliefs about coaching lesbian athletes. This finding is similar to data found in other reports which indicate that the level of masculinity within sport could contribute to a more negative team environment for LGB athletes and issues (Anderson, 2005; Gill et. al, 2006) and that, in general, men are significantly more sexist and "antigay" than females (Harry, 1995).

The direct avoidance of issues surrounding LGB inclusion can come from coaches, administration, parents, teammates, or even from the athletes themselves in an attempt to act and physically appear heterosexual to escape potential harassment. However, homonegative atmospheres are further exacerbated when overt jokes and comments are tolerated and accepted by people in powerful positions (coaches/administrators/parents). Discrimination and homonegativity are both behaviors that are overtly and inadvertently taught to others. Anderson (2000) found that while there was a lack of overt discrimination against openly gay athletes, 
sport remains steadfast in the continuation of heterosexual hegemony and hegemonic masculinity.

Notable concerns for coaches and LGB inclusion include parents, athletic trainers, and the athletic department overall. Unlike the majority of collegiate sports, at the high school level, parents may still be heavily involved in their child's day to day activities. Sartore and Cunningham (2009) reported that sexual prejudice is high among parents of athletes. Parents also prefer heterosexual coaches (Sartore \& Cunningham, 2009). These prejudices due to sexual orientation are observed by their children and outwardly demonstrated in the adolescents' choice to engage in contact with LGB individuals (Mata, Ghavani, \& Wittig, 2010), their willingness to remain friends with LGB individuals (Horn, 2010), the justification of behaviors towards to LGB individuals (Horn, 2006), and the use of anti-gay language (Poteat \& DiGiovanni, 2010). The prejudices and accompanying behaviors can also be developed by observing coaches or others who may be in leadership roles within the team setting.

In conjunction with sport coaches, athletic training staff work very closely with athletes, commonly developing close relationships with the athletes. In a recent study that viewed 964 heterosexual athletic trainers' (AT) attitudes toward homosexual athletes, the majority of ATs held positive or somewhat positive views of LGB athletes, but approximately $15 \%$ still held negative views of the LGB population (Ensign, Yiamaouyiannis, White, \& Ridpath, 2011). Female ATs, individuals with a LGB friend or family member, and Catholics or individuals with no religious affiliation held the most positive views of LGB student-athletes. Religious institutions represent one of the most robust macro-level factors for creating a basis for people's prejudice toward LGB individuals (Finlay \& Walther, 2003; Whitley, 2009). Even though holding a negative attitude may not translate into treating an athlete differently, a more positive 
attitude is more likely to result in a more positive experience and vice versa with negative attitudes.

Stoelting (2011) identified the importance of sexual orientation diversity within athletic departments in assisting athletes in feeling comfortable enough to be open with their sexualities earlier, insinuating the perception of a safe environment. The size of university, racial diversity of department employees, and gender diversity were all positively associated with sexual orientation diversity (Cunningham, Sartore, \& McCullough, 2010; Human Rights Campaign, 2009). In a review of NCAA Division III athletic department administrators, $46 \%$ of the participating athletic departments were considered low in sexual orientation diversity while $17 \%$ reported no sexual orientation diversity within the department (Cunningham et al., 2010). Larger cities and cities in which large universities are located, generally have greater diversity and citizens are oftentimes more prone to express an interest in diversity and social justice (Fassinger, Shullman, \& Stevenson, 2010; Hall \& Lee, 2010).

Within occupational settings, such as athletic departments or other sport-related careers, overt and subtle forms of bias have been exhibited towards sexual minorities. Sexual prejudice is high among current and future sport and exercise psychology professionals (Gill, Morrow, Collins, Lucey, \& Schultz, 2006) and current and former athletes (Sartore \& Cunningham, 2009, Study 1), indicating less positive views of gay and lesbian individuals than other minority groups (Gill, Morrow, Collins, Lucey, \& Schultz, 2006). Additionally, Morrow and Gill (2003) reported that physical education teachers and students in public schools had been witness to significant levels of homophobic and heterosexist behavior, yet they did not see those behaviors confronted by individuals of authority. More subtle displays of bias have been observed during interviews (Hebl, Foster, Mannix, \& Dovidio, 2002). Lesbian, gay, and bisexual candidates received less 
time with, fewer words to, and perceived more negative interactions with employers than the presumed heterosexual candidates. This was further supported in a study by Cunningham, Sartore, and McCullough (2010) which reviewed applicant perceptions at a fitness club. Nonheterosexual applicants were regularly ascribed less positive personal attributes. These concerns, while not studied directly on a sport team environment could be detrimental if experienced by youth athletes who are attempting to develop their personal identity as well as technical sport skills.

Coaches can often be the catalyst for establishing a LGB inclusive team climate. Many LGB adolescents in school settings hold the expectation that individuals in authority positions would not help or support them in cases of harassment or violence (D’Augelli, 1992). This is of particular concern due to LGB athletes also having few LGB role models or other sources of support (Safren \& Rogers, 2001). Lack of resources and social support can create personal feelings of isolation and disconnection between team members. Despite gradual improvements and awareness, researchers and activists continue to push for a more LGB inclusive atmosphere at all levels of sport (Barber \& Krane, 2007). Therefore, examining coaches' perceptions and experiences with LGB athletes will add to the current paucity of literature, specifically within high school athletic programs, and could lead to strategies to change the culture and team environment for both heterosexual and homosexual athletes in the future. 


\section{Extended References}

Anderson, E. (2000). Trailblazing: America's first openly gay high school coach. Hollywood, CA: Alyson Press.

Anderson, E. (2002). Openly gay athletes: Contesting hegemonic masculinity in a homophobic environment. Gender \& Society, 16, 860-877.

Anderson, E. (2005). In the game: Gay athletes and the cult of masculinity. Albany, NY: SUNY Press.

Anderson, E. (2008). "Being masculine is not about who you sleep with...”: Heterosexual athletes contesting masculinity and the one-time rule of homosexuality. Sex Roles, 58, 104-115.

Anderson, E. (2011). Updating the outcome: Gay athletes, straight teams, and coming out in educationally based sport teams. Gender \& Society, 25, 250.

Anderson, M.B., Butki, B.D., \& Heyman, S.R. (1997). Homophobia among athletes: A survey from the heartland. Academic Athletic Journal, 12, 27-38.

Anderson, R.A. \& Mowatt, R.A. (2013). Heterosexism in campus recreational club sports: An exploratory investigation into attitudes toward gay men and lesbians. Recreational Sports Journal, 37, 106-122.

Barber, H. \& Krane, V. (2007). Creating a positive climate for lesbian, gay, bisexual, and transgender youths. Journal of Physical Education, Recreation, and Dance, 78, 6-52.

Beylin, M. (2006). Homosexual athletes feel pressure to stay in the closet. The Campanile.

Blake, Ledsky, Lehman, \& Goodenow, 2001

Blinde, E.M. \& Taub, D.E. (1992). Women athletes as falsely accused deviants: Managing the lesbian stigma. Sociological Quarterly, 33(4), 521-533. 
Blumenfeld, W.J. \& Raymond, D. (1988). Looking at gay and lesbian life. Boston: Beacon Press.

Bowen, A.M. \& Bourgeouis, M. (2001). Attitudes towards lesbian, gay, and bisexual college students: The contribution of pluralistic ignorance, dynamic social impact, and contact theories. Journal of American College Health, 50, 91-96.

Bredemeier, B.J.L., Carlton, E.B., Hills, L.A., \& Oglesby, C.A. (1999). Changers and the changed: Moral aspects of coming out in physical education. Quest, 51(4), 418-431.

Burr, C. (2005). The only question that matters: Do people choose their sexual orientation? Washington, D.C.: Liberty Education Forum.

Cahn, S.K. (1994). Coming on strong: Gender and sexuality in the $20^{\text {th }}$ century. New York: The Free Press.

Cass, V. C. (1979). Homosexual identity formation: A theoretical model. Journal of Homosexuality, 4, 219-235.

Cass, V.C. (1990). The implications of homosexual identity formation for the Kinsey model and scale of sexual preference. In D.P. McWhirter, S.A. Sanders, \& J.M. Reinisch (Eds.), Homosexuality/heterosexuality: Concepts of sexual orientation. New York, NY: Oxford University Press.

Cass, V.C. (1996). Sexual orientation identity formation: A western phenomenon. In R.P. Cabaj \& T.S. Stein (Eds.), Textbook of homosexuality and mental health. Washington, DC: American Psychiatric Press, Inc.

Chan, C.S. (1994). Asian-American adolescents: Issues in the expression of sexuality. In J. M. Irvine (Ed.), Sexual Cultures and the Construction of Adolescent Identities. Philadelphia: Temple University Press. 
Chan, C.S. (1995). Issues of sexual identity in an ethnic minority: The case of Chinese American lesbians, gay men, and bisexual people. In A. D’Augelli \& C. Patterson (Eds.), Lesbian, gay, and bisexual identities over the life span: Psychological perspectives. New York: Oxford University Press.

Collier, K., Bos, H., Merry, M., \& Sandfort, T. (2013). Gender, ethnicity, religiosity, and samesex sexual attraction and the acceptance of same-sex sexuality and gender noncomformity. Sex Roles, 68, 724-737.

Creswell, J.W. (2007). Qualitative inquiry and research design: Choosing among five approaches ( $2^{\text {nd }}$ ed.). Thousand Oaks, CA: Sage Publications.

Crotty, M. (1998). The foundations of social research: Meaning and perspective in the research process. Thousand Oaks, CA: Sage Publications.

Cunningham, G.B. \& Melton, E.N. (2014). Varying degrees of support: Understanding parents' positive attitudes toward LGBT coaches. Journal of Sport Management, 28, 387-398.

Cunningham, G.B., Sartore, M.L., \& McCullough, B.P. (2010). The influence of applicant sexual orientation and rater sex on ascribed attributions and hiring recommendations of personal trainers. Journal of Sport Management, 24, 400-415.

D’Augelli, A.R. (1994). Identity development and sexual orientation: Toward a model of lesbian, gay, and bisexual development. In E.J. Trickett, R.J. Watts \& D. Birman (Eds.), Human diversity: Perspectives on people in context. San Francisco: Jossey-Bass.

Dale, G.A. (1996). Existential phenomenology: Emphasizing the experience of the athlete in sport psychology research. The Sport Psychologist, 10, 307-321.

Dempsey, C.L. (1994). Health and social issues of lesbian, gay, and bisexual adolescents. Families in Society, 75, 160. 
Denzin, N.K. (1978). Sociological Methods. New York, NY: McGraw-Hill.

Duckitt, J.H. (1992). The social psychology of prejudice. Westport, CT: Praeger Publishers.

Ensign, K.A., Yiamouyiannis, A., White, K.M., \& Ridpath, B.D. (2011). Athletic trainers' attitudes towards lesbian, gay, and bisexual National Collegiate Athletic Association student-athletes. Journal of Athletic Training, 46, 69-75.

Evans, N.J., Forney, D.S., Guido, F.M., Patton, L.D., \& Renn, K.A. (2010). Student development in college: Theory, research, and practice ( $2^{\text {nd }}$ ed.). San Francisco, CA: Jossey-Bass.

Fassinger, R.E., Shullman, S.L., \& Stevenson, M.R. (2010). Toward an affirmative lesbian, gay, bisexual, and transgender leadership paradigm. American Psychologist, 65(3), 201-215.

Fink, J., Burton, L., Farrell, A., \& Parker, H. (2012). Playing it out. Journal for the Study of Sports and Athletes in Education, 6(1), 83-106.

Flick, U. (2004). A companion to qualitative research. London: Sage Publications.

Gill, D.L., Morrow, R.G., Collins, K.E., Lucey, A.B. \& Schultz, A.M. (2006). Attitudes and sexual prejudice in sport and physical activity. Journal of Sport Management, 20, 554564.

Glesne, C. (2006). Becoming qualitative researchers: An introduction ( $3^{\text {rd }}$ ed.). New York, NY: Pearson.

Kosciw, J.G., Greytak, E.A, Bartkiewicz, M.J., Boesen, M.J., \& Palmer, N.A. (2012). The 2011 National School Climate Survey: The experiences of lesbian, gay, bisexual and transgender youth in our nation's schools. New York: GLSEN.

Griffin, P. (1992). From hiding out to coming out: Empowering lesbian and gay educators. Journal of Homosexuality, 22, 167-196. 
Griffin, P. (1994). Homophobia in sport: Addressing the needs of lesbian and gay high school athletes. The High School Journal, 77, 80-87.

Griffin, P. (1998). Strong women, deep closets: Lesbians and homophobia in sport. Champaign, IL: Human Kinetics.

Griffin, P. (2012). LGBT equality in sports: Celebrating our successes and facing our challenges. In G.B. Cunningham (Ed.). Sexual Orientation and Gender Identity in Sport (pp. 1-12). College Station, TX: Center for Sport Management Research and Education.

Groenewald, T. (2008). Memos and memoing. In L.M. Given (Ed.), The SAGE encyclopedia of qualitative research methods. Thousand Oaks, CA: SAGE Publications.

Guthrie, S. (2005). "Following the straight and narrow": An exploratory study of lesbophobia and eating disorder symptomology among lesbian athletes. Women in Sport \& Physical Activity Journal, 14(1), 6-23.

Haas, A.P., Eliason, M., Mays, V.M., Mathy, R.M., Cochran, S.D., D'Augelli, A.R., Silverman, M.M., Fisher, P.W., Hughes, T., Rosario, M., Russell, S.T., Malley, E., Reed, J., Litts, D.A., Haller, E., Sell, R.L., Remafedi, G., Bradford, J., Beautrais, A.L., Brown, G.K., Diamond, G., Friedman, M.S., Garofalo, R., Turner, M.S., Hollibaugh, A., Clayton, P.J. (2011). Suicide and suicide risk in lesbian, gay, bisexual, and transgender populations: Review and recommendations. Journal of Homosexuality, 58, 10-51.

Halbrook, M. \& Watson II, J.C. (in preparation). High school coaches' perceptions of their efficacy to work with lesbian, gay, and bisexual athletes. Anticipated submission to the International Sport Coaching Journal for consideration.

Hall, M. \& Lee, B. (2010). How diverse are US suburbs?. Urban Studies, 4(1), 3-28. 
Hebl, M.R., Foster, J.B., Mannix, L.M., \& Dovidio, J.F. (2002). Formal and interpersonal discrimination: A field study of bias toward homosexual applicants. Personality and Social Psychology Bulletin, 28, 815-825.

Hekma, G. (1998). “As long as they don’t make an issue of it...”: Gay men and lesbians in organized sports in the Netherlands. Journal of Homosexuality, 35, 1-23.

Herek, G.M. (1991). Stigma, prejudice, and violence against lesbians and gay men. In J. Gonsiorek and J. Weinrich (Eds.), Homosexuality: Research implications for public policy. Newbury Park, CA: Sage.

Herek, G.M. (1992). Psychological heterosexism and antigay violence: The social psychology of bigotry and bashing. In G.M. Herek \& K.T. Berrill (Eds.), Hate Crimes: Confronting violence against lesbians and gay men. Thousand Oaks, CA: Sage.

Herek, G.M. (2002). Gender gaps in public opinion about lesbians and gay men. Public Opinion Quarterly, 66, 40-66.

Hoepfl, M.C. (1997). Choosing qualitative research: A primer for technology education researchers. Journal of Technology Education, 9(1).

Hogg, M.A. \& Abrams, D. (1988). Social identifications: A social psychology of intergroup relations and group processes. London: Routledge.

Hoover, R. \& Fishbein, H.D. (1999). The development of prejudice and sex role stereotyping in white adolescents and white young adults. Journal of Applied Developmental Psychology, 20, 431-448.

Horn, S.S. (2006). Heterosexual adolescents' and young adults' beliefs and attitudes about homosexuality and gay and lesbian peers. Cognitive Development, 21, 420-440. 
Horn, S.S. (2010). Contemporary attitudes about sexual orientation. In C. Patterson \& A. D’Augelli (Eds.), The handbook for the psychology of sexual orientation. Oxford: Oxford University Press.

Hudson, W.W. \& Ricketts, W.A. (1980). A strategy for the measurement of homophobia. Journal of Homosexuality, 5(4), 357-372.

Kian, T. \& Anderson, E. (2009). John Amaechi: Changing the way sport reporters examine gay athletes. Journal of Homosexuality, 56, 1-20.

Kimmel, M. (1994). Masculinity as homophobia: Fear, shame, and silence in the construction of gender identity. In Theorizing Masculinities, Harry Brod and Michael Kaufman (Eds.). Thousand Oaks, CA: Sage.

Kramer, L. (1991). The sociology of gender. New York: St. Martin's Press.

Krane, V. (1996). Lesbians in sport: Toward acknowledgement, understanding, and theory. Journal of Sport and Exercise Psychology, 18, 237-246.

Krane, V. \& Baird, S. (2005). Using ethnography in applied sport psychology. Journal of Applied Sport Psychology, 17(2), 27-107.

Krane, V., Waldron, J.J., Kauer, K.J., \& Semerjian, T.Z. (2010). Queering Sport Psychology. The Cultural Turn in Sport Psychology (pp. 153-179). Morgantown, West Virginia: Fitness Information Technology.

Kvale, S. (1983). The qualitative research interview: A phenomenological and a hermeneutical mode of understanding. Journal of Phenomenological Psychology, 14, 171-196.

Lather, P. (2006). Paradigm proliferation as a good thing to think with: Teaching qualitative research as a wild profusion. Qualitative Studies in Education, 19(1), 35-57.

Lenskyj, H. (1986). Out of bounds: Women, sport, and sexuality. Toronto: Women's Press. 
Lenskyj, H. (1990). Power and play: Gender and sexuality issues in sport and physical activity. International Review for Sociology of Sport, 25, 235-245.

Lenskyj, H. (1992). Unsafe at home base: Women's experience of sexual harassment in university sport and physical education. Women in Sport and Physical Activity Journal, 1, 19-33.

Leyens, J.P., Yzerbyt, V.Y., \& Schadron, G. (1994). Stereotypes and social cognition. London: Sage.

Loftus, J. (2001). America's liberalization in attitudes toward homosexuality, 1973 to 1998. American Sociological review, 66(5), 762-782.

Loughran, M.J. (2009). Counseling the LGBTQ student athletes: Issues and intervention strategies. In E.F. Etzel (Ed.), Counseling and psychological services for college studentathletes. Morgantown, WV: West Virginia University.

Martens, M.P. \& Mobley, M. (2005). Straight guys working with gay guys: Homophobia and sport psychology service delivery. In M.B. Anderson (Ed.), Sport psychology in practice. Champaign, IL: Human Kinetics.

Marshall, C. \& Rossman, G.B. (2011). Primary data collection methods designing qualitative research. Los Angeles, CA: Sage Publications.

Mata, J., Ghavami, N., \& Wittig, M.A. (2010). Understanding gender differences in early adolescents' sexual prejudice. Journal of Early Adolescence, 30(1), 50-75.

Mathison, S. (1988). Why triangulate? Educational Researcher, 17(2), 13-17.

Maxwell, J.A. (2012). Qualitative research design: An interactive approach (3 ${ }^{\text {rd }}$ ed.). Los Angeles, CA: SAGE Publications. 
Maykut, P. \& Morehouse, R. (2000). Beginning Qualitative Research: A Philosophic and Practical Guide. London: Routledge.

McCabe, Hughes, Bostwick, West, \& Boyd, 2009

McCormack, M. \& Anderson, E. (2010). The re-production of homosexually-themed discourse in educationally-based organized sport. Culture, Health, \& Sexuality, 12, 913-927.

Messner, M.A. (2002). Taking the field: Women, men, and sports. Minneapolis: University of Minnesota Press.

Miles, M.B., Huberman, A.M., \& Saldana, J. (2014). Qualitative data analysis: A methods sourcebook and the coding manual for qualitative researchers. Thousand Oaks, CA: Sage Publications.

Mills, C.W. (1959). On intellectual craftsmanship. In C.W. Mills (Ed.), The sociological imagination. London: Oxford University Press.

Montini, T. (2000). Compulsory closets and the social context of disclosure. Sociological Perspectives, 43(4), 121-132.

Morrison, T., McLead, L., Morrison, M., Anderson, D., \& O’Connor, W.E. (1997). Gender stereotyping, homonegativity, and misconceptions about sexually coercive behavior among adolescents. Youth and Society, 28, 451-465.

Morrow, R.G., \& Gill, D .L. (2003). Perceptions of homophobia and heterosexism in physical education. Research Quarterly for Exercise and Sport, 74, 205-214.

Morrow, S.L. (2005). Quality and trustworthiness in qualitative research in counseling psychology. Journal of Counseling Psychology, 52(2), 250-260.

Neisen, J. (1993). Healing from cultural victimization: Recovery from shame due to heterosexism. Journal of Gay and Lesbian Psychotherapy, 2(1), 49-63. 
Nelson, M.B. (1991). “A silence so loud it screams.” In M.B. Nelson (Ed.), Are we winning yet?: How women are changing sports and sports are changing women. New York: Random House.

O’Bryan, M., Fishbein, H., \& Ritchey, P.N. (2004). Intergenerational transmission of prejudice, sex role stereotypes, and intolerance. Adolescence, 39, 407-426.

Patton, M.Q. (1999). Enhancing the quality and credibility of qualitative analysis. Health Services Research, 34(5), 1189-1208.

Peper, K. (1994). Female athlete = lesbian. A myth constructed from gender role expectations and lesbiphobia. In R.J. Ringer (Ed.), Queer words, queer images: Communication and construction of homosexuality. New York: New York University Press.

Pew Research Global Attitudes Project. (2013). The global divide on homosexuality. http://www.pewglobal.org/2013/06/04/the-global-divide-on-homosexuality/

Ponterotto, J.G. (2005). Qualitative research in counseling psychology: A primer on research paradigms and philosophy of science. Journal of Counseling Psychology, 52(2), 126-136.

Poteat, V.P. \& DiGiovanni, C.D. (2010). When biased language use is associated with bullying and dominance behavior: The moderating effect of prejudice. Journal of Youth \& Adolescence, 39, 1123-1133.

Price, M. (2000). Rugby as a gay men's game. Unpublished Ph.D. diss., University of Warwick, Coventry, UK.

Pronger, B. (1990). The arena of masculinity: Sports, homosexuality, and the meaning of sex. New York: St. Martin’s.

Pronger, B (2000). 'Homosexuality and sport: Who's winning?' in J. McKay, M. Messner, and D. Sabo (Eds.), Masculinities, Gender Relations, and Sport. London: Sage, 222-244. 
Rankin, S. \& Merson, D. (2012). LGBTQ College Athlete Report. Campus Pride. http://www.campuspride.org

Ravel, B. \& Rail, G. (2008). From straight to gaie? Quebec sportswomen's discursive constructions of sexuality and destabilization of the linear coming out process. Journal of Sport and Social Issues, 32, 4-23.

Remafedi, G. (1987). Homosexual youth. Journal of the American Medical Association, 258, 222-225.

Rose, G. (2007). Visual methodologies: An introduction to the interpretation of visual materials ( $2^{\text {nd }}$ ed.). Los Angeles, CA: Sage.

Russell, K.M. (2004). On versus off the pitch: The transiency of body satisfaction among female rugby players, cricketers, and netballers. Sex Roles, 51, 561-574.

Ryan, S. (2000). Examining social workers' placement recommendations of children with gay and lesbian adoptive parents. Families in Society, 81, 517-528.

Ryba, T.V. (2007). Cartwheels on ice: A phenomenological exploration of children's enjoyment in competitive figure skating. Athletic Insight, 9(2), 58-73.

Safren, S.A. \& Rogers, T. (2001). Cognitive-behavioral therapy with lesbian, gay, and bisexual clients. Journal of Clinical Psychology, 57, 629-643.

Savin-Williams, R.C. (1994). Verbal and physical abuse as stressors in the lives of lesbian, gay male, and bisexual youths: Associations with school problems, running away, substance abuse, prostitution, and suicide. Journal of Consulting and Clinical Psychology, 62(2), 261-269.

Savin-Williams, R.C. (2005). The new gay teenager. Cambridge, MA: Harvard University Press. 
Schwandt, T. (2007). Dictionary of qualitative inquiry ( $3^{\text {rd }}$ ed.). Thousand Oaks, CA: Sage Publications.

Shilo, G. \& Savaya, R. (2011). Effects of family and friend support on LGB youths' mental health and sexual orientation milestones. Family Relations, 60, 318-330.

Smith, Shin, \& Officer, 2011

Staurowsky, E.J. (2012). Sexual prejudice and sport media coverage. Exploring an ethical framework for college sport journalists. Journal for the Study of Sports and Athletes in Education, 6, 121-140.

Stoelting, S. (2011). Disclosure as an interaction: Why lesbian athletes disclose their sexual identities in intercollegiate sport. Journal of Homosexuality, 58(9), 1187-1210.

Taifel, H. \& Turner, J.C. (1986). The social identity theory of intergroup behavior. In S. Worchel \& W.G. Austin (Eds.), Psychology of intergroup relations (2 ${ }^{\text {nd }}$ ed.). Chicago, IL: NelsonHall.

Turner \& Rubinson (1993). Contemporary human sexuality. Prentice Hall College Div.

Waldron, J.J. \& Krane, V. (2005). Whatever it takes: Health compromising behaviors in female athletes. Quest, 57, 315-329.

Wargo, W.G. (2015, August 15). Identifying assumptions and limitations for your dissertation. Academic Information Center. Retrieved on June 1, 2016.

Watson II, J.C. \& Halbrook, M. (2014). Incorporating technology into practice: A service delivery approach. In J.G. Cremades \& L.S. Tashman (Eds.), Becoming a sport, exercise, and performance psychology: A global perspective. New York, NY:

Routledge/Psychology Press. 
Watson II, J.C., Tenenbaum, G., Lidor, R., \& Alfermann, D. (2001). Ethical uses of the internet in sport psychology: A position stand. International Journal of Sport Psychology, 31, 201-222.

Wolf-Wendel, L.E., Toma, J.D., \& Morphew, C.C. (2001). How much difference is too much difference? Perceptions of gay men and lesbians in intercollegiate athletics. Journal of College Student Development, 42, 465-479.

Varenne, H. (1982). Jocks and freaks: The symbolic structure of the expression of social interaction among American senior high school students. In G. Spindler (Ed.), Doing the ethnography of schooling educational anthropology in action. New York: Holt, Rinchart, and Winston.

Vargas-Tonsing, T.M. \& Oswalt, S.B. (2009). Coaches' efficacy beliefs towards working with lesbian, gay, and bisexual athletes. International Journal of Coaching Science 3, 29-42.

Young, P.D. (1995). Lesbians and gays and sports. New York: Chelsea House.

Ziegler, C. (2011, November 28). Gay softball settles lawsuit: Court upholds straight limit, dismisses discrimination claims. Outsports.com. Retrieved on June $1^{\text {st }} .2016$. 
APPENDIX C 


\section{Personal Background}

One of the best memories I have of my childhood is running around the bases, which were well-placed trees, in my grandmother's backyard during pickup games of baseball with my cousins. My grandfather had a "green thumb" and spent much time outside working in his flower beds and trimming bushes that lined the road next to the house. He loved his grandchildren, and he loved baseball, but he was consistently frustrated with us, as there was a diamond of dirt in his pristine yard that refused to grow grass from years of stealing bases and homeruns. Rain, shine, or snow, my cousins and I were outside until dark most days of the year.

Despite being an only child for the vast majority of my childhood, I grew up with four cousins and an assortment of other neighborhood kids my age. We all spent extensive time at my grandmother's house before we were old enough to enter school, and then after school until we reached middle school and were participating in extracurricular activities. I was in the middle, age-wise, of my cousins and one of only two girls. My youngest cousin, and only other female, despised sports. She would frequently refuse to play with my three male cousins and me when we would play sports, which, incidentally, did not bother us. We were much too competitive to be worried about trying to teach someone else the rules or adapt even the slightest bit to include her.

However, because we were the only two girls, I was often treated in contradictory ways. My mother and grandmother often encouraged me to wear dresses, "act like a girl," and liked when I participated in activities like "house" or baking. My father and grandfather, on the other hand, loved how athletic I was. My dad encouraged me to play all kinds of sports growing up and I was often the "right hand man" of my grandfather as he broadcasted high school and college baseball games during the week. I was enrolled in soccer and baseball (because softball 
was not an option in my hometown) at the age of five and played soccer until I graduated high school. I was always more comfortable on a field, in athletic clothes, sweating, than I was in situations that required me to dress femininely, watch my manners, and talk about feelings or express emotion. These stereotypes ran deep in my family and in my own thoughts.

Once I got to high school, I was able to begin participating in softball for the first time, after playing baseball on boys' teams up until that point. My father actually had to bribe me to try-out for the softball team in high school. I was mildly repulsed at the idea of playing such a "girlish sport" and felt that I would be much too skilled to find enjoyment. While I do not believe the men in my life intentionally created these perceptions in me, it was very evident, at the age 14 years old, that there was a difference in my mind of how boys and girls participated in sport and I perceived the "boy's way" to be more competitive and elite.

It was also around this time that I started to come to terms with my sexuality. I had developed a crush on my female best friend in sixth grade and, after being both excited and terrified at this revelation, decided it was in my best interest to keep this information to myself. My hometown had a population of approximately 14,000 and was situated in rural, southeast Missouri. I did not know anyone who was gay or lesbian until I was 12 years old when my family doctor came out as being gay after 20 years of marriage to a woman. Homosexuality was not common in my town and was not perceived by me, and many others, to be widely accepted.

I was able to keep my sexuality a secret from everyone I knew until I met my first girlfriend when I was 15 years old. Despite our best efforts to keep this relationship a secret, I was outed by a "friend" a couple of months later. Similar to the feelings I felt after my first crush, I was both excited and terrified at the fact that I would now be living openly as a lesbian, a term I still find to not be comfortable when describing myself. I told my mother about my 
sexuality and was met with tolerance, which was expected given her perspective of our family doctor. However, my father made his negative feelings about my first girlfriend, as a person, very clear so I chose to not to tell him about my sexuality for fear of being rejected, but also from fear of disappointing him.

Once I became more open about my sexuality, some aspects of my life improved while other aspects declined. While I did not have to lie to my mother and friends anymore, I also started experiencing discrimination for the first time in my life. I was often the target of jokes in class and on my teams, even from people I was originally very close with prior to being open about my sexuality. I was often not invited to group dates or asked about my significant other. I was never physically abused but was referred to as a "dyke," "queer," and "lesbo" frequently. I had adults in my life recommend attending church services as a way of repentance and the word "faggot" was written on my car in soap on two separate occasions. One of the most upsetting things, though, was how divided my softball team was on my participation. Some of my teammates were highly supportive and became not only closer friends but often my protectors in the sense that they were popular upperclassmen and did not put up with others making fun of me.

Others on the team began distancing themselves from me, though. In an attempt to create less conflict, I distanced myself from them as well. I stopped changing openly in front of others, in the locker room or the bus, for fear that they would be uncomfortable. I stopped talking about relationships and I isolated, often with my girlfriend, from others. Being open about my sexuality became my biggest fear. Any type of public display of affection, immediately caused me to push my partner away. I began dressing more femininely to avoid being even more directly stereotyped. The desire to fit in was so strong at this age that I often mislead my peers 
into believing I was someone I was not, causing my own identity to be lost and my relationships, particularly romantic, to suffer.

Despite these personal changes, sport was still my sanctuary. I was considered an important role player in soccer and was a starter all four years on the varsity softball team. Because of my need to belong, I was very invested in the teams and developed differing, but good, relationships with my coaches. My soccer coach was a volatile man with a passion for winning that often led him to push us harder than I ever believed was possible. He was impossible to have a personal conversation with because of his closed off personality and he took little interest in our lives outside of soccer. While some may see his coaching style as cold, it was a relief to me. Whether he knew of my sexuality or not, I am not sure, but I never felt like I was treated differently or not given opportunities to participate. He was extremely task focused and appeared to fairly decide on who should play and when, through observation of our skill and work ethic.

My softball coach in high school was very different than my soccer coach. My softball coach was one of the most genuinely sweet and caring men I have had the pleasure of knowing in my life thus far. He was married to his high school sweetheart and he had a daughter who was two years older than me, who also played softball. He regularly joked that coaching females was the most challenging experience he had ever faced, but it was also the most rewarding. He took a direct interest in me and my family from my first day of tryouts coming into my freshmen year of high school. Due to my own distanced relationship with my father, he was often who I went to for advice or when I needed support. He was funny, dedicated to the sport and to our team, and always had a piece of wisdom to share. 
When I was outed my sophomore year of high school, it seemed like the news spread quickly and I was immediately concerned about what his reaction would be when he too found out. I remember one practice that was especially frustrating. I was upset when I got to the field and then proceeded to misjudge fly balls and swing at pitches that were way beyond my reach. At the end of practice, he asked to talk to me. I broke down immediately and, in his way, he told me that he knew that I was going through a lot but that it would pass. It was important to him that I stayed true to myself and that he would continue to coach me to his best ability regardless of my own doubts. The conversation did not last more than 10 minutes, but it was one of the most influential moments I had during my softball career. I knew that I would be accepted on his team and negativity would not be tolerated.

It is always surprising how the turns that life can take end up leading us in directions that were not intended. I was recruited to play at a junior college for softball in St. Louis which was incredibly exciting to me. Although, I didn't know it at the time, my college coach was a lesbian, as were a couple of my teammates. I actually can't recall a time when I felt uncomfortable or discriminated against at that college. It was refreshing to be living openly, for the most part, for the first time in my life.

One year after I started playing at the junior college, a number of things changed. I decided to graduate with my Associate's degree, the coach who recruited me left, and I was asked to fill the role. I had been planning to transfer to Columbia College in Columbia, MO to finish my Bachelor's degree and continue playing softball. However, when I was asked to coach I realized I couldn't turn down the opportunity.

I coached for two years at the junior college while I finished my Bachelor's Degree at a local university and found it both rewarding and completely exhausting. I was greatly unaware 
of the large number of responsibilities of a coach and quickly found that I was not prepared. Not to be found out, I immersed myself in my studies and started reading and researching ways of improvement. The other coach on the team was very much into psychological skills training, particularly imagery and self-talk. We would often discuss ways of improving team dynamics and performance. It was through her, and my undergraduate adviser, that I realized sport and exercise psychology would be a great fit for my graduate work.

My Master's degree work was spent trying to better understand coaching, motivation, and team cohesion. I wanted to be able to motivate people the same way my high school coach had for me. He was often in the back of my mind when I was frustrated or simply reviewing research on coaching. When I started my doctoral work, I realized I wanted to give back to the field one of the things that I found most imperative through the years of being a student-athlete, an inclusive environment. I had found a safe space during my college years and I attribute this partly to location but also to having a coach my first year that was not ashamed of her sexuality and set the precedent for how a team treats each other and other people.

My coach in high school was a huge support system for me, but his support for LGB athletes was one that I can only say for sure was shared with me. While he was never discriminatory, he was also not openly vocal about support and did not intervene in team dynamics or relationships. Had the culture of our town been different or had he had more resources, I wonder if the result would have been the same? Through coach education I hope to eventually help coaches better understand LGB athletes and develop supportive team environments that emphasize appreciation, inclusion, and growth on personal and performance level. 


\section{APPENDIX D}

Previous Research Study

High School Coaches' Perceptions of their Efficacy to Work with

Lesbian, Gay, and Bisexual Athletes

Meghan Halbrook

Jack Watson II

West Virginia University 
High School Coaches' Perceptions of their Efficacy to Work with Lesbian, Gay, and Bisexual Athletes

\section{Methods}

\section{Participants}

Surveyed participants were male $(n=444)$ and female $(n=179)$ high school coaches in the United States. Head $(n=502)$ and assistant coaches $(n=124)$ were located in all nine regions of the United States identified by the United States Census Bureau and reported coaching 25 different sports. The sports most frequently coached within the sample were basketball $(\mathrm{n}=$ 156), football $(n=149)$, and track and field $(n=116)$. The largest number of respondents reported being over the age of 50 years $(n=190)$, with each lower age group decreasing in size $(40-49$ year $=176,30-39$ years $=142$, and 18-29 years $=117)$. Approximately $43 \%$ of the sample reported that their highest level of education was a four year degree, while $48 \%$ had a graduate degree. Less than $3 \%$ of the sample identified as gay, lesbian, or bisexual and only $11 \%$ identified their ethnicity as other than White/Caucasian. The most prominent religious denominations were Catholic $(n=140,23 \%$ of the sample), Baptist $(n=137,22 \%$ of the sample), Protestant Christian $(\mathrm{n}=123,19 \%$ of the sample $)$, and no religious affiliation $(\mathrm{n}=107$, $16 \%$ of the sample).

Measures

Participants completed a demographics questionnaire, team demographic questionnaire, and the Efficacy Scale to Coach Gay, Lesbian, and Bisexual Athletes to measure how effective they perceived themselves to be when coaching or working with LGB athletes. ${ }^{5}$ All questionnaires were completed online using Qualtrics survey software (Qualtrics, Provo, UT), taking on average, less than 15 minutes to complete. 
Demographics Questionnaire. The demographics questionnaire was developed by the researcher to gain information about the participating coaches. It consisted of questions and topics designated as important from previous literature regarding sport and LGB individuals. The questions related to age, sex, sexual orientation, ethnicity, number of years coaching, coach position (head or assistant), religious denomination, education level, number of openly gay athletes coached in the past, and any coach education completed in the past five years, with special emphasis on diversity training.

Team Demographic Questionnaire. The team questionnaire was also developed by the researcher in order to assess team atmosphere by gaining additional information about team and player characteristics. Questions addressed type of sport, age of athletes, sex of athletes, location of team, number of athletes on the team, and number of openly LGB athletes on the team.

Efficacy Scale to Coach Gay, Lesbian, and Bisexual Athletes. In collaboration with sexual orientation and self-efficacy experts, Vargas-Tonsing and Oswalt developed the 20-item Efficacy Scale to Coach Gay, Lesbian, and Bisexual Athletes to assess coaches' confidence, efficacy, and beliefs regarding their work and skill development with LGB athletes. ${ }^{5}$ All items use a 5-point Likert type scale ranging from 1 ("Not at all Confident") to 5 ("Extremely Confident"). The scale was developed for use with coaches of high school and collegiate athletes and revealed a Cronbach's Alpha of .92. The current study utilized a single aggregate score for all 20 items. Scores ranged from 20 to 100, with higher scores indicating more perceived self-efficacy relative to coaching LGB athletes. All questions were prefaced with the stem "How confident are you that you can..." and followed by a specific element of coaching (e.g., “create a 'safe' environment for LGB athletes?”). 


\section{Procedures}

Once Institutional Review Board approval was obtained, the researcher contacted state high school athletic associations to gain email access to school Athletic Directors. Upon approval, 34 state high school associations were sent an email to forward to their high school Athletic Directors to then disseminate to coaches, 15 state high school associations directed the researcher to email lists on the high school athletic association website or provided the researcher with an email list, and one state refused to participate. For consistency, the same email with the established on-line Qualtrics survey link and survey completion instructions was sent to high school athletic directors from the researcher and the state high school associations. The link and survey completion instructions were requested to be forwarded from the athletic directors to high school head and assistant coaches. In addition to the 631 completed surveys, 314 surveys were opened but not completed. The email recipients were able to access the link which included information regarding the study, demographics questionnaire, team demographic questionnaire, and Efficacy Scale to Coach Gay, Lesbian, and Bisexual Athletes. The survey instruments were completed in order starting with the coach demographics questionnaire, followed by the team demographic questionnaire, and then the Efficacy Scale to Coach Gay, Lesbian, and Bisexual Athletes. While responses were anonymous, upon completion of the survey, coaches were able to volunteer to enter their contact information in order to receive follow-up information for future studies and information about the current study results.

\section{Results}

Descriptive statistics were calculated for coach demographics, team demographics, and Efficacy Scale variables. All data were entered and statistical analyses were run using SPSS 22.0. Using the single score obtained from responses on the Efficacy Scale to Coach Gay, 
Lesbian, and Bisexual Athletes as the Dependent Variable, multiple T-tests and ANOVAs were run to determine variables within the coach demographics and team demographics that most significantly determined differences in the Efficacy Scale score. Independent variables within the coach demographic questionnaire included age, religious denomination, education level, and the presence of diversity training. The number of openly LGB athletes currently on the team was analyzed from the team demographic questionnaire. These variables were chosen due to their relationship with individual perceptions of the LGB population within sport and the general community.

For hypothesis one, an independent samples t-test was run and results revealed that coaches with diversity or LGB training had a higher mean score $(M=90.71, \mathrm{SD}=11.68)$ on the Efficacy Scale to Coach Gay, Lesbian, and Bisexual Athletes than coaches with no diversity or LGB training $(M=87.94, \mathrm{SD}=13.09)$. However, despite the distinction, hypothesis two was not supported as this result did not reveal statistically significant differences between groups, $\mathrm{t}(622)=-1.596, \mathrm{~ns}$.

In order to address hypothesis two, another independent samples t-test revealed that the difference between male and female coach responses in this particular study was not statistically significant at the .05 level $\mathrm{t}(621)=-1.711$, ns. Female coaches had an average score of 89.56 on the Efficacy Scale to Coach Gay, Lesbian, and Bisexual Athletes, while male coaches reported an average score of 87.60 .

For hypothesis three, a one-way ANOVA was utilized to assess for differences in coach sexuality and Efficacy Scale scores. This study found statistically significant differences in perceptions between self-identified heterosexual and homosexual coaches, $\mathrm{F}(2,618)=1.214, p=$ .038. The mean score from heterosexual coaches on the Efficacy scale was $88.05(\mathrm{SD}=13.09)$, 
while coaches who identified as homosexual had an average score of $93.33(\mathrm{SD}=7.23)$. This finding does not support the research hypothesis that LGB coaches would report higher average scores on the Efficacy Scale to Coach Gay, Lesbian, and Bisexual Athletes.

A large number of religious affiliations were identified within the sample, with Baptist (n =137), Catholic $(\mathrm{n}=140)$, Protestant Christian $(\mathrm{n}=123)$, and No Religious Affiliation $(\mathrm{n}=107)$ being the most widely chosen. Due to the small sample size of other religions, only differences between these four aforementioned groups were assessed. As stated in hypothesis four, individuals with no religious affiliation had the highest average Efficacy Scale score $(M=91.99$, $\mathrm{SD}=9.014)$, followed by Catholic $(\mathrm{M}=88.99, \mathrm{SD}=12.595)$, Protestant Christian $(\mathrm{M}=87.87$, $\mathrm{SD}=11.818)$, and then Baptist $(\mathrm{M}=84.88, \mathrm{SD}=16.157)$. Multiple independent sample t-tests revealed statistically significant differences in scores on the Efficacy Scale to Coach Gay, Lesbian, and Bisexual Athletes at the .05 level between coaches reporting no religious affiliation and those coaches who identified as Catholic, $\mathrm{t}(245)=-2.087, p=.038$, Protestant Christian, $\mathrm{t}(228)=-2.939, p=.004$, and Baptist, $\mathrm{t}(242)=-4.080, p=.000$.

With regard to hypothesis five and the age and perceptions of the coaches, there was a statistically significant difference between groups as determined by one-way ANOVA $(F(3,621)$ $=3.839, p=.010)$. A Tukey post-hoc test revealed that the 18-29 year old age group's Efficacy Scale scores were significantly higher $(\mathrm{M}=90.5, p=.041)$ compared to the 50 years or older age group $(M=86.49)$. There were no statistically significant differences between the $18-29$ year old age group and 30-39 year old age group $(p=.996)$ or the $40-49$ year old age group $(\mathrm{p}=.128)$. The differences in scores for the 30-39 year old age group and the 50 years or older coaching group were not statistically significant, indicating that the strongest differences were between the 
two younger age brackets and coaches 50 years or older. Table 1 shows the decrease in Efficacy Scale scores from the 18-29 year old coaches to coaches 50 years and older.

\begin{tabular}{|c|c|c|c|c|c|}
\hline \multicolumn{6}{|l|}{ Table 1} \\
\hline Years of Age & $\underline{\mathrm{N}}$ & Mean & Std. Deviation & Minimum & Maximum \\
\hline $18-29$ & 117 & 90.5 & 10.931 & 51 & 100 \\
\hline $30-39$ & 142 & 90.15 & 11.417 & 45 & 100 \\
\hline $40-49$ & 176 & 87.14 & 13.128 & 38 & 100 \\
\hline 50 or Older & 190 & 86.49 & 14.668 & 32 & 100 \\
\hline
\end{tabular}

Lastly, for hypothesis six, $85 \%$ of the coaches sampled had coached three or less openly LGB athletes in their careers. There was a significant difference between groups as determined by one-way ANOVA $(F(3,613)=2.774, p=.041)$. However, a Tukey post-hoc test revealed that there were no clear significant differences between the specific groups of $0-3,4-7,8-11$, or over 11 openly gay athletes coached. It should be noted though that coaches with the least experience working with LGB athletes (0-3 coached previously) had the lowest mean scores on the Efficacy Scale $(M=87.64, \mathrm{SD}=13.198)$, followed by coaches who had worked with 4-7 LGB athletes $(M=90.41, S D=10.329)$, over 11 openly LGB athletes $(M=92.81, S D=9.565)$, and then 8-11 openly LGB athletes coached previously $(\mathrm{M}=94.47, \mathrm{SD}=10.329)$, in that order. These results partially support the final hypothesis of the current study.

\section{Discussion}

\section{Training}

While the majority of high schools across the United States do require classes or specialized training for coaches to be allowed to work with the high school athletes, diversity or LGB training is not a requirement for coaches at most schools. In fact, some private schools may not even require certification beyond CPR and first aid. Despite the best of intentions, 
many youth coaches choose not to complete additional trainings (diversity or otherwise) or attend conferences unless mandated to do so. The current study did not find a significant difference between coaches who did and did not report taking a diversity course previously, but the result still speaks to the issue at hand. Less than $10 \%$ of the high school coaches in the sample had taken a diversity course in their coaching career.

Team cohesion and performance may suffer if homophobia and/or homonegativity are allowed to exist in the sport domain, making the importance of coach training paramount. ${ }^{14}$ Diversity education, specifically with regard to LGB athletes, often teaches the use of inclusive language, development of team policies, and appropriate response strategies to deal with concerns, incidents, or biases. ${ }^{12}$ The ability of the coach to create an inclusive and supportive environment for all athletes can drastically impact sport enjoyment and continued participation..$^{5,15}$

\section{Sex Differences}

As an increasing number of LGB athletes openly reveal their sexuality at younger ages, high school athletic directors, coaches, and teammates will likely be faced with opportunities to share in the support of their LGB team members. ${ }^{3}$ While the current results coincide with previous studies that have failed to find a clear difference between genders, other studies have supported the notion that females often hold more positive views of the LGB population. ${ }^{2,16}$ This perception may be imbedded in the notion that females are often put in charge of nonmedia, non-physically aggressive sports, making the likelihood of coaching an openly gay athlete higher as it has been reported that the level of masculinity, specifically in football and basketball, may be directly related to the culture surrounding LGB issues. ${ }^{1}$ Male coaches and athletes that 
participate in a sport viewed as "traditional," may end up conforming to the expected societal norms of heterosexism.

While many things may have contributed to the current results, it should be noted that male respondents more than doubled female respondents and the largest single sex sport coached by the participants in the current study was football, followed by baseball, and boy's basketball. Despite, female coaches averaging two points higher on the Efficacy Scale to Coach Gay, Lesbian, and Bisexual Athletes, a potential positive shift of acceptance can be viewed within the current study by the lack of a significant difference in perceptions of efficacy in coaching LGB athletes between male and female coaches.

\section{Sexual Orientation of Coach}

While it would be expected that coaches who identified as gay or lesbian would hold significantly more positive perceptions of LGB athletes and their efficacy due to the potential of having dealt with their own experiences as a youth LGB athlete, a few findings were unexpected with regard to the sexual orientation of coaches. First, $97 \%$ of coaches reported being heterosexual. While heterosexuality is by far the predominant sexuality worldwide, it was anticipated in a sample size as large as the current study's, that participant's reported sexuality would replicate the general population and previous study results indicating a LGB population percentage of approximately 5-7\%. ${ }^{12}$ The lowered percentage in the current sample could be attributed to the large number of male respondents and the fear of being perceived as having feminine characteristics in a masculinized sport culture.

Potentially, the most interesting observation from the data surrounding sexuality of the coaches is the low Efficacy Scale score for Bisexual coach respondents. Only three coaches selfselected bisexual as their sexuality and another 10 coaches chose not to select a sexuality at all. 
Bisexual coaches had the lowest average overall score out of 100 on the Efficacy Scale to Coach Gay, Lesbian, and Bisexual Athletes. Similar to gay and lesbian coaches, it was anticipated that the three bisexual coaches would hold higher perceptions of LGB athletes than heterosexual coaches. A follow up interview with the bisexual coaches could lead to a much better understanding of their low average scores.

\section{Religious Affiliation}

Individuals with no religious affiliation had the highest average Efficacy Scale score (91.99), followed by Catholic (88.99), Protestant (87.87), and then Baptist (84.88). The differences between the scores of Catholic, Protestant Christian, and Baptist coaches were significantly different than those scores of coaches who reported no religious affiliation. These results are supported by previous research which revealed that athletic trainers who selfidentified as Catholic or as not having a religious affiliation held more positive views of LGB student-athletes. $^{8}$

Rankin and Merson found that a higher proportion of LGB collegiate student-athletes identified with a religious affiliation other than Christian (primarily no religious affiliation) compared to sampled heterosexual athletes. ${ }^{12}$ Therefore, it is not surprising that Efficacy Scale scores to coach LGB athletes would be associated with differences in religious beliefs. Coaches with similar beliefs to LGB athletes may be more comfortable and confident in their abilities to refrain from imposing different religious beliefs and preventing LGB stereotypes, often taught in various religions, from affecting their coaching.

\section{Age Differences}

In the current study, increases in Efficacy Scores directly corresponded to the coach's age with younger coaches consistently having higher perceptions of their coaching efficacy with 
LGB athletes. The increase in efficacy and positive perceptions of LGB athletes may be attributed to the transition of younger coaches moving into high school coaching roles. The Pew Research Global Attitudes Project found that $70 \%$ of individuals surveyed between the ages of 18-29 believed that homosexuality should be an accepted part of society compared to approximately $50 \%$ of respondents ages 50 and older. ${ }^{17}$ As older coaches retire, so do stereotypes, homophobic language, and strategies that were accepted and common practice just a few a years ago. In 2012, coaches and teammates were the most common perpetrators of harassment reported by student-athletes, with LGB athletes reporting being ignored, excluded, and harassed at opponent's venues more than their heterosexual teammates. ${ }^{12}$ It is this continued statistic that reinforces the notion that regardless of age, sexuality, or religious affiliation, heterosexual allies are the key to combatting homonegativity and helping to create long term positive outcomes, especially in the sport setting that has historically been intimidating for young LGB athletes. ${ }^{4}$ However, according to the current study, age may be one of the most important predictors for the creation of inclusive environments.

\section{Experience with Openly LGB Athletes}

The current project yielded numerous interesting findings with regard to coaches' experiences coaching LGB athletes. Some of these results are supported by outside research, while other outcomes are contrary to popular beliefs and previous literature. For example, in a study with recreation club sport participants, those individuals who reported no personal contact with LGB individuals held significantly more negative attitudes about LGB sport participants than those who did have contact with a LGB friend or teammate prior to taking part in the study. ${ }^{18}$ Therefore, it was anticipated and statistically shown that coaches who are currently coaching an openly LGB athlete or have coached LGB athletes previously hold more positive 
views (higher scores) on the Efficacy Scale to Coach Gay, Lesbian, and Bisexual Athletes. However, while not statistically significant, there was a small decrease in average Efficacy scores for coaches who have coached 8-11 openly LGB athletes, it is possible that simply being in close proximity to LGB individuals is not the sole indicator of creating an accepting and inclusive team environment. Other experiences must contribute to coaches' efficacy beliefs, such as geographical location, religious beliefs, and personal experiences that cannot be quantified. A person's sexuality is but a single part of who that athlete is on and off the field. Efficacy Scale to Coach Gay, Lesbian, and Bisexual Athletes

The current study sought to identify coaches' beliefs, characteristics, deficiencies, and experiences with LGB athletes at the high school level, as the literature with regard to coaches and LGB athletes has been described as deficient.5 When comparing results of all coaches to findings from five years ago using the same scale but with collegiate coaches there were several notable similarities and differences. ${ }^{5}$ Positive changes include coaches perceptions of their efficacy to coach gay athletes increased significantly, rising from being ranked 18/20 overall to being tied for 5 th. Similar results were observed with coaches' efficacy to coach lesbian athletes increasing its overall ranking from $8 / 20$ to 4 th. While both increases in average scores are important, it is particularly encouraging to see such a drastic increase in perceptions of coach efficacy with regard to gay male athletes. Gay male athletes have continually been identified as a population who have to hide their sexual identity and experience significantly increased harassment in competitive sports compared to their heterosexual teammates. ${ }^{12}$

The only item from the Efficacy Scale to Coach Gay, Lesbian, and Bisexual Athletes that did not show an average increase was the coach's perception of being able to identify LGB resources for their athletes. It remained low on the list at 19/20, which is the same rank as 
Vargas-Tonsing and Oswalt's study result. ${ }^{5}$ The only item ranked lower was perceived ability to identify LGB resources for coaching. This is particularly salient in the current study due to such a low number of coaches receiving any type of diversity or LGB training in their coaching careers. This was also the lowest ranked item five years ago, indicating that while growth has been made in other areas of comfort and knowledge, being able to identify resources, such as materials or classes, has not been well communicated or developed for coaches.

\section{Limitations}

The results of the study add much to the limited existing literature on coaches' beliefs about LGB athletes. However, limitations to the current study need to be identified. First, there is the potential for bias within the selected population. While the Athletic Directors were contacted without prejudice by the researcher, the decision to pass on the survey to the coaches at each school was made at the discretion of the individual Athletic Directors. Athletic Directors that held more positive views of the subject matter, may have been more likely to forward on the survey link to coaches based upon a perception of how they viewed the topic. Moreover, coaches who were more comfortable with the subject matter may have been more willing to respond to the survey link. However, male respondents more than doubled female respondents, who have at times been described as more accepting of the LGB population. ${ }^{2}$

Additionally, the results from the current study may differ for those from coaches who work with teams outside of the high school environment. While the sample size was large and heterogeneous in some domains (e.g. age, geographical location and religion), the population was homogeneous in other areas such as ethnicity and sexuality. Therefore, the results of this study cannot be entirely generalized to coach ethnicities outside of White/Caucasian or sexualities other than heterosexual. While White/Caucasian males are highly prominent in the 
coaching community, obtaining responses from minority populations about the current subject matter is essential to gaining a more holistic perspective of the sport environment for LGB athletes.

Lastly, it may be important to consider the participants' education level. Almost $50 \%$ of the respondents stated that they had a graduate degree, which increases the likelihood that these participants would have a more liberal attitude toward LGB individuals and LGB rights in general. $^{19}$

\section{Future Implications}

The potential implications of this study are far reaching. The deliberate avoidance of addressing LGB issues thus far within athletics at all levels is typical of the masculine sport culture. Yet, after many years of research, foundational support is developing within intercollegiate and professional athletics, but more support is needed at the high school and youth levels. The percentage of openly gay youth participating in sport is growing, causing attention to be paid to this environment and the strategies to be developed and implemented to ensure the inclusion and safety of all youth athletes. ${ }^{3}$ By accessing high school coaches that were willing to consider their coaching experiences and LGB athlete perceptions, the researcher has gained information that may create opportunities for collaboration and development with the goal of improving the youth and high school sport environment over time. Future studies could evolve to include interviews of coaches and athletes to better understand the current sport team environment and beliefs associated with coaching LGB athletes.

Furthermore, by identifying qualities of coaches with more favorable perceptions of LGB athletes, and areas of perceived strength and weakness, researchers can develop training courses for high school coaches that can be directed at increasing their understanding and acceptance of 
LGB individuals and, therein, decrease incidences of bullying and harassment within the team setting. Similar to the manual developed for NCAA coaches, the development of a manual specifically for high school level coaches, could be created to disseminate and reinforce diversity education. Lesbian, gay, and bisexual youth are more likely to attempt and commit suicide making the psychological implications of this subject of the utmost importance. ${ }^{20}$ Educating coaches about effective ways to create an inclusive team and to navigate LGB youth concerns within the group, will result in athletes of all sexualities becoming more comfortable and confident in their roles, on and off the field. 


\section{Quantitative Study References}

1. Anderson E. In the game: Gay athletes and the cult of masculinity. Albany, NY: SUNY Press, 2005.

2. Gill, Morrow, Collins, Lucey, \& Schultz. Attitudes and sexual prejudice in sport and physical activity. Journal of Sport Management 2006; 20: 554-564.

3. Griffin, P. LGBT equality in sports: Celebrating our successes and facing our challenges. In G.B. Cunningham (Ed.). Sexual Orientation and Gender Identity in Sport. College Station, TX: Center for Sport Management Research and Education, 2012, p. 1-12.

4. Wolf-Wendel LE, Toma, JD and Morphew CC. How much difference is too much difference? Perceptions of gay men and lesbians in intercollegiate athletics. Journal of College Student Development 2001; 42: 465-479.

5. Vargas-Tonsing, TM and Oswalt, SB. Coaches' efficacy beliefs towards working with gay, lesbian, and bisexual athletes. International Journal of Coaching Science 2009; 3: $29-42$.

6. Krane V. Lesbians in sport: Toward acknowledgement, understanding, and theory. Journal of Sport and Exercise Psychology 1996; 18(3): 237-246.

7. Barber H. and Krane V. Creating a positive climate for lesbian, gay, bisexual, and transgender youths. Journal of Physical Education, Recreation, and Dance 2007; 78: 652.

8. Ensign KA, Yiamouyiannis A, White KM, and Ridpath BD. Athletic trainers' attitudes towards lesbian, gay, and bisexual National Collegiate Athletic Association studentathletes. Journal of Athletic Training 2011; 46: 69-75. 
9. Morrow RG and Gill DL. Perceptions of homophobia and heterosexism in physical education. Research Quarterly for Exercise and Sport 2003; 74: 205-214.

10. Cunningham GB. Predictors of sexual orientation diversity in intercollegiate athletics. Journal of Intercollegiate Sport 2010; 3: 256-269.

11. Bowen AM and Bourgeouis M. Attitudes towards lesbian, gay, and bisexual college students: The contribution of pluralistic ignorance, dynamic social impact, and contact theories. Journal of American College Health 2001; 50: 91-96.

12. Rankin S \& Merson D. LGBTQ College Athlete Report. Campus Pride. http://www.campuspride.org (2012).

13. Ryan S. Examining social workers' placement recommendations of children with gay and lesbian adoptive parents. Families in Society 2000; 81: 517-528.

14. Krane, V. Gender noncomformity, sex variation, and sport. In R.J. Schinke \& K.R. McGannon (Eds.), The psychology of sub-culture in sport and physical activity: A critical approach. New York: Routledge, 2014, p. 1-28.

15. Kauer KJ and Krane V. Heteronormative landscapes: Exploring sexuality through tales of elite women athletes. Psychology of Women Section Review 2012; 14(2): 10-19.

16. Marback TL, Short SE, Short MW, and Sullivan PJ. Coaching confidence: An exploratory investigation of sources and gender differences. Journal of Sport Behavior 2005; 28: 18-34.

17. Pew Research Global Attitudes Project. The global divide on homosexuality. http://www.pewglobal.org/2013/06/04/the-global-divide-on-homosexuality/ (2013). 
18. Anderson RA and Mowatt, RA. Heterosexism in campus recreational club sports: An exploratory investigation into attitudes toward gay men and lesbians. Recreational Sports Journal 2013; 37: 106-122.

19. Grapes K. Ignorant discrimination: How education levels affect attitudes toward homosexuality and gay rights. Sociological viewpoints 2006; 22: 51-59.

20. Haas AP, Eliason M, Mays VM, Mathy RM, Cochran SD, D’Augelli AR, and Clayton PJ. Suicide and suicide risk in lesbian, gay, bisexual, and transgender populations: Review and recommendations. Journal of Homosexuality 2011; 58: 10-51. 


\section{APPENDIX E}

West Virginia University Institutional Review Board Approval 


\section{W. WestVirginiaUniversity. \\ Office of Research Integrity and Compliance

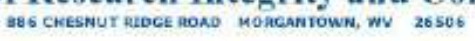

\section{Acknowledgement Letter Exempt Initial Protocol Review}

$\begin{array}{ll}\text { Action Date } & \begin{array}{l}11 / 17 / 2016 \\ \text { To }\end{array} \\ \text { Jack Watson } \\ \text { WvU Office of Research Integrity and Compliance } \\ \text { Approval Date } & 11 / 17 / 2016 \\ \text { Expiration Date } & 11 / 16 / 2019 \\ \text { Subject } & \text { Acknowledgement Letter Exempt Initial Protocol Review } \\ \text { Protocol Number } & \text { 1610320620 } \\ \text { Title } & \text { High School Coaches' Experiences with Openly Lesbian, Gay, and Bisexual } \\ & \text { Athletes }\end{array}$

The above-referenced study was reviewed by the West Virginia University Institutional Review Board IRB and was granted exemption in accordance with 45 CFR 46.101 .

- This research study was granted an exemption because the Research involves educational tests, survey procedures, interview procedures or observation of public behavior and (i) information obtained is recorded in such a manner that human subjects cannot be identified, directly or through identifiers linked to the subjects; and (ii) any disclosure of the human subjects responses outside the research could not reasonably place the subjects at risk of criminal or civil liability or be damaging to the subjects financial standing, employability, or reputation [45 CFR 46.101(2)]. All exemptions are only good for three years. If this research extends more than three years beyond the approved date, then the researcher will have to request another exemption. The following documents have been acknowledged for use in this study and are available in the WVU+kc system:

- We encourage [Jack Watson and Meghan Halbrook-Galloway] to complete the following course on the CITI program site (www.citiprogram org): 1.Conflicts of Interest Thank you.

Documents for use in this study have been acknowledged and are available in the WVUkc system in the Notes and Attachments section of your protocol.

The Office of Research Integrity and Compliance is here to provide assistance to you from the initial submission of an IRB protocol and all subsequent activity. Please feel free to contact us by phone at 304.293 .7073 with any question you may have. Thank you.

WVU Office of Research Integrity and Compliance

Date: $11 / 17 / 2016$

Signed:

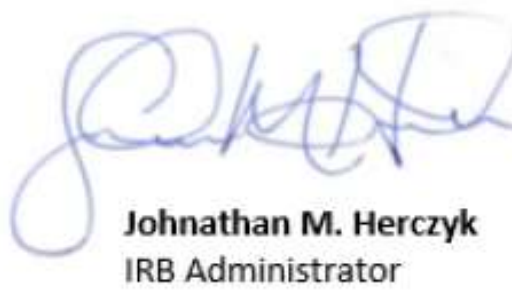




\section{Cover Letter}

Dear Participant,

This letter is a request for you to take part in a research project to assess the experiences of coaching an openly gay, lesbian, or bisexual high school athlete. This project is being conducted by Meghan Halbrook, M.S in the Department of Sport Sciences at West Virginia University with supervision of Dr. Jack Watson II, Professor and Chair of the Department of Sport Sciences, in fulfillment of her $\mathrm{PhD}$ Dissertation requirement.

Your participation in this project is greatly appreciated. A video conference interview will be conducted through Go-To-Meeting and will take approximately 1-2 hours to complete. All interviews will be recorded and kept on a password protected computer in a password protected file in a locked room. The interviews will be transcribed verbatim, with only Dr. Jack Watson, Meghan Halbrook, and two other PhD students within the Department of Sport Sciences having access to your recording, transcription, and demographic data. Your involvement in this project will be kept as confidential as legally possible. Your real name will be replaced with a pseudonym and any other identifiable data will be changed to protect your privacy. All recordings will be erased from the password protected file after the completion of the study.

You must be 18 years of age or older to participate, currently coaching at a high school in the United States, and have completed the previous online survey regarding your efficacy to coach openly gay, lesbian, and bisexual athletes. Your participation in the current study is completely voluntary. You may skip any question that you do not wish to answer and you may discontinue at any time. Your current position at your respective high school will not be affected by refusal to participate or by withdrawal from the study. West Virginia University's Institutional Review Board acknowledgement of this project is on file.

I hope that you will participate in this research project, as it will be beneficial in better understanding high school coaching experiences with openly gay, lesbian, or bisexual athletes. Should you have any questions about this letter or the research project, please feel free to contact Meghan Halbrook at (573) 747-6582 or by e-mail at mkhalbrook@ mix.wvu.edu. Additionally, if you have further questions or concerns that develop due to questions asked during the interview, you may also contact Dr. T.Anne Hawkins at the Carruth Center for Psychological and Psychiatric Services at (304) 293-4431. Thank you for your time and help with this project.

Sincerely,

Meghan K. Halbrook 


\section{Interview Guide}

\section{Introduction:}

- Welcome and thank the participant. My primary interest in this interview is to better understand the experiences of high school coaches who have coached an openly lesbian, gay, or bisexual athlete.

- I am here to learn from you. I will ask certain questions, but I encourage you to include anything you feel is relevant. There are no right or wrong answers to these questions; I just want to better understand your perspective.

- I am going to be audio recording our discussion. The recordings and transcripts of the conversation are confidential, as outlined in the consent form. Information and quotations will be used in publications and presentations of this research, but your name and any other information that could identify you will be removed.

- You have the right to choose not to answer any particular question or to end the interview at any point if you wish.

- Are there any questions before we begin? (Start the interview)

\section{Questions:}

Part 1: Background information and rapport building

1. When did you first begin coaching your current sport?

a. What made you want to coach (sport)?

b. What do you enjoy most/least about coaching? 


\section{$\underline{\text { Part 2: Main research question }}$}

1. When was the first time you realized you were coaching an openly LGB athlete?

a. What were the challenges associated with coaching an openly LGB athlete, if any? Did you seek guidance to help address these challenges??

2. How have your perceptions of LGB individuals changed after having coached an LGB athlete?

a. How would you describe the cultural perception of LGB individuals in the area in which you coach?

3. Describe any training you have you received related to providing a safe and supportive environment for athletes on your team?

a. How effective do you believe LGB diversity trainings would be/are to coach education?

4. Do you have anything else you would like to add?

a. Anything else that has been important for you in your experiences coaching an openly LGB athlete?

\section{Thank You:}

Thank you very much for your participation in this research. I really appreciate your time and effort in completing the initial questionnaire and interview for this study.

General Probes to be used:

- Can you tell me more about that?

- Could you give me an example of what you mean?

- Can you describe specifically what you mean? 
APPENDIX H

Email Correspondence 


\section{Initial Contact}

Hello (name),

My name is Meghan Halbrook and I am in the process of completing my Doctoral Dissertation from West Virginia University. Two years ago, you completed a research questionnaire which examined high school coaches' perceptions of their efficacy to coach openly gay, lesbian, and bisexual athletes. At the end of that survey, you stated that you would be interested in participating in a follow-up study about your experiences coaching gay, lesbian, and bisexual athletes. Based on your responses and demographics (location, sport coached, etc.), I believe that your insights would be incredibly valuable. I have attached a cover letter that further outlines the study and expectations if you so willingly choose to participate. The one-time interview, which we would schedule at your convenience, will last approximately one hour.

Please look over the cover letter and let me know if you are still interested in participating. If you have any questions at all, do not hesitate to call (573-747-6582) or email me back. I appreciate your time and hope to hear from you soon!

Thank you!

Meghan Halbrook

\section{Follow-Up Recruiting Email}

Hi (name),

I hope this email finds you well. This is a second plea for your help with the high school coaches' study. Two years ago you completed a survey and designated that you would be interested in participating in this current follow up study. Out of approximately 220 coaches, you were hand-selected by a small research team to be one of only 10-12 coaches interviewed. Due to the sport you coach, your age, years of experience, and geographic location, your perceptions and responses during the interview could be invaluable to other coaches, athletes, and teams.

The interviews are generally lasting approximately one hour and can be scheduled at a time that is most convenient to you (morning, afternoon, evening, weekend). If you are still interested, please email or call (573-747-6582) so that we can get your interview scheduled. I know how busy you may be during this point in the year and sincerely appreciate your time! All the best,

Meghan Halbrook, M.S. 


\section{Instructional Email}

Hi (name),

Below is a link that you will need to click on when you are ready to start the interview. I will be logged in and waiting for you so that I can help navigate the site (GoToMeeting) if you need help. However, I have specifically chosen this site because of how easy it is to navigate so you hopefully won't have any issues. It is similar to Skype, so please just make sure that your audio, microphone, and webcam are on. If you are not around a computer, you can log on using your smartphone as well. Please do not hesitate to let me know if you have any questions. I really appreciate your help with this study!

https://global.gotomeeting.com/join/256826045

I'm looking forward to talking with you more tomorrow!

Thank you,

Meghan

\section{Member Checking}

Hello (name),

I hope you are doing well! First of all, thank you again for your participation in my research study regarding coaches' experiences with openly lesbian, gay, and bisexual athletes. You ended up being one of only 10 interviews conducted for this project. The interviews have all been completed, transcribed, and reviewed for common themes across coaches. I have attached a table of these themes with a short description of each. There is also a blank space next to each theme if you would like to ask questions, provide comments, give additional information, or suggest changes. The whole purpose of this email is to allow for you, as a participant, to review the data before it is finalized and presented. Two questions to consider when reviewing the table.

1. Do you agree with the major categories/theme identified?

2. Is there something that you would add to better represent your experience?

Thank you again for your assistance in this research study. Your participation and experiences greatly add to the current information in the field of high school sport.

All the Best,

Meghan Halbrook, M.S. 


\section{APPENDIX I}

Research Participant Information 


\section{Research Participant Summary - 10}

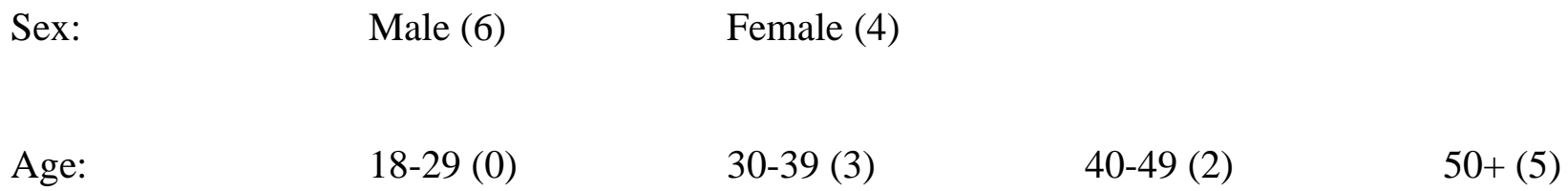

Sexual Orientation: Heterosexual (9) Gay (1)

$\begin{array}{llll}\text { Ethnicity: } & \text { Caucasian (7) } & \text { Black (2) } & \text { Asian (1) }\end{array}$

$\begin{array}{llll}\text { Years Coaching: } & \text { 1-3 Years (1) } & \text { 4-6 Years (2) } & \text { 7-9 Years (0) } \\ & 10-12 \text { Years (0) } & \text { 13-15 Years (3) } & \text { Over } 15 \text { Years (4) }\end{array}$

Religious Affiliation: Atheist (1)

Methodist (1)

Education:

Prev LGB Training: Yes (2)

Sports Coached:

Basketball (3)

Soccer (2)

Track \& Field (2)

\section{Baptist (3)}

No Affiliation (3)

Catholic (1)

Unspecified (1)

Geographic Region: $\quad$ East North Central - WI, MI, IL, IN, OH (1)

East South Central - KY, TN, MS, AL (1)

Mountain - ID, MT, WY, NV, UT, CO, AZ, NM (2)

Pacific - AK, WA, OR, CA, HI (2)

South Atlantic - DE, MD, VA, WV, NC, SC, GA, FL (4) 


\begin{tabular}{|c|c|c|c|c|c|c|c|c|c|c|}
\hline 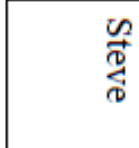 & 宸 & 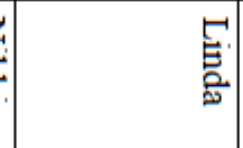 & 苞 & 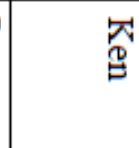 & $\begin{array}{l}\breve{d} \\
\overrightarrow{0}\end{array}$ & $\overleftrightarrow{\overrightarrow{\mathrm{E}}}$ & 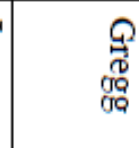 & 串 & 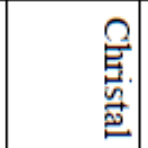 & \\
\hline is & $\stackrel{\omega}{\omega}$ & $\vec{b}$ & ळ & 出 & $\stackrel{\omega}{\omega}$ & $u$ & $\underset{\infty}{\infty}$ & ని & $\underset{\leftarrow}{w}$ & 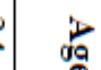 \\
\hline 蛋 & 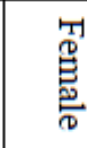 & 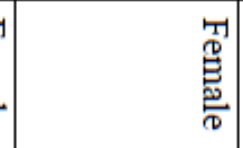 & 蛋 & 逽 & 常 & $\begin{array}{l}\text { T/1 } \\
\text { 㘁 }\end{array}$ & 常 & 逽 & 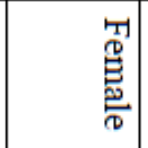 & $\mathscr{b}$ \\
\hline 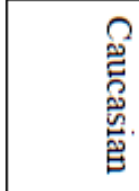 & 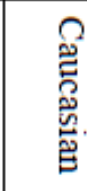 & 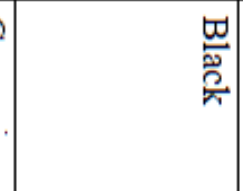 & 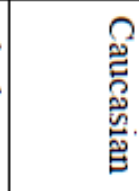 & 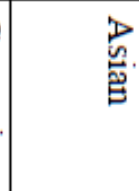 & 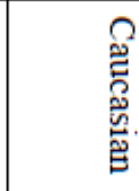 & 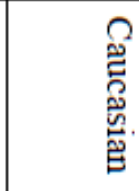 & 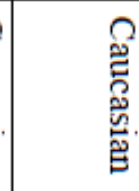 & 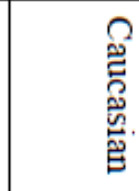 & 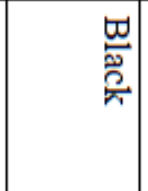 & 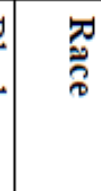 \\
\hline 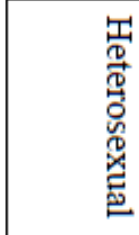 & 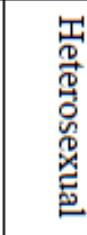 & 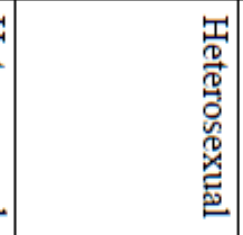 & 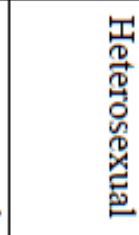 & 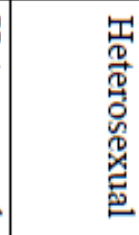 & 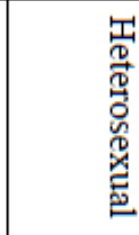 & 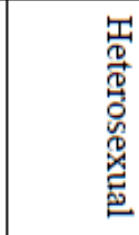 & $\stackrel{\leftrightarrow}{4}$ & 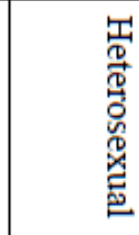 & 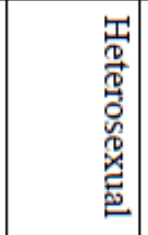 & 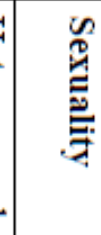 \\
\hline 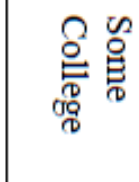 & 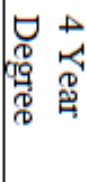 & 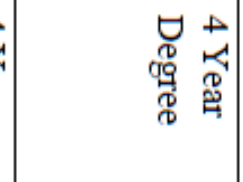 & 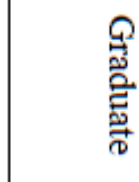 & 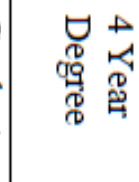 & $\begin{array}{l}Q 9 \\
\text { 总 } \\
\text { 产 }\end{array}$ & 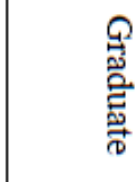 & 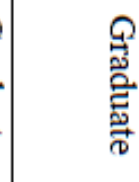 & 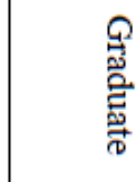 & 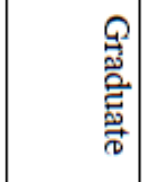 & 范 \\
\hline 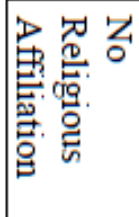 & $\begin{array}{l}\frac{3}{0} \\
\text { 总 } \\
\frac{0}{2}\end{array}$ & 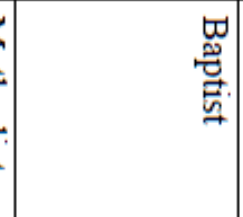 & 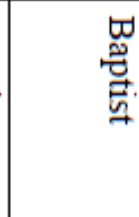 & 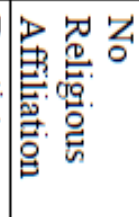 & $\begin{array}{l}\text { 䗆 } \\
\text { 点 }\end{array}$ & 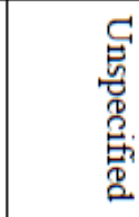 & 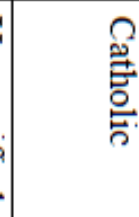 & 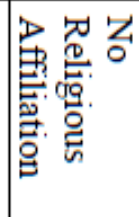 & 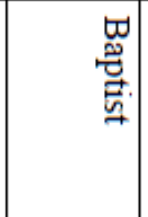 & 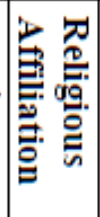 \\
\hline 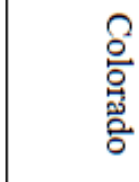 & 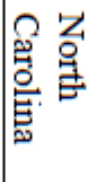 & 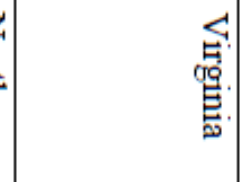 & 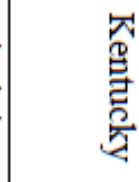 & 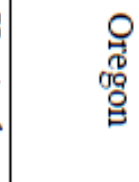 & 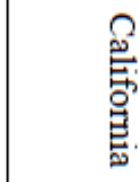 & 具 & 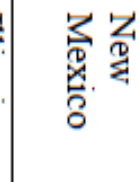 & 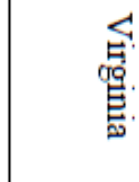 & 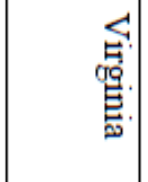 & 局 \\
\hline 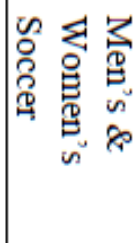 & 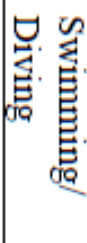 & 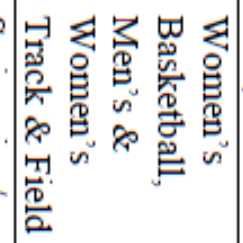 & 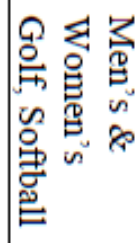 & 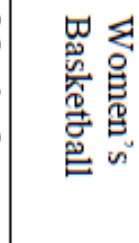 & 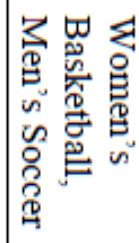 & 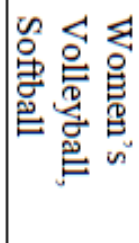 & 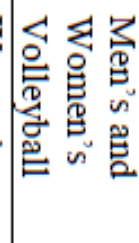 & 㣎 & 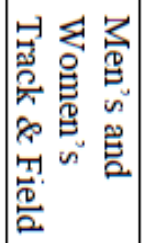 & 管 \\
\hline$\tilde{\circ}$ & + & $\vec{\omega}$ & $\tilde{\sim}$ & $\vec{u}$ & + & $\tilde{\sigma}$ & $N$ & $\omega$ & $w$ & 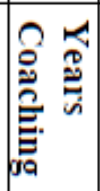 \\
\hline$\stackrel{\circ}{\perp}$ & 8 & 호 & 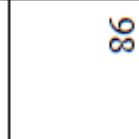 & 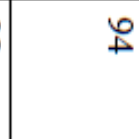 & 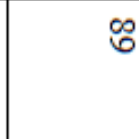 & $\infty$ & 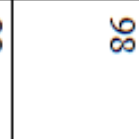 & $\nabla$ & 히 & 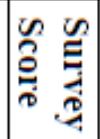 \\
\hline
\end{tabular}


APPENDIX J 


\section{Table of Themes}

\begin{tabular}{|c|c|c|}
\hline Code & Brief Description & Selected Representative Quote \\
\hline \multicolumn{3}{|l|}{$\begin{array}{l}\text { Team Environment } \\
\text { Dogmas and } \\
\text { Observations }\end{array}$} \\
\hline "Void of sexuality" & $\begin{array}{l}\text { Not seeing sexuality as a } \\
\text { necessary topic or concern } \\
\text { to be addressed in a team } \\
\text { setting due to not } \\
\text { experiencing issues } \\
\text { associated with athlete } \\
\text { sexuality. }\end{array}$ & $\begin{array}{l}\text { It's just, it seems as though the on } \\
\text { the field interaction is void of } \\
\text { sexuality itself, it's not something } \\
\text { that exists on the field. (Jeren) }\end{array}$ \\
\hline Teammate First & $\begin{array}{l}\text { Higher importance is put } \\
\text { on being a good teammate } \\
\text { than on the athlete's } \\
\text { sexuality or potential } \\
\text { concerns associated with } \\
\text { athlete sexuality. }\end{array}$ & $\begin{array}{l}\text {...all I care about is, "Are you a } \\
\text { good teammate? It doesn't matter } \\
\text { your sexual preference or what you } \\
\text { do, whenever you do it." "Did you } \\
\text { come to practice? Are you a good } \\
\text { teammate? Did you try your best?" } \\
\text { That's all that should matter. To me, } \\
\text { it's that simple. (Christal) }\end{array}$ \\
\hline "In vogue" & $\begin{array}{l}\text { Belief that social } \\
\text { acceptance and following } \\
\text { the crowd is more } \\
\text { important that expressing } \\
\text { personal viewpoints that } \\
\text { may be contrary to } \\
\text { surrounding beliefs. }\end{array}$ & $\begin{array}{l}\text { I would say it's very in vogue right } \\
\text { now to be accepting of people of } \\
\text { different mindsets and cultures. I } \\
\text { think there is, especially at the } \\
\text { junior high and high school level, } \\
\text { there is a general feeling of not } \\
\text { wanting to go against the grain. } \\
\text { (Jeren) }\end{array}$ \\
\hline Jokes & $\begin{array}{l}\text { Comments and jokes } \\
\text { made at the expense of the } \\
\text { LGB athlete, but often } \\
\text { perceived to be "in jest" } \\
\text { or innocent. }\end{array}$ & $\begin{array}{l}\text { So they may say things, like, "I don't } \\
\text { wanna share a bed with this one, } \\
\text { 'cause I don't want her touching } \\
\text { me." But they don't say it like, "I'm } \\
\text { disgusted, don't touch me." They } \\
\text { say it like, "Alright now, don't touch } \\
\text { me." And then they laugh and then } \\
\text { they make jokes. (Christal) }\end{array}$ \\
\hline
\end{tabular}




\begin{tabular}{|c|c|c|}
\hline $\begin{array}{l}\text { Fundamental Beliefs } \\
\text { Contributing to } \\
\text { Perceptions of LGB } \\
\text { Athletes }\end{array}$ & & \\
\hline Nature vs. Nurture & $\begin{array}{l}\text { Belief that sexuality is } \\
\text { either an inherent } \\
\text { characteristic or is due to } \\
\text { upbringing or deliberate } \\
\text { "choice." }\end{array}$ & $\begin{array}{l}\text { If you could control those things } \\
\text { and you could make a conscious } \\
\text { choice you wouldn't be struggling } \\
\text { with that mentally. I believe that it } \\
\text { is a biological thing that they're } \\
\text { born with... (Larry) } \\
\text { I have my own beliefs and I have my } \\
\text { own opinions, but I'm not gonna be } \\
\text { one of those that runs around and } \\
\text { damns you to hell 'cause you've } \\
\text { chose that lifestyle. (Nikki) }\end{array}$ \\
\hline Role of the coach & $\begin{array}{l}\text { Coach perception about } \\
\text { the purpose of their role as } \\
\text { a head coach working } \\
\text { with high school athletes. }\end{array}$ & $\begin{array}{l}\text { We're trying to build young people } \\
\text { into being responsible adults, and } \\
\text { showing any kind of tolerance for a } \\
\text { misbehavior because of gender, } \\
\text { race, sexuality, there's just no place } \\
\text { for it in an athlete team } \\
\text { environment. (Steve) }\end{array}$ \\
\hline $\begin{array}{l}\text { All the same vs. } \\
\text { "Underdogs" }\end{array}$ & $\begin{array}{l}\text { Having an openly LGB } \\
\text { athlete may lead to the } \\
\text { LGB athlete being treated } \\
\text { with more caution and } \\
\text { understanding than } \\
\text { heterosexual teammates } \\
\text { OR being treated exactly } \\
\text { the same. }\end{array}$ & $\begin{array}{l}\text { I really didn't ever think that my } \\
\text { perception changed. I might've } \\
\text { become more protective of them, } \\
\text { more sensitive to what might be } \\
\text { going on around them, behavior of } \\
\text { other players...I have a very low } \\
\text { tolerance for any type of racism, or } \\
\text { anything like that. (Steve) }\end{array}$ \\
\hline Reactive Response & $\begin{array}{l}\text { Waiting for an issue to } \\
\text { arise or an incident to } \\
\text { occur before considering } \\
\text { how to effectively respond } \\
\text { rather than addressing the } \\
\text { team before an incident or } \\
\text { issue occurs. }\end{array}$ & $\begin{array}{l}\text { I think you work it out as you go } \\
\text { whether it's a problem or not } \\
\text {... "Hey, let's have this meeting on } \\
\text { gays or someone with handicaps or } \\
\text { whatever." I just don't think you } \\
\text { have to do that... Now, if you have } \\
\text { a problem then you deal with it. But } \\
\text {... before you even start...It } \\
\text { shouldn't be a big deal... (Jan) }\end{array}$ \\
\hline Upbringing & $\begin{array}{l}\text { How the coach attributes } \\
\text { their upbringing to their } \\
\text { current perception of LGB } \\
\text { individuals. }\end{array}$ & $\begin{array}{l}\text { I think it was probably, as much as } \\
\text { anything, upbringing, parents who } \\
\text { were accepting of other people's } \\
\text { differences in life, and so obviously } \\
\text { that passed on to me. It's just the } \\
\text { way I've always been... (Ken) }\end{array}$ \\
\hline
\end{tabular}




\begin{tabular}{|c|c|c|}
\hline $\begin{array}{l}\text { Types and Timing of } \\
\text { Sexual Orientation } \\
\text { Disclosure }\end{array}$ & & \\
\hline Social Media & $\begin{array}{l}\text { Following and checking } \\
\text { the athlete's social media } \\
\text { in an attempt to } \\
\text { understand the personal } \\
\text { life of the athlete. }\end{array}$ & $\begin{array}{l}\text {...he had a cake that was rainbow } \\
\text { colored and he'd posted it on his } \\
\text { Facebook page. And I think at that } \\
\text { point I had not really realized that } \\
\text { he was bisexual until that point } \\
\text { where he openly had put it on social } \\
\text { media. After that, I started kinda } \\
\text { paying more attention... (Nikki) }\end{array}$ \\
\hline Teammate Disclosure & $\begin{array}{l}\text { Hearing about LGB } \\
\text { athlete's sexuality from } \\
\text { another member of the } \\
\text { team. }\end{array}$ & $\begin{array}{l}\text { I recognized almost everybody. But } \\
\text { there was one kid who I just didn't } \\
\text { know and one time after our match } \\
\text { I'm all, "Who is that kid?" And one } \\
\text { of the other players on the team just } \\
\text { said, "Oh, that's her girlfriend!" } \\
\text { And I was like, "Oh, okay." (Gregg) }\end{array}$ \\
\hline Direct Conversation & $\begin{array}{l}\text { The LGB athlete directly } \\
\text { discussed sexuality with } \\
\text { coach. }\end{array}$ & $\begin{array}{l}\text { She was openly gay with me and } \\
\text { sometimes to the point... where she'd } \\
\text { go, "Hey, see that girl over there?" } \\
\text { "Yes." "She asked me out." That } \\
\text { kind of thing. And I'd go, "Oh } \\
\text { that's great Rachel, but we need to } \\
\text { concentrate on defending the wing." } \\
\text { That kind of thing. (Ken) }\end{array}$ \\
\hline Assumptions & $\begin{array}{l}\text { Coach assumes sexuality } \\
\text { of athlete based on } \\
\text { appearance, rumors, or } \\
\text { other unsubstantiated } \\
\text { pieces of evidence. }\end{array}$ & $\begin{array}{l}\text { I coached her for five years, and the } \\
\text { haircut, not going to prom, going to } \\
\text { prom with girls, how she carried } \\
\text { herself, those types of things. I } \\
\text { inferred that probably, but maybe in } \\
\text { the environment she was, she didn't } \\
\text { feel... great coming out. (Craig). }\end{array}$ \\
\hline College & $\begin{array}{l}\text { Common occurrence of } \\
\text { athlete's waiting until } \\
\text { college to "come out" } \\
\text { about their sexuality. }\end{array}$ & $\begin{array}{l}\text { Yeah, I knew after that, 'cause I keep } \\
\text { up with my athletes and that. They } \\
\text { are now openly saying, "Yes, I'm } \\
\text { finally out of high school. I admit it. } \\
\text { I am..." (Jan) }\end{array}$ \\
\hline Parental Concerns & $\begin{array}{l}\text { Openness about sexuality } \\
\text { due to parent's support or } \\
\text { aversion to LGB issues. }\end{array}$ & $\begin{array}{l}\text { Her parents were definitely against } \\
\text { it. And they did not want them } \\
\text { sitting together on the bench, wanted } \\
\text { me to keep them separate at all } \\
\text { times. They couldn't sit at the } \\
\text { restaurant together at the same } \\
\text { table, things like that. (Linda) }\end{array}$ \\
\hline
\end{tabular}




\begin{tabular}{|c|c|c|}
\hline $\begin{array}{l}\text { Differential LGB Athlete } \\
\text { Characteristics }\end{array}$ & & \\
\hline Talent Level & $\begin{array}{l}\text { Athlete talent level } \\
\text { potentially equates to } \\
\text { treatment by teammates } \\
\text { and coaches. }\end{array}$ & $\begin{array}{l}\text { This is going to sound like a } \\
\text { horrendously superficial thing to } \\
\text { say, but both were really good } \\
\text { players. And so, when you're in a } \\
\text { team environment, you could pretty } \\
\text { much be a serial killer and if you're } \\
\text { good enough, everybody's gonna } \\
\text { accept it. I think that made things } \\
\text { easier, especially on the boys'side. } \\
\text { The young man was a phenomenal } \\
\text { talent. (Jeren) }\end{array}$ \\
\hline Sex Differences & $\begin{array}{l}\text { The differences in } \\
\text { teammate responses } \\
\text { between male and female } \\
\text { teams and athletes. }\end{array}$ & $\begin{array}{l}\text { I think that the males though, as far } \\
\text { as the females, it was fine. But when } \\
\text { it came to the males, I felt there was } \\
\text { a double standard. People did make } \\
\text { the males feel different, I would say } \\
\text { (Linda) }\end{array}$ \\
\hline Sport Played & $\begin{array}{l}\text { Coach belief that their } \\
\text { sport is more accepting of } \\
\text { athlete diversity or that } \\
\text { other sports are less } \\
\text { accepting, based merely on } \\
\text { individual perception. }\end{array}$ & $\begin{array}{l}\text { And I say this all the time about } \\
\text { distance runners, you can't find a } \\
\text { better group to have your kids, your } \\
\text { own children hang around. You } \\
\text { can't find a more accepting group } \\
\text { than distance runners. You can't } \\
\text { find a better behaved group than } \\
\text { distance runners. They're } \\
\text { incredible. So, if you were going to } \\
\text { be... If you ever want to be accepted, } \\
\text { there's the group you wanna be with, } \\
\text { in my eyes. (Craig) }\end{array}$ \\
\hline Location & $\begin{array}{l}\text { The impact of } \\
\text { geographical location on } \\
\text { athlete comfort in being } \\
\text { open about their sexuality. }\end{array}$ & $\begin{array}{l}\text { Well, I just tried to make her aware } \\
\text { that a lot of people do not see } \\
\text { openly, or want to see openly that } \\
\text { that's a correct behavior. We're in } \\
\text { a really strong Bible Belt. There's a } \\
\text { lot of people who absolutely are not } \\
\text { going to agree with it, not matter } \\
\text { what. (Larry) }\end{array}$ \\
\hline
\end{tabular}


APPENDIX K 


\section{Identified Themes Expanded}

Team Environment Dogmas and Observations. Many of the coaches spent extensive time talking about the team environments of their respective sports. These discussions included their own perceptions and beliefs about the general culture of sport, as well as the observed actions with regard to their specific athletes and teams. Very few coaches expressed any substantial concerns surrounding LGB athletes on their own teams, and instead justified their own beliefs and actions, as well as those by heterosexual athletes on their teams.

"Void of sexuality". The notion that sexuality within the sport arena was either nonexistent or not important was a recurring theme across coaches. Many coaches even reported that "it's not something that matters" or that it "shouldn't" matter when it comes to athletes and sport. Jeren, a 31 year old woman's basketball and men's soccer coach, discussed this notion often:

I think unless you, as a human being, personally make an effort to make it known that you are different in your sexual orientation, I think an athletic environment is somewhere, that that hides that, but it just isn't an existent entity. It's not something that matters in that particular realm...It's just, it seems as though the on the field interaction is void of sexuality itself, it's not something that exists on the field.

He was one of several coaches who expressed the idea that an athlete's sexuality does not impact perceptions of or their ability to coach the LGB athlete. The coaches perceived this viewpoint to be one of acceptance, not avoidance, and was reinforced due to many coaches not experiencing many issues surrounding athlete's sexuality.

Teammate First. Because the coaches did not see sexuality as a topic or concern that needed to be addressed commonly within their teams, their focus was more centered around the concept of "team." Specifically, the importance of each athlete's role on the team and the 
preferred hierarchy of athlete concerns. Christal, a 34-year-old track and field coach, was very direct in her beliefs:

...all I care about is, "Are you a good teammate? It doesn't matter your sexual preference or what you do, whenever you do it." "Did you come to practice? Are you a good teammate? Did you try your best?" That's all that should matter. To me, it's that simple.

"It's that simple" was the perception of many coaches, indicating that a higher importance should be given to being a good teammate, than to the athlete's sexuality or any potential concerns associated with the athlete's sexuality. Gregg, a 48-year-old volleyball coach, reiterated the teammate first mentality by stating:

To be a part of a team, it means to support everybody on the team, on the court, off the court. Being a part of a team isn't when practice starts at 3:00, you turn the switch on and when it's over at 6:00, now you turn it off and you're not part of a team. On our practice jerseys, I always have printed " $24 / 7$ " because they're representing themselves, the team, me, and the school 24/7.

In short, concerns across all coaches when discussing LGB athletes was more about overall team cohesion than about focusing on a single athlete's concern, heterosexual or LGB.

"In vogue". Several coaches discussed their perception of the shift in sport, as well as the overall culture, with regard to LGB individuals. Several discussed how people would have probably reacted more negatively five, 10, or even 20 years ago. However, with the current changes in policies for gay marriage and transgender legislation, even in sport, many coaches felt that the athletic environment benefited from the stated societal changes. Moreover, many coaches talked about how the younger generation appears to be more accepting overall.

Jeren: I would say it's very in vogue right now to be accepting of people of different mindsets and cultures. I think there is, especially at the junior high and high school level, there is a general feeling of not wanting to go against the grain.

Gregg: I don't know if it was because it was a cool thing to, “Oh, we've got a gay kid on our team," or "I've got a gay friend," if it was in fashion. But it was never an issue with anybody, it was... super easy, never a problem, ever. 
It should be noted that it being "cool" to have an openly LGB athlete on the team does differ with being afraid to "go against the grain" and be outwardly against an LGB teammate. One insinuates a level of excitement, while the other elicits feelings of fear. While both approaches may mean fewer incidents on the team, the LGB athlete's interactions with other teammates, as well as their overall comfort, may differ between environments.

Jokes. The last common theme between coaches and perceptions and actions within the team environment was the occurrence of periodic jokes aimed at the LGB athlete. Interestingly, each coach perceived any joking as being "good natured." They believed the joking between teammates, even when done at the expense of the LGB athlete, was done "with affection" and in a way that was not meant to exclude or create bad feelings. Gregg talked about his experience with an openly gay male volleyball player:

Yeah, as I remember back, there would be some teasing, but it would be with affection. It wouldn't be, like a bullying kind of tease...I remember this, 'cause I still use this line. He went up to swing, and he made an error, and one of the other kids on the team said, "Hey, Ryan, next time put your purse down and swing on the ball." And everyone, Ryan and I really laughed. It was funny...As I'm saying this, I could see that, out of context, and not having been there, I could see where it could look like a slur, it could look like... But it simply wasn't the way that the camaraderie of the team was. It was a fun group of guys.

Context was often brought up when the coaches were talking to the researcher. There was an awareness that jokes can be cruel, but they did not perceive this to be the case on their respective teams, between their athletes. As Gregg stated above, there was a sense on these teams that the teasing was helpful in the team environment, not hindering or hurting the LGB athlete.

Fundamental Beliefs Contributing to Perceptions of LGB Athletes. Across all interviews, coaches were unquestioning and passionate in their responses regarding beliefs they hold to be true about LGB athletes and individuals, in general. Some of these opinions and ideas developed when the coaches were young, while others evolved over the course of college or their 
beginning years coaching. Also, within this identified theme, there were certain differences in how coaches perceived LGB athletes and individuals and their approach to coaching them.

Nature vs. Nurture. Over the years, there has been an ongoing debate surrounding sexuality. Some individuals believe that sexuality is an inherent, biological characteristic of a person (nature). Others believe that sexuality is a "preference" or "choice" that one makes deliberately or due to their upbringing (nurture). Larry, a 68-year-old softball coach, discussed his understanding of sexuality:

And from most of the information that I read and we discussed in class... is that a lot of people think that it's always a choice. That you choose to do this. After most of the stuff that I read, I think that there is more to it than that. I think that there's just something different, that they can't control it a lot of times. That it's just not a choice. It's something in them that drives them.

As a differing perspective, Nikki, a 31-year-old swimming and diving coach, regularly referred to sexuality as a choice, preference, and lifestyle

I have my own beliefs and I have my own opinions, but I'm not gonna be one of those that runs around and damns you to hell 'cause you've chose that lifestyle.

While neither side has been completely supported, one way or another, a person's belief on this topic can often influence perceptions of the LGB individual.

Upbringing. The beliefs about whether sexuality is determined genetically or influenced throughout life, may be attributed back to the coaches' childhood influences or significant events while growing up. Examples about accepting and positive childhoods were often given when discussing how the coaches have come to their approach to coaching LGB athletes.

Ken: I think it was probably, as much as anything, upbringing, parents who were accepting of other people's differences in life, and so obviously that passed on to me. It's just the way I've always been, more or less.

Linda: We never judged anyone in our family. Like I said, I'm weird, eccentric myself. I don't know, I've just been... I have always been a neutral person. I don't take sides. I guess it's just the way I was raised and just the way I think. That's the only thing I can 
come up with. I've never judged anyone by what they wear, who they are, their religion. If I like you, I like you, and that's it.

Additionally, several of the coaches were high school or collegiate athletes themselves and reported having an LGB teammate on their own teams while playing. These experiences, for coaches who discussed such occurrences, seemed to create a sense of comfort and positive feelings and associations with having an openly LGB athlete while coaching.

Nikki: I was part of a softball team that had openly gay girls on the team. And I guess just from being exposed in college, my opinions were that they're real people, they have feelings too...

It appeared, through interviews with the coaches, that opinions and beliefs were often developed young but had the ability to shift or change as the coach developed and experienced new situations growing up.

Role of the coach. Most of the coaches interviewed seemed to have strong beliefs surrounding their overall purpose and responsibility as a high school head coach. Some even discussed the importance of intentionally creating a coaching philosophy. Part of the rapport building during the interviews involved asking each coach what they enjoyed most and least about coaching at the high school level. Responses varied in length and specificity, but all were passionate. Ken, a 52-year-old women's basketball coach, often focused on being a role model for young student-athletes:

You offer, as a coach, a moment of stability and structure every day, in some form or another during that season, and so I never forget the fact that how I carry myself is also a major influence on athletes.

Gregg, reiterated Ken's statement, and spent a lot of the interview giving examples of how much he values his position and the opportunities he has had over his 22 years of coaching:

But really, I think the overall umbrella idea of our job is we want to help these studentathletes turn into these strong, beautiful young women, or strong beautiful young men, 
who are independent, who are courageous, who feel of worth and valued, and who want to give back to the community.

Even those coaches, like Gregg, who had been coaching for an extended period of time had appeared to keep their investment and desire to coach. Two of the coaches had even coached at the collegiate level and had transitioned back to high school because of the enjoyment.

All the same vs "Underdogs". A large majority of the coaches reported that their interactions with openly LGB athletes were and would be exactly the same as their interactions with heterosexual student-athletes. They stated that they would have the same expectations regarding romantic relationships, commitment to the team, and behaviors during practices and competition. Jan elaborated on this concept:

I think the most important thing is to treat everybody the same... To me, that promotes consistency, and no matter if you're gay, lesbian, star athlete, not very athletic at all, that you're an important part of the team. So, that atmosphere, everybody knows... And that's why we call it a family. Instead of saying, "We're on this volleyball team," "We're a volleyball family."

The notion of "family" was mentioned several times and seemed to indicate an overall level of togetherness and acceptance of the openly LGB athlete within the team. However, a couple of the interviewed coaches did admit that there were some differences, although not believed to be negative according to the coaches. For example, Nikki felt like she was more sensitive towards her openly bisexual athlete:

...those things are almost imprinted on me because I've always been attracted to people with disabilities and people who are different or like I said again, the underdogs.

Nikki was one of two coaches to use the term "disability" when discussing openly LGB athletes. The researcher did not perceive this language to be intentional, but it could indicate that coaches equate being LGB to being weak or vulnerable. 
Reactive Response. The potential for diversity training related to openly LGB athletes was a focus of each interview. The beliefs about how training should be facilitated, how it would be received, and the contents of training was commonly debated. Yet, all of the coaches agreed on one thing, the desire to learn more about LGB athletes and to talk to their teams about LGB athletes should generally occur after an issue or situation occurs.

Christal: I mean if it became an issue, maybe someone said, for religious reasons, or personal beliefs, "I don't want this person on the team" or, "I can't be team mates with this person" or something to that effect, then yes, I would seek outside support...

Jan: I think you work it out as you go whether it's a problem or not ..."Hey, let's have this meeting on this," or about gays or someone with handicaps or whatever, I just don't think you have to do that, to me personally. Now, if you have a problem then you deal with it. But do you make a big deal before you even start? It shouldn't be. It shouldn't be a big deal, it should be who they are. They're the person, they're your friend, they're your teammate, that kind of stuff.

This reactive response was rationalized across coaches with the belief that drawing attention to an athlete's difference would make it harder for the athlete. Additionally, other coaches felt competent in their ability to handle potential situations that may arise due to having an openly LGB athlete, so they were less likely to proactively seek resources of support since they did not perceive needing them.

Types and Timing of Sexuality Disclosure. Between the 10 coaches interviewed there was a myriad of ways coaches found out that one or more of their athletes were LGB. At times, the athletes were blunt or very "matter of fact" in their conversations with coaches, but other times required more investigation or experiences with the athletes prior to learning of their sexuality.

Social Media. In the current times, technology is paramount. Many of the coaches disclosed that they believed their athletes were more accepting of teammate "differences" because they had constant access to each other and to information, in general. However, coaches 
were often a part of their student-athletes' social media. Several coaches reported being

"friends" with their athletes on SnapChat, Facebook, or Instagram. It was through these

mediums that coaches found out about their athletes' sexualities.

Christal: 'Cause I told him I saw his Snapchat, and he said, "Oh, I'm embarrassed." and I said, "Never be embarrassed of who you are. Be you."

Nikki: And I think at that point I had not really realized that he was bisexual until that point where he openly had put it on social media. After that, I started kinda paying more attention...

Following and checking the athlete's social media pages can alert coaches to potential problems in the athlete's life. It also opens up the amount of information that a coach can know about each athlete, even if that athlete is not ready for adults to know certain pieces of information.

Teammate Disclosure. In some circumstances, other athletes were the ones to out the LGB athlete to the coach. In some cases this was done nonchalantly, by the teammate, like in Gregg's case:

I recognized almost everybody. But there was one kid who I just didn't know about and one time after our match I'm all, "Who is that kid?" And one of the other players on the team just said, "Oh, that's her girlfriend!" And I was like, "Oh, okay."

In other situations, the athlete disclosed the LGB athlete's sexuality out of concern about team dynamics. This happened to Christal after a couple of her athletes were joking around about sexuality:

But one of the kids came to me and said, "...I think that... I think he is gay. He's on some website, some chat something, and my friend knows this person, and I think he's gay. I think he's trying to talk to other guys. And that the other one [teammate] shouldn't play with him because I don't think he realizes that he really is gay, and he thinks it's a joke and it's not."

While this information may be helpful in certain situations, it does take the LGB athlete's choice and voice away. It no longer becomes the athlete's choice about when to come out, who they are comfortable coming out to, and how they wish to disclose their sexuality to others. 
Direct Conversation. There were times when coaches ended up having very direct conversations, generally initiated by the LGB athlete, about the athlete's sexuality. Coaches expressed that these athletes often seemed very comfortable and confident in themselves and had no hesitation exposing their sexuality to the coach. Christal walked in on one of her athletes kissing another female, leading to the athlete outing herself verbally:

But they were very much kissing, and together, but I knew her to like one of the boys on the team. And so it caught me off-guard and then she said, "What Ms. [Christal]? You didn't know I was gay?" And I said, "No, I did not know. I thought you liked a boy." And she said, "Well, I like him, too, but I really like girls." And I said, "Okay."

Gregg had a similar experience after practice with one of his male volleyball players. Seemingly, the athlete felt, at that moment, that he was comfortable enough to be open about his sexuality, potentially out of concern about what his teammates may think or say:

But it was after the first open gym, at the end of practice he just came up to me and was asking about, mostly philosophical questions as far as my coaching style...And at the end, he was all, "Well, you know I'm gay, right?” And I was like, "Well, no, I didn't know you were gay." He goes, "Yeah, just so you know, in case anybody says anything. Alright, have a good night." That was pretty much it.

In both of these cases, and in others, the athletes were the ones to initiate the conversation. Interviewed coaches were periodically surprised by the news, but seemed to appreciate the athlete's candor.

Assumptions. In order to be eligible for the current study, coaches had to have experience with at least one openly LGB athlete as a head coach at the high school level. While all the coaches interviewed fit this criteria, many of the coaches also had athletes who they assumed were LGB but did not know for certain or found out at a later time. These assumptions were often, admittedly, stereotypical, but did carry weight with the coaches' perceptions of the athletes. For male athletes, femininity was generally an indicator: 
Christal: He's very open, and he's more feminine. I don't know if that's the right word to say that, but... You just knew, you just knew.

For female athletes, it was appearance and "playing like a guy" as one coach stated, that often lead coaches to believe the athlete was LGB:

Craig: I coached her for five years, and the haircut, not going to prom, going to prom with girls, how she carried herself, those types of things. I inferred that probably, but maybe in the environment she was, she didn't feel... great coming out.

Even though coaches did not believe that these perceptions changed any interactions between themselves and the potential LGB athlete, it's worth noting that these athletes stuck in their minds as they recalled others during the interviews.

College. Very few coaches expressed any concerns about their current school or team environments with regard to LGB athletes or individuals, in general. In fact, many of them felt like their school was the "exception" or an oasis amidst conservative surrounding areas. It is interesting then that coaches often discussed additional LGB athletes that they had coached that decided not to become open about their sexuality until after they finished high school and started college. Jan attributes this hesitancy to coming out in high school to potential bullying between males:

'Cause we actually had a couple that ... Boys, and they didn't come out until after high school. And that's a different situation. They felt like... The boys felt like they were picked on...

However, Jan also had athletes that waited to come out about their sexualities for reasons unbeknownst to them or the researcher. Some of these athletes self-disclosed on social media and some returned to their high school and then chose to talk to their coach about their sexuality after graduating.

Parental Concerns. The last reason that was commonly discussed across coaches for how and when athletes disclose their sexuality is the athlete's perceived relationship with his or 
her parents. Coaches believed that many student-athletes were hesitant to be open about their sexuality while still in high school because the "risk" was too great. Athletes may have had fears about losing family emotional and financial support. Jeren, having coached both openly gay males and females, discussed his perception:

It was a pretty well-known deal that she was gay and she had no issue with that. Parents had no issues with that. And I think that was one of the sticking points on the female side. Living in a very conservative area, it made her openness about it a much easier ordeal because her parents were supportive of that. On the opposing side, the young man had super conservative parents. It wasn't something that was accepted within the family. It wasn't something that was accepted in the church. It was kind of something that was endured instead of fostered. I think that had a lot to do with the level of openness that they felt around other people.

Parents, in general, were brought up by the coaches often. They were noted as the number one reason that coaching at the high school level is difficult and one of the many reasons that athletes often felt uncomfortable being open about their sexuality at younger ages.

Differential LGB Athlete Characteristics. In addition to team environment and coach beliefs, there were several characteristics that stood out across the openly LGB athletes. These characteristics could potentially impact their likelihood to be comfortable coming out and their interest in staying in sport as they get older. Some of these themes have been discussed before, while others seem to be less focused on or discussed in previous literature. However, only some of these characteristics are within the athlete's control.

Talent Level. One of the more interesting findings from the coach interviews was that the majority of athletes who were openly LGB were also very talented athletes. The correlation between talent and comfort level about sexuality is one that has not been explored thoroughly, but is worth considering. This is especially true due to how confident coaches were in their own reasoning. 
Gregg: That's one of the things that I've always found is that the kids on my team that have been openly gay are usually one of the better athletes on the team and almost all of them have gone on to play at the collegiate level...And I think that lends to them being one of the better kids on the team. They are in kind of a leadership role and maybe feel a little more comfortable, maybe feel a little more okay with sharing about themselves.

There are most likely many factors that go into an athlete feeling comfortable enough to disclose their sexuality. But if being talented is the most important thing, like Jeren states below, then it does make one wonder what else is considered acceptable and what are the experiences of lesser talented openly LGB athletes?

This is going to sound like a horrendously superficial thing to say, but both were really good players. And so, when you're in a team environment, you could pretty much be a serial killer and if you're good enough, everybody's gonna accept it. I think that made things easier, especially on the boys' side. The young man was a phenomenal talent... This is just completely conjecture on my part, but I think if it had been the type of deal where...I think if it had been the case where he was a lesser talent...I don't think he would have had the social interaction that he displayed during practices and games, or the confidence that he had in himself and his orientation, if it had been a different level of talent.

Sex Differences. One finding that has been discussed and debated quite heavily in previous research is the difference in sport experience for males and females. While it is almost expected that women in sport are lesbians, stereotypically, a gay male in sport is seen as exceptional and uncommon. Jeren had this perception with two female athletes on his basketball team:

I feel like on the girls' side, it's a much more accepted and comfortable situation for them. It's something in an environment that, at least from my experience, the two girls that I had, had no problem putting it out there. They were comfortable in who they were, they were comfortable in their sexual orientation.

Ken, like Jeren, had coached openly lesbian athletes, but had not coached openly gay males, despite coaching male teams for several years. He noted the lack of openly gay males:

The odds are I've coached gay athletes, gay male athletes. It's just not a comfortable place for most guys to go, I think, right now. 
The perception that sport is not a "comfortable place" for male athletes is reflected in other interviews and across themes. Despite a perception of growth and advancement for LGB rights and individuals, coaches still perceive males to not have an accepting space in sport.

Sport Played. When discussing their sports, many of the coaches felt like their sport was an accepting environment for openly LGB athletes. For example, Craig spoke very highly about his distance runners:

And I say this all the time about distance runners, you can't find a better group to have your kids, your own children hang around. You can't find a more accepting group than distance runners. You can't find a better behaved group than distance runners. They're incredible. So, if you were going to be... If you ever want to be accepted, there's the group you wanna be with, in my eyes.

Many coaches, like Craig, felt positively about their sports' inclusivity, but often felt this way because of the environments that they had created on their teams. The coaches took a lot of responsibility for promoting acceptance and building a very trusting and "familial" environment. Coaches had opinions regarding sports other than their own. These opinions were generally focused around football and men's basketball. Linda brought up football during her interview:

And I could be totally off-base. I would think that the football coaches would have a problem with it. But as I said, I don't know for sure, but just because the whole macho, manly thing.

The "whole macho, manly thing" can lead to "closed-minded homophobic kind of banter that dudes have." This banter may create an environment that is hostile to openly gay or bisexual males.

Location. Coaches were specifically selected to represent different areas within the United States. It was expected that location could play a part in how accepting the culture was surrounding the high school or sport. As stated earlier, most teams felt like the high school and team were very open and inclusive of LGB athletes and individuals. However, across the board, 
areas that were perceived to be less accepting were those areas that had a strong religious

presence. Nikki, located in North Carolina, speaks to this:

A lot of times we are described as the Bible Belt. There is lots of opinions here, lot of church goers. I would label them as "Christians." I mean, I would consider myself a Christian as well, but there are a lot of, I would say, opinions, and people are not scared to really say it, they openly accept, but again I feel like there's still kinda like those barriers there with those old school, old-fashioned people, because there's lot of older people in this area as well.

To further elaborate on this point, Craig brought up North Carolina specifically, stating "there's been an incredible culture shift, except for many in North Carolina." With this state being in the news frequently due to oppressing transgender rights, it was perceived that certain geographical locations still hold on to beliefs and ideals about sexuality and sport. 
APPENDIX L 


\section{Proposed Future Coach Education Workshop \\ Addressing the High School Sport Team Environment}

\section{A Coaches Introduction to Lesbian, Gay, and Bisexual Student-Athlete Inclusivity}

Purpose: The proposed curriculum is for a coach education workshop that will target high school coaches in an attempt to help them explore their current perceptions and approach to working with LGB athletes. Additionally the workshop will encourage evaluation of potential changes needed in their coaching practices and team environments. These learning objectives were developed through extensive review of previous research, as well as the results gleamed from the current qualitative study.

Set-up: Upon registering, all coaches will receive an educational participant manual to guide the coaches through the workshop, as well as be a resource at the completion of the training. Content will be presented in sequence and will use a variety of instructional methods, designed to most effectively teach adult learners. Therefore, an emphasis will be placed on structured sessions that involve presentations, multimedia, worksheets, small group work, vignettes, and practical interactive exercises.

Learning Objectives and Rationale:

1. Describe and reflect on stereotypes of LGB individuals and athletes.

- Many of the coaches in the current study stated that they "knew" an athlete was LGB after making assumptions based on their appearance or mannerisms. These assumptions are generally based on stereotypes and while that may not indicate differential treatment, there is research indicating that even perception of LGB sexual orientation may lead to bullying from peers.

2. Explore beliefs and research surrounding the Nature vs Nurture debate with regard to sexual orientation.

- There were differing perspectives from coaches in the current study about whether sexual orientation was biological or a choice made by the studentathlete as they developed. While research within the field is not certain about the formulation of sexual orientation, the perception has been shown to influence overall support for LGB rights and desire to be inclusive. 
3. Recognize the impact of team dynamics and social cohesion on LGB athlete's identity development.

- There has been much research that demonstrates the impact of social cohesion on performance. Based on information from the current study, coaches' perceptions supported this notion as they discussed the importance of being a good teammate. This session could talk more about the reasoning behind the research and specific practices that could be implemented to assist in developing a positive, inclusive team environment.

4. Understand common, yet homonegative language used in a team setting can affect the confidence and overall health of an LGB athlete.

- Language used, even if believed to be innocent or "joking," can impact the level of comfort, confidence, and even physical health of LGB athletes. Several of the coaches in the current study discussed the need to limit certain words or phrases in the team environment, but this was more evident on male teams. However, research shows that females may be even more influenced by homonegative language.

5. Build awareness of available resources for high school coaches, athletes, and teams.

- Based on the current study, as well as previous quantitative study by the researcher, high school coaches reported not having a high awareness of available resources for information regarding LGB athletes. Time spent researching available sources and sites revealed a small variety of items that coaches can access, but many coaches are unaware making less effective and confident in creating an inclusive environment.

6. Establish structured approach to parent interactions and meetings.

- The number one complaint from high school coaches in the current study was having to interact with parents. Beyond just personal concerns about overprotective parents, the coaches often discussed athletes perceptions about parental acceptance and how this influenced the LGB athlete's comfort and ability to be open about their sexuality to others.

7. Develop a personalized coaching philosophy, specifically incorporating the approach to LGB athletes.

- The culminating event of the current coach education workshop involves developing a coaching philosophy that specifically integrates an approach and perspective of LGB athletes. All of the coaches were very passionate and aware of their role as a coach, but very few had any true idea of how to address LGB athletes and teams proactively and reactively. 


\section{APPENDIX M}

Quantitative Study Comparison to Qualitative Responses 
Question Prompt: How confident are you that you can...

\begin{tabular}{|c|c|c|c|c|}
\hline Name & $\begin{array}{l}\text { treat all athletes, } \\
\text { regardless of sexuality, } \\
\text { in a similar manner? }\end{array}$ & $\begin{array}{l}\text { manage conflicts } \\
\text { between an LGB } \\
\text { athlete and a non-LGB } \\
\text { athlete? }\end{array}$ & $\begin{array}{l}\text { prevent LGB issues } \\
\text { from becoming a } \\
\text { distraction to your } \\
\text { team? }\end{array}$ & $\begin{array}{l}\text { prevent LGB } \\
\text { stereotypes from } \\
\text { affecting your } \\
\text { coaching? }\end{array}$ \\
\hline Nikki & 5 & $\begin{array}{l}5 \text { - she made someone } \\
\text { else uncomfortable, } \\
\text { because she was just } \\
\text { looking at them. }\end{array}$ & 5 & 5 \\
\hline Christal & $\begin{array}{l}5 \text { - all I care about is, } \\
\text { "Are you a good } \\
\text { teammate?' It doesn't } \\
\text { matter your sexual } \\
\text { preference. }\end{array}$ & $\begin{array}{l}5 \text { - I don't do bullying, } \\
\text { and if someone is } \\
\text { messing with your } \\
\text { teammate, then we } \\
\text { together fix that. }\end{array}$ & $\begin{array}{l}5 \text { - "We are a family, } \\
\text { and if you don't like it } \\
\text { and you d5on't wanna be } \\
\text { a part of this family and } \\
\text { accept people for who } \\
\text { they are, you can go." }\end{array}$ & 5 \\
\hline Linda & $\begin{array}{l}5 \text { - I would handle it the } \\
\text { same way I would } \\
\text { handle a male/female } \\
\text { relationship }\end{array}$ & 5 & 5 & $\begin{array}{l}5 \text { - But she kinda } \\
\text { dressed tomboyish and } \\
\text { kinda had mannerisms } \\
\text { that kinda led to the } \\
\text { fact... And I hate to } \\
\text { stereotype people, but } \\
\text { kind of led to the fact } \\
\text { that, "You may be... }\end{array}$ \\
\hline Jan & $\begin{array}{l}5 \text { - Handle them as you } \\
\text { would any athlete. To } \\
\text { me they're no different, } \\
\text { just because of their } \\
\text { sexual preferences. }\end{array}$ & 4 & 4 & 5 \\
\hline Jeren & $\begin{array}{l}5 \text { - I've never been the } \\
\text { kind of person who will } \\
\text { judge a person just on } \\
\text { face value. }\end{array}$ & $\begin{array}{l}5 \text { - The only thing that I } \\
\text { had to curtail on the } \\
\text { boys' side is the rampant } \\
\text { use of the word "fag }\end{array}$ & 5 & 5 \\
\hline Ken & $\begin{array}{l}5 \text { - The old coaching } \\
\text { saying, "Well, I treat } \\
\text { everybody the exact } \\
\text { same." Well, I don't } \\
\text { really buy that. Every } \\
\text { personality is different. }\end{array}$ & 5 & 5 & 5 \\
\hline Larry & $\begin{array}{l}5 \text { - Because the kids see } \\
\text { it. They will see } \\
\text { through you, and they } \\
\text { will see that you aren't } \\
\text { treating someone the } \\
\text { same that you're treating } \\
\text { someone else. }\end{array}$ & 5 & 4 & 5 \\
\hline Steve & $\begin{array}{l}5 \text { - We strive to be equal } \\
\text { in a term of equality on } \\
\text { the teams, regardless of } \\
\text { gender }\end{array}$ & $\begin{array}{l}5 \text { - I would say I heard } \\
\text { some derogatory } \\
\text { comments, and I would } \\
\text { always address those } \\
\text { with the player that it } \\
\text { was coming from. I } \\
\text { would just shut it down. }\end{array}$ & $\begin{array}{l}4 \text { - Myself and my } \\
\text { coaching staff, we had } \\
\text { an understanding, that it } \\
\text { was not gonna be, it was } \\
\text { not happening on our } \\
\text { team. }\end{array}$ & 5 \\
\hline Gregg & 5 & $\begin{array}{l}5 \text { - it was derogatory, } \\
\text { and so I got involved not } \\
\text { necessarily because she } \\
\text { was gay but because of } \\
\text { the behind the back } \\
\text { talking. }\end{array}$ & 5 & $\begin{array}{l}5 \text { - if you can't have } \\
\text { words and actions that } \\
\text { produce independent } \\
\text { thinkers and strong } \\
\text { people, then maybe this } \\
\text { isn't your profession }\end{array}$ \\
\hline Craig & 3 & 2 & 3 & 2 \\
\hline
\end{tabular}




\begin{tabular}{|c|c|c|c|c|}
\hline Name & $\begin{array}{l}\text { create an environment } \\
\text { of inclusion (i.e. an } \\
\text { environment that is / } \\
\text { welcoming and } \\
\text { nonjudgmental)? }\end{array}$ & $\begin{array}{l}\text { set an example of } \\
\text { inclusion? }\end{array}$ & $\begin{array}{l}\text { prevent feelings of } \\
\text { isolation for LGB } \\
\text { athletes? }\end{array}$ & $\begin{array}{l}\text { identify LGB resources } \\
\text { for coaching? }\end{array}$ \\
\hline Nikki & 5 & 5 & 4 & 5 \\
\hline Christal & 5 & 5 & 5 & $\begin{array}{l}5 \text { - They came and did a } \\
\text { presentation and they } \\
\text { talked about how there } \\
\text { are children in our } \\
\text { building who could } \\
\text { possibly be part of that } \\
\text { community, and there } \\
\text { are resources. }\end{array}$ \\
\hline Linda & 5 & 5 & 5 & 5 \\
\hline Jan & 5 & 5 & 4 & 3 \\
\hline Jeren & 5 & 5 & 4 & 2 \\
\hline Ken & 5 & 5 & 4 & 3 \\
\hline Larry & $\begin{array}{l}5 \text { - Compassion has to } \\
\text { be there because you can } \\
\text { push someone over the } \\
\text { edge by the rejection, } \\
\text { belittlement, } \\
\text { condemning them. I } \\
\text { never want that to be } \\
\text { way I treat people }\end{array}$ & 5 & 4 & $\begin{array}{l}5 \text { - I've known some } \\
\text { adults that have a } \\
\text { different lifestyle... And } \\
\text { I've talked to them some } \\
\text {...Just trying to pick } \\
\text { their brain about how } \\
\text { they see things, how } \\
\text { they think about things. }\end{array}$ \\
\hline Steve & 4 & 5 & 5 & 3 \\
\hline Gregg & $\begin{array}{l}5 \text { - to be a part of a } \\
\text { team, it means to } \\
\text { support everybody on } \\
\text { the team, on the court, } \\
\text { off the court }\end{array}$ & 5 & 5 & $\begin{array}{l}5 \text { - I really relied on } \\
\text { Shannon to help me } \\
\text { bring resources to our } \\
\text { team as far as sexuality } \\
\text { was concerned. }\end{array}$ \\
\hline Craig & $\begin{array}{l}3 \text { - that's something I've } \\
\text { always worked hard on, } \\
\text { trying to create a climate } \\
\text { that we're all in this } \\
\text { together working toward } \\
\text { a common goal. }\end{array}$ & 3 & 2 & 4 \\
\hline
\end{tabular}




\begin{tabular}{|c|c|c|c|c|}
\hline Name & $\begin{array}{l}\text { coach lesbian, gay, and } \\
\text { bisexual athletes? }\end{array}$ & $\begin{array}{l}\text { refrain from imposing } \\
\text { your beliefs on your } \\
\text { athletes? }\end{array}$ & $\begin{array}{l}\text { identify LGB resources } \\
\text { for my athlete? }\end{array}$ & $\begin{array}{l}\text { create a "safe" } \\
\text { environment for LGB } \\
\text { athletes? }\end{array}$ \\
\hline Nikki & 5 & $\begin{array}{l}5 \text { - I have my own } \\
\text { beliefs and I have my } \\
\text { own opinions, but I'm } \\
\text { not gonna be one of } \\
\text { those that runs around } \\
\text { and damns you to hell }\end{array}$ & 5 & 5 \\
\hline Christal & 5 & 5 & $\begin{array}{l}5 \text { - I would seek outside } \\
\text { support... I would seek } \\
\text { guidance, our guidance } \\
\text { counselors. }\end{array}$ & $\begin{array}{l}5 \text { - I always try to make } \\
\text { them at least know that } \\
\text { it's okay, I'm gonna } \\
\text { support them either way } \\
\text { and be a safe place }\end{array}$ \\
\hline Linda & 5 & 5 & 5 & 5 \\
\hline Jan & $\begin{array}{l}5 \text { - no matter if you're } \\
\text { gay, lesbian, star athlete, } \\
\text { not very athletic at all, } \\
\text { that you're an important } \\
\text { part of the team. }\end{array}$ & 5 & 2 & 5 \\
\hline Jeren & 5 & 5 & 2 & $\begin{array}{l}5 \text { - if I have a individual } \\
\text { or multiple individuals } \\
\text { who are hindering that } \\
\text { environment, then it's } \\
\text { my job to take steps to } \\
\text { either remove them from } \\
\text { the environment }\end{array}$ \\
\hline Ken & 5 & 5 & 3 & 5 \\
\hline Larry & $\begin{array}{l}5 \text { - they're an athlete, } \\
\text { their gender preference } \\
\text { is not part of how we } \\
\text { would judge them as an } \\
\text { athlete }\end{array}$ & 5 & 5 & 5 \\
\hline Steve & 5 & 5 & 3 & $\begin{array}{l}5 \text { - showing any kind of } \\
\text { tolerance for a } \\
\text { misbehavior because of } \\
\text { gender, race, sexuality, } \\
\text { there's just no place for } \\
\text { it in an athlete team } \\
\text { environment. }\end{array}$ \\
\hline Gregg & 5 & 3 & 5 & $\begin{array}{l}5 \text { - I feel like I'm the } \\
\text { common denominator, I } \\
\text { think the tone that I set } \\
\text { as far as the team is } \\
\text { concerned. }\end{array}$ \\
\hline Craig & 5 & 5 & 3 & \\
\hline
\end{tabular}




\begin{tabular}{|c|c|c|c|c|}
\hline Name & $\begin{array}{l}\text { instill an attitude of } \\
\text { respect for others? }\end{array}$ & $\begin{array}{l}\text { remain unbiased } \\
\text { toward athletes who do } \\
\text { not follow traditional / } \\
\text { gender expectations for } \\
\text { appearance and/or } \\
\text { dress? }\end{array}$ & $\begin{array}{l}\text { discipline athletes who } \\
\text { engage in anti-gay } \\
\text { actions? }\end{array}$ & $\begin{array}{l}\text { deal with parental } \\
\text { concerns and } \\
\text { complaints about LGB } \\
\text { issues in a / way that } \\
\text { values diversity? }\end{array}$ \\
\hline Nikki & 5 & 5 & 5 & 5 \\
\hline Christal & 5 & 5 & 5 & $\begin{array}{l}5 \text { - But at the end of the } \\
\text { day, he is who he is. } \\
\text { And I know that he was } \\
\text { trying really hard not to } \\
\text { be, because his mom } \\
\text { and church. }\end{array}$ \\
\hline Linda & 5 & 5 & 5 & $\begin{array}{l}5 \text { - Her parents were } \\
\text { definitely against it. } \\
\text { And they did not want } \\
\text { them sitting together on } \\
\text { the bench, wanted me to } \\
\text { keep them separate at all } \\
\text { times. }\end{array}$ \\
\hline Jan & 4 & 5 & 5 & 4 \\
\hline Jeren & 5 & 5 & $\begin{array}{l}5 \text { - it's my job to take } \\
\text { steps to find a way to } \\
\text { help them see the } \\
\text { negative impact they are } \\
\text { having }\end{array}$ & 5 \\
\hline Ken & 5 & $\begin{array}{l}5 \text { - If you can get past } \\
\text { your prejudice or } \\
\text { whatever preconceived } \\
\text { perceptions that you } \\
\text { had, you'll find that } \\
\text { you're back to just } \\
\text { dealing with athletes. } \\
\end{array}$ & 5 & 4 \\
\hline Larry & 5 & 5 & 5 & 5 \\
\hline Steve & 5 & 5 & 5 & 5 \\
\hline Gregg & 5 & 5 & 5 & 5 \\
\hline Craig & 2 & $\begin{array}{l}3 \text { - I coached her for five } \\
\text { years, and the haircut, } \\
\text { not going to prom, going } \\
\text { to prom with girls, how } \\
\text { she carried herself, those } \\
\text { types of things. }\end{array}$ & 5 & 1 \\
\hline
\end{tabular}


APPENDIX N 


\section{Member Check Responses}

Jeren:

"This all looks great and is fairly in line with my ideas on the issue as a whole."

\section{Christal}

"I wish you the best for tackling such a polarizing topic. Many may not understand this research however it is needed from my experience with high school athletes and personal experiences remembered as a result of this study. I agree with the themes identified and have no additional information to add." 


\section{Analytic Memos}

December $3^{\text {rd }}, 2016$

After many months of writing, preparation, and planning I have started setting up my bracketing interviews. Because the qualitative research process is relatively new to me, I did some additional research about bracketing interviews and found one article in particular that clearly laid out the process and variations. I will continue referring to this article as I progress.

Tomorrow is my first bracketing interview with a current high school coach who I met through consultations at WVU. I know she has had lesbian athletes at the collegiate level but will be examining her interactions with any high school openly LGB athletes. More than anything, this is a chance to test out my interview questions as well as the Go-To-Meeting software. Here we go!

\section{December $4^{\text {th }}, 2016-\mathrm{SVO}$}

My first interview went well but was not exactly how I expected. It turns out that SVO has not had any open LGB athletes at the high school level which in turn made the interview relatively short (36 minutes). However, in this time, we discussed her beliefs about effective coaching of LGB athletes, and how she has had to adjust her coaching in some situations (room assignments, bus seats, etc.) due to teammate concerns about interteam dating. I anticipate that this will continue to be a topic of discussion, as it is something to consider at the high school and collegiate levels. SVO was also open about her coach education opportunities, or lack thereof, and ways that diversity training could be implemented more effectively in the future.

One of the biggest things that I found interesting, that I may not find with my sample of coaches, is that she often discussed the differences between coaching at the college and high school level. Most notably was how difficult parents can be at the high school level, just overall more involved. I remember this about my own time coaching at the youth level. It was frustrating and even caused some coaches I knew to retire from coaching much earlier than anticipated.

I found that while talking to SVO, my mind often went to how I would facilitate a diversity training for coaches. What would it look like? How long would it be? What topics HAVE to be covered? While this is important, I want to be sure that I stay present and engaged during the interviews.

December $8^{\text {th }}, 2016-$ OR

Tonight, I completed my second bracketing interview. I thought of this coach after wanting to intentionally target a coach who I know has had interesting experiences. 
Unfortunately, I assumed that this coach, in her 12 years of coaching basketball, softball, and lacrosse, had coached at least one openly LGB athlete. I was wrong, however her wife has some experience coaching an open lesbian athlete. I may consider talking to her at a later time.

As for OR, her situation is a little different, though. She taught at a Catholic high school in the Midwest for 12 years before getting fired for being married to a woman. The situation was incredibly sad and traumatic for her and her athletes who were very open publically about their disappointment in the school's decision. OR has since completely changed her line of work, but stated that she misses coaching immensely.

I was very interested in her perspective of coaching LGB athletes due to being a lesbian. Results from my quantitative study indicated that there weren't any statistical differences in LGB coaches and heterosexual coaches, but I still believe the dynamic to be interesting. I believe this to be even truer in situations like OR where the athletes and coaches are bound by the religious views of the institution. The results of the quantitative study also showed no statistically significant differences with regard to religion but it's so hard to solely rely on that data when I have had my own life experiences. This is something that I will have to continue to keep in mind as I complete and code the interviews.

One of the big things that she brought up that I would love to look into more in the future is "negative recruiting" by collegiate coaches. OR stated that she was negatively recruited and despite intentionally choosing not to attend the university that specific coach was at, ended up playing for him 3 years later when he was hired to coach at her university. She stated that she will never forget how uncomfortable she was and that lead her to wanting to be a good role model for her athletes, LGB and heterosexual.

On a side note, Go-To-Meeting is excellent! It's very easy to use and none of my participants so far have had any issues accessing the meeting or using the controls. Plus, recording is very simple and easy to convert to a file for transcription. The audio is clear and I'm really grateful that I decided to use this site instead of Google+ Hangout (even if it costs a few bucks a month).

December $14^{\text {th }}, 2016-\mathrm{JH}$

This was the first male coach I have interviewed since starting the bracketing process. I was really excited to talk to him because he was also the first coach that I did not know prior to completing the interview. Before starting the interview I was curious if not knowing the coach would make it easier or harder to ask the right questions. In the end, I think it was both.

It was easier because I had no preconceived ideas of what his responses would be. He was suggested to me by SVO since I was having a hard time finding a male coach to use for 
these bracketing interviews after two fell through. I knew very little about him prior to starting the interview, but I felt really close to him by the end.

He told me a story about how one time, he was coaching and he said something homonegative to his male team. After practice, one of is athletes approached him and said, very matter of fact, the he was gay. He said it completely changed his whole perspective of his coaching. He had already been attempting to change is language surrounding women (calling players "pussies, wusses, girls, etc." This was in large part to his wife calling him out on his negative comments. However, when this male athlete told him he was gay, he realized it went way deeper than comments about women. He then took it upon himself to completely change the culture of his team and the style of his own coaching. I think one of the neatest things he said was that determination and toughness have no gender. Pretty cool. I love this research.

December $19^{\text {th }}, 2016-\mathrm{LE}$

LE was recommended to me by a friend who studies coaching practices. LE is the director of women's basketball at a large, private academy. She was a collegiate athlete as well, like all of my other bracketing interviews. Also, similar to OR, LE is a lesbian, with a wife and child (but I didn't know this until the end of the interview). However, unlike the other coaches thus far, LE was not sold on the idea of coach education with regard to LGB athletes. She was more of the belief that coaches should be self-aware and spend time developing a coaching philosophy that suits them. Great thought, but unrealistic?

It was so enjoyable (does this matter?) listening to her perspective and her experiences, which were numerous. She has dealt with a large variety of situations, such as mentoring lesbian athletes, dealing with conflict from homonegative coaches, and experiencing negative recruiting. She was passionate but controlled. She had obviously reflected quite a bit and developed beliefs about coaching, sexuality, and life in general.

She was incredibly helpful and I felt like we could have just sat down and talked for hours had we been in person. She was comfortable with herself and her abilities. Because I identified more with her than other coaches and felt that level of comfort, it was a balance of keeping boundaries and the "structure" of the interview and wanting to delve deeper into her responses and experiences. Maybe that is what I should be doing? I'm not entirely sure. Where does exploration stop and curiosity start? Is that to be avoided? Time to do more research.

December $19^{\text {th }}, 2016$ - Emails Sent!

The email has been drafted and sent to the coaches selected by Bill, Stefanee, and me. Overall we, as a research team, had similar ideas as to who may be most impactful to interview. 
It created some really good conversations about what matters, characteristic-wise. It was also a really good check on my own perceptions. Bill and Stefanee both had really good feedback for why they ranked certain coaches the way they did. I feel like at the conclusion of our discussion we have established a really diverse group of coaches that could produce some really intriguing interviews. I can't wait to see who responds!

December $26^{\text {th }}, 2016$ - Responses

I have had a couple coaches reach out the last few days but the follow up is lacking once I respond. I had one coach, a football coach, email and directly tell me that he didn't want to be a part of this study. To be honest, this surprised me because all of the coaches who were contacted were contacted because they explicitly stated that they were interested in doing a follow up study. So, at first when I received this email, I got pretty frustrated. I wanted to interview a football coach and here he is, having no interest in being interviewed. I almost responded back to him, encouraging him to have a change of heart, but refrained. This was also my first rejection for potential participants and it got me thinking that this whole recruiting participants might be more difficult than I originally anticipated.

However, I am also very aware that it was just Christmas and that most of the coaches are probably on break from their respective schools. Not everyone checks all of their emails everyday like I do. I just hope that these coaches don't take too long to respond and that future responses are more optimistic.

December $29^{\text {th }}, 2016$ - Jeren (Men's Soccer, Women's Basketball - 46 minutes)

Jeren was my first "real" interview for the study. He was a really good one to start. He was friendly, talkative, and had some really strong beliefs on best practices for coaching openly LGB athletes. Additionally, he had coached both openly gay males and females. Despite having many male coaches who responded to the quantitative study, I worry that there will not be a lot of male coaches who have coached openly gay male athletes that will discuss their experiences. Jeren didn't have a problem talking about it though. He was witty and had a few really good quotes. He also brought up something that I hadn't really thought about yet - how the athlete's talent may dictate how they are treated on the team. I can definitely see how that could be the case in some situations. I guess I just never really felt like it was my experience. Rationally, this is silly but true. I feel like I have to bounce between these roles. It may take me some time to figure out the best way to integrate them all.

When I finished this interview and felt incredibly energized. I enjoyed his insights and found myself agreeing with him a lot. I tried to be very neutral during the actual interview 
though for fear of influencing his responses. I will probably have more trouble not agreeing with people than with handling participants who have very different opinions than myself. I believe I can be neutral in those situations, but it's hard to contain excitement sometimes.

January $4^{\text {th }}, 2017$ - Transcription Service

So after spending the past several days trying to figure out the best transcription service, I think I finally have one that will work well. I had decided on TranscriptionHub weeks ago, but when I went to submit the file, it wouldn't let me pay. I tried to call the customer service number to figure out what was happening but no one answered so I got frustrated and decided to find another transcription agency. I'm not sure why I didn't do this earlier, but I looked up the most popular transcription companies and found reviews of the best. Scribie stood out for whatever reason so I selected that and went with and I am so glad I did! It's substantially cheaper than TranscriptionHub and includes time stamps. Plus the turnaround time is only 5 days, which is pretty quick. Looking forward to seeing how the first transcript turns out so I know whether I need to find a new service for the rest.

January $5^{\text {th }}, 2017-$ Follow-up Emails

It has been over two weeks since I sent the initial recruiting email to the selected coaches. Today, I sent a follow up to hopefully remind coaches about the study. I figure since coaches were probably on break, celebrating holidays, and then busy getting back to work, a second email may be a good reminder for those coaches who may potentially be interested. If I don't get responses based on this email, I will have to consider finding replacement coaches from the sample to represent a variety of characteristics that have not been fulfilled yet.

January $7^{\text {th }}, 2017$ - Gregg (Men's and Women's Volleyball - 75 Minutes)

So far, Gregg is the only LGB coach who has responded to my participation request. Both LGB female coaches are no longer eligible and there aren't actually any others who can replace them for that characteristic representation so I may not be able to have many LGB coaches in my final sample, which is disappointing. However, I would like to do a follow up study eventually that only utilizes LGB coaches (head and assistant). After talking to two coaches during my bracketing interviews and now Gregg, it does seem that their experiences and thoughts are somewhat more complex than the heterosexual coaches.

Anyway, Gregg, what a talkative fellow. He was very animated and talked quite a bit longer than Jeren. He had a lot of experience and was able to shed some light on the acceptance 
of LGB student athletes at various locations, being that he has coached in 3 different states. The odd thing about his interview was that he was not very open about his own sexuality. And while I understand that this was not the purpose of the interview, exactly, the two lesbian coaches that I interviewed were much more open. This is one of those times where I was curious but felt a pull to "stick to the script." This interview was what I anticipated a lot of the interviews to be like, with lots of storytelling and free flowing dialogue. It was easier to get information because it was readily available. Like counseling, these interviews could be much more difficult if coaches are less inclined to open up like Gregg did. I have another interview scheduled for tomorrow with Craig, a cross country coach.

January $8^{\text {th }}, 2017$ - Craig (Men's and Women's Cross Country - 39 Minutes)

Craig was a very different experience than Gregg. Craig was very excited about completing the interview and even sent me a video some news station did about him working with his team at the high school. He was passionate and good natured but did not seem entirely prepared for the interview. We discussed openly LGB athletes when we set up the interview, but come time to actually be interviewed, he seemed uncertain. But he had a lot of years to pull from and is on the verge of retiring so once he started talking, he seemed to loosen up. He talked a lot about how culture has changed since he was growing up and how much more accepting it is for LGB individuals these days. Yet, he also talked about how cruel kids can be even though he hasn't observed any type of negativity or harassment on his teams toward LGB student-athletes.

One thing I have noticed is that I have had some type of experience in each of the sports thus far (soccer, basketball, volleyball, and track) and I have memories associated with each sport. I think about my teams and experiences, positive and negative. It's that balance between my own thoughts and being present with the coach. It's difficult sometimes because I can rarely anticipate what they will say. It's been interesting for me to reflect after each interview about my own high school athletic experiences.

January $10^{\text {th }}, 2017$ - Christal (Men's and Women's Track \& Field - 59 Minutes)

I really enjoyed Christal's interview. She was extremely personable and had a lot of very specific examples of situations she has been in with openly LGB athletes. So far, she gave the most comprehensive interview. She talked about her family, religion, specific athletes, and concerns she had when she first found out she had an LGB athlete on one of her teams. A lot of the coaches seem to be hesitant to bring up any concerns (or they legitimately don't have any). I'm not sure. But she was clear that she was worried about what this athlete's experience would be on the team. However, most of the team environments so far have been incredibly accepting and Christal's was no different. 
At the very end of the interview, she talked about this training that she went to that showed a video of an LGB individual talking about how they had thoughts of suicide and how it wasn't fair how they were treated because they had no control over who they were attracted to. She said this one video changed her perspective completely and she has never forgotten that experience, despite growing up in a religious family and having her grandmother explicitly talk about lesbians negatively. Great interview.

January $13^{\text {th }}, 2017$ - Steve (Men's and Women's Soccer - 65 Minutes)

Today I completed an interview with Steve, a soccer coach. Steve took a few minutes to warm up and get comfortable with the interview process but once he did, he was a real pleasure to talk to. He was very self-reflective and had a very clear idea of what his role was intended to be as a head coach. He gave some good examples of situations he has been in recently with LGB athletes, but he also talked about a situation that happened when he was 16 or 17 and was playing football. His coach essentially chastised him for having feelings and he said that he has shaped his coaching around NOT being his high school coach.

Steve is the only coach so far that has dedicated training specifically about coaching LGB athletes. He talked about going to Soccer Coaches Conferences and getting the sense that the sport as a whole is really progressive. He even knew the name of a book author that often does research on LGB issues. I was impressed. At the very end of the interview, I asked if there was anything else he wanted to add and he talked about how perception can be everything and he added, "the more educated everyone is, the stronger we'll all be." That's my whole purpose for doing this research. I want to educate coaches, with the intent of helping LGB athletes and coaches to have better experiences on teams. That hit home with me a lot. It's nice to know that there are coaches out there with this perspective.

January $18^{\text {th }}, 2017-$ Ken (Women's Basketball - 39 Minutes)

Ken's interview was a quick one, but it provided some good insights. He spoke of really only one athlete during the entire interview and was animated in his experiences with her. They were funny, but also complex. I felt like I had known people like her growing up and found myself wanting to get more information. With this athlete, he had to deal with concerns from parents, teammates, and even himself. But through all of that, it seemed like he had a really good relationship with her. There was an openness that he apparently had with her that was made to seem simple and straightforward. He said he was able to address concerns very matter of fact and she responded well. I don't think that just happens. There's a relationship that has to be built in order for that to be effective. He also talked about how this athlete would try to get a reaction from him, pushing him into uncomfortable situations intentionally. He found this 
entertaining and stated that he didn't feed into her attempts. She was comfortable with her own sexuality and tested him to see if he was. No other coach has brought this up yet. Even though some of the athletes seem comfortable or confident, very few seem to want it broadcasted in this direct manner.

For me, I have mixed feelings. Does this behavior make it easier to have an openly LGB athlete or does it make it worse? Or is it just how it is? Do heterosexual athletes talk to him this directly about their boyfriends? I should have asked. I think back to one of Jeren's statements about how if the LGB community really wants to be equal then does sexuality need to be discussed at all. I think it does, in the right context, but to what extent. And then I think about Christal saying that an awareness of someone's sexuality creates conversations where there may have not been one, and this is good. I have just always been so private. I couldn't imagine making the kind of jokes like Ken's athlete, especially to someone in a leadership role. To each their own. For her, it seemed to have worked.

January $19^{\text {th }}, 2017$ - Larry (Men's and Women's Golf, Women's Softball - 67 Minutes)

Larry was one coach that I really wanted to interview. He has a $\mathrm{PhD}$ and has been coaching for a long time. He was excellent. He was the only coach so far to challenge me or ask me about my own perceptions on issues. Of course, I had to navigate this carefully. I generally just tried to redirect back to specific questions, but I found myself wanting to engage in a dialogue with him about the various topics and viewpoints.

He was very southern, having done his $\mathrm{PhD}$ in Mississippi but he was very aware of the issues surrounding LGB athletes. He talked about the debate between nature and nurture and how taking a class and talking to LGB acquaintances really opened his eyes to the fact that being LGB isn't a choice. This realization to him has adjusted his coaching style toward LGB student -athletes. This was also the case with Christal and her watching a video about LGB youth.

However, he gave an example of how he reacted when he found out his assistant softball coach was a lesbian and it was really concerning. He clearly had the view that if the Assistant coach was a lesbian that she was more likely to have inappropriate relationships with the team. This is a study that has to happen! I'm really curious about coach interactions and perceptions surrounding sexuality. I definitely want to have those conversations in the future, if it hasn't happened already.

January $27^{\text {th }}, 2017-$ Research Meeting

Had my first research meeting with my team (Bill and Stefanee). I'm stoked that they have both agreed to help. I know they have good experience and can provide some insights that 
hopefully challenge my own. We just covered timelines and expectations. I also created a packet to help Bill and Stefanee with any questions they may have about the coding process since we are getting closer and there are so many different kinds/preferences for coding. I will, obviously, be available to them, but as I was trying to get my own thoughts and understanding down about qualitative phenomenological open coding, putting the packet together was helpful. I got a clearer perception of the process and wanted to give this to them as well. I know each of them are working on their own projects and I'm incredibly grateful for their assistance.

January 30 ${ }^{\text {th }}, 2017$ - Last Attempt Emails

At this point, I am at 7 completed interviews and I have another scheduled for today. The issue is that only two (if the one follows through today), are female. While this is about the same percentage of female coaches who completed the quantitative study, it is fewer than what should actually be represented considering the percentage of female coaches at the high school level. I really thought that females would be more interested in participating (stereotype?). Females, according to the research, usually have more accepting views of LGB individuals so since coaches are self-selecting for this interview, I just figured they would be likely to reach out. Turns out I was wrong. It could just be that there are fewer female coaches to pull from or that they have more responsibilities in the school setting, making email checking/responding more difficult. In either event, I need more females. Hopefully Linda is good to go and this last email gets a couple more female coaches to agree to an interview so I can finally wrap up these interviews. I didn't think it would be this difficult!

January $30^{\text {th }}, 2017$ - Linda (Men's and Women's Track \& Field - 57 Minutes)

Throughout this whole process, the number one thing that coaches disliked about the high school level was having to deal with parents. During Linda's interview, she talked extensively about this situation where a parent found out her daughter was attracted to another female on her team, who was also attracted to her daughter. The parent told the coach that her daughter was not allowed to be near the other girl at all. What?! What a weird situation to be in as a head coach. You have a team of people and you have to specifically keep two of them separate. Not only is that hard for the coach and two athletes, but it's also a really awkward situation for the teammates. She said it was kind of funny though, because the team ended up finding out and ended up covering for the two girls quite a bit. This speaks volumes to how that team environment must have been as far as acceptance of having LGB teammates. Pretty cool.

January $31^{\text {st }}, 2017$ - Jan (Women's Volleyball and Softball - 57 Minutes) 
Had an interview with Jan today. Several of the coaches who I have had the pleasure of interviewing have actually been incredibly successful in their careers, and Jan was no exception. She has coached for years and won a lot of games while coaching volleyball. You never would have known that by talking to her though. She was very composed and direct. She didn't elaborate much unless directly instructed to do so. Main points of her interview including talking about how her experiences playing softball with lesbians in college influenced her perceptions about current interactions with LGB athletes. She said that being on a team with openly LGB individuals just showed her that they are people and it's not something to be afraid of. I think there is some truth to that, in my own experiences and in the research. Will examine this more when it comes to coding.

February $1^{\text {st }}, 2017$ - Nikki (Men’s and Women’s Swimming \& Diving - 67 Minutes)

Oh, Nikki. This interview, which I anticipate will be my last for this study, was a good one. She called me yesterday after looking over the email and cover letter and volunteered to be a part of the study. What was amusing was that when I asked if she had ever coached an openly lesbian or gay athlete, she said yes, that she was coaching one right now. She said he was "bilingual." It confused me for a minute so I asked if she meant bilingual or bisexual and she said "tomato, tomato." I couldn't believe it. It was kind of funny, but also kind of disturbing.

Up until this point, the coaches have been pretty self-aware and aware of LGB issues. I was anticipating that Nikki might be one coach that had a completely different perspective. In some ways she was: she was very religious, commonly called being LGB a "choice", and was younger than a lot of the other coaches. However, at the end of the interview, I was also aware that she was caring and tolerant and didn't stand for bullying or harassment between athletes on her teams. It's hard to say how her athletes perceive her, but with examples she gave, which were all over the place at times, she demonstrated concern and a willingness to learn.

There were times where I caught myself trying to justify her thoughts and my own. She was very southern with an accent and a pride in her school and community. She was who, as people, generally frustrate me the most. Those individuals that have lived in one place their entire life and often don't understand the need to branch out or look at situations from anyone's perspective than their own. The most upsetting part during the interview was when she discussed how there is only "one judger." She was very much "hate the sin, love the sinner." I work with a guy that has this perspective. I never know how to take that so I usually get defensive. Obviously I didn't do that during the interview but I was very aware of my words. I haven't been like that in many of the other interviews. 
February $6^{\text {th }}, 2017-$ Transcriptions Complete

Today, I received the final transcription back from Scribie. I have sent the first few transcripts to Bill and Stefanee and have started reviewing the transcriptions I got back earlier but this means that all data has been officially returned and is now able to be analyzed. I know that this, in some ways, is just the beginning, but it feels like a huge accomplishment. I will give the research team some time to finish up their initial coding, but am hoping to get all of their initial codes back so that I can review and begin categorizing before we meet on the $17^{\text {th }}$. I have scheduled a conference room for us to meet in and to discuss themes. By the end of the meeting I want to at least have a general idea of potential final themes/categories so that I can start writing up the results right away.

February $15^{\text {th }}, 2017$ - Transcriptions Received back from Team

Got all the coded transcripts back from Bill and Stefanee. I organized them in a couple binders so that they are all together, according to coach, so that I can go through each coach and start assigning categories, which we will discuss on Friday when I am in Morgantown. We all ended up having really different methods of coding, which is fine. It may just take a bit longer to work through all them.

Based on what I have read so far, there are definitely a few things that are standing out. Of course, several of these categories started appearing to me as I was completing the interviews. I wonder how much agreement Bill and Stefanee will have or if they noticed the same things. This part is exciting! All of the research, prep, and coach contacts have lead us to here. I want to know what it will all end up meaning. Not much time to get through these before Friday so that's my goal tonight and tomorrow after I get in town.

February $17^{\text {th }}, 2017-$ Research Meeting

The research meeting with the team went well. It got me really excited to write up the results. We had a great discussion about themes that emerged to them specifically and any contradictions between the three of us. I took a lot of notes and will write these up and return them to the team for final approval. It did create a lot of questions though, like how many themes can I actually have? How will they end up looking once organized? I'm definitely thinking about how I will arrange subthemes. This is a big step, but now it's real and I have to start writing! I'm worried that it's going to take some time to get back into the groove of writing but I guess doing these memos is helpful.

I talked to Dr. Watson and I know that he is concerned about my ability to get everything done in time to graduate in May but that's all I want to do. I met with Carol Straight and she said I'm good to go as far as her end. I have also applied for graduation. This is it. I have to 
finish in May. My job and sanity is relying on it. The summer off is just what I need. Next step - develop a timeline and send to Dr. Watson.

March $2^{\text {nd }}, 2017$ - Results Complete

I finally finished the write-up of the results of the study. Stefanee and Bill looked over the codes and provided feedback last week and it all makes so much sense. I'm really happy with how it all played out and looks. I created a table with the themes, descriptions, and participant quotes. I have also updated all of the appendices in the document and have been going through feedback from Dr. Voelker again. There were a few things that still needed to be addressed and it seems I have a better idea of what she was expected in the first draft. I underestimated how much had to be done before this draft would be in a good enough place to submit to Dr. Watson. I have touched each part of the proposal document and am excited to see what he says when I finally get the rest done. Now onto the discussion!

\section{March $5^{\text {th }}, 2017$ - Complete Rough Draft}

I just finished a complete draft of my Dissertation! This week has been chaotic but I have also made a lot of progress and I'm excited to see what Dr. Watson has to say regarding feedback. I think the manuscript looks better than ever and I'm really starting to believe that this all may come together. I'm also proud that through all of this, I am feeling a lot better about the qualitative process. I have learned a lot along the way and have grown to really respect qualitative research. Hell, I think I even want to do more qual research in the future. I enjoyed the interview process, once I got participants, and feel like although I learned a lot from the coaches, I have even more questions. I have been jotting down ideas for future studies once I get settled in at Randolph in the Fall. I'm so ready to start my career. I hope the document holds up to the scrutiny and I will be able to make the corrections in time to graduate in May. That continues to be the goal!

\section{March $31^{\text {st }}, 2017$ - Completed Defense Document}

After several revisions and elaborating more on the methods and discussion, I'm at a point where I feel really good about the document and am excited to defend in a couple of weeks. My continued concern revolves around the qualitative methods but, if anything, at some points I feel like I did more than necessary. While this may not be completely clear as written, I know I will be able to thoroughly explain the process during the defense. I will also be sure to clearly present this information in a format that flows well in the PowerPoint.

Adding in a few different appendices has really set me up to approach future research after graduation with more direction. I have written down several ideas that will build on the current research on this topic in the sport and exercise field. In short, I have learned so much throughout this entire project and am so grateful for the opportunity to present this research and complete my $\mathrm{PhD}$ from this outstanding program! 